Portland State University

PDXScholar

Spring 5-29-2015

\title{
Climate Change Assessment in Columbia River Basin (CRB) Using Copula Based on Coupling of Temperature and Precipitation
}

Yueyue Qin

Portland State University

Follow this and additional works at: https://pdxscholar.library.pdx.edu/open_access_etds

Part of the Climate Commons, and the Environmental Engineering Commons Let us know how access to this document benefits you.

\section{Recommended Citation}

Qin, Yueyue, "Climate Change Assessment in Columbia River Basin (CRB) Using Copula Based on Coupling of Temperature and Precipitation" (2015). Dissertations and Theses. Paper 2312.

https://doi.org/10.15760/etd.2309

This Thesis is brought to you for free and open access. It has been accepted for inclusion in Dissertations and Theses by an authorized administrator of PDXScholar. Please contact us if we can make this document more accessible: pdxscholar@pdx.edu. 
Climate Change Assessment in Columbia River Basin (CRB) Using Copula Based on

Coupling of Temperature and Precipitation

by

Yueyue Qin

A thesis submitted in partial fulfillment of the requirements for the degree of

Master of Science

in

Civil and Environmental Engineering

Thesis Committee:

Hamid Moradkhani, Chair

Ian H. Dinwoodie

Arun Rana

Portland State University

2015 
C2015 Yueyue Qin 


\begin{abstract}
The multi downscaled-scenario products allow us to better assess the uncertainty of the variations of precipitation and temperature in the current and future periods. Joint Probability distribution functions (PDFs), of both the climatic variables, might help better understand the interdependence of the two, and thus in-turn help in accessing the future with confidence. In the present study, we have used multi-modelled statistically downscaled ensemble of precipitation and temperature variables. The dataset used is multimodel ensemble of 10 Global Climate Models (GCMs) downscaled product from CMIP5 daily dataset, using the Bias Correction and Spatial Downscaling (BCSD) technique, generated at Portland State University. The multi-model ensemble PDFs of both precipitation and temperature is evaluated for summer (dry) and winter (wet) periods for 10 sub-basins across Columbia River Basin (CRB). Eventually, Copula is applied to establish the joint distribution of two variables on multi-model ensemble data. Results have indicated that the probabilistic distribution helps remove the limitations on marginal distributions of variables in question and helps in better prediction. The joint distribution is then used to estimate the change in trends of said variables in future, along with estimation of the probabilities of the given change. The joint distribution trends are varied, but certainly positive, for summer and winter time scales based on sub-basins. Dry season, generally, is indicating towards higher positive changes in precipitation than temperature (as compared to historical) across sub-basins with wet season inferring otherwise. Probabilities of changes in future, as estimated by the joint precipitation and temperature, also indicates varied degree and forms during dry season whereas the wet season is rather constant across all the sub-basins.
\end{abstract}




\section{Acknowledgements}

I have received too many favor from different individuals while I am studying in PSU. I would love to acknowledge them here in appreciation of their efforts from bottom of my heart. First, to my advisor Dr. Hamid Moradkhani, thank you for giving me a chance to join Remote Sensing and Water Resources group. I have learned many advanced knowledge and techniques in the past two years. With your mentoring, I have also obtained the ability to do research. Second, I would like to thank Dr. Ian Dinwoodie, you are such knowledgeable and patient instructor. Taking your class and working with you is one of my most wonderful experiences in PSU. Thank you for always being patient and responsible to help me solve problems. Third, I would love to thank Dr. Arun Rana. Thank you for being such a great supervisor. I have learned a lot from you, not only about how to do research, but also how to be a good communicator. Last but not least, I would like to thank my families and all of my friends, your unconditional love and support is always giving me the strength to overcome all the difficulties. 


\section{Table of Contents}

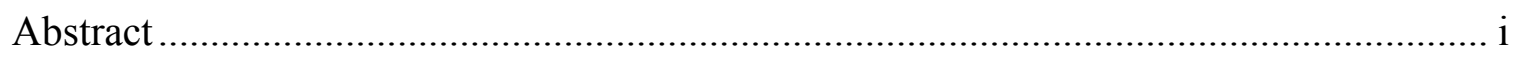

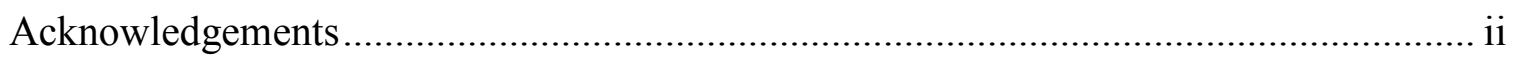

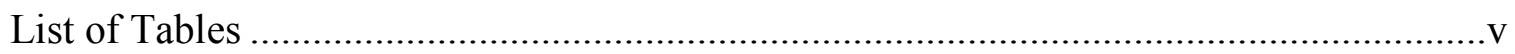

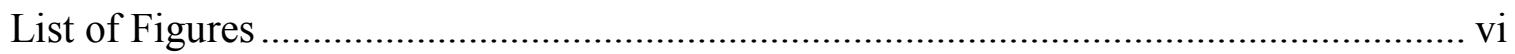

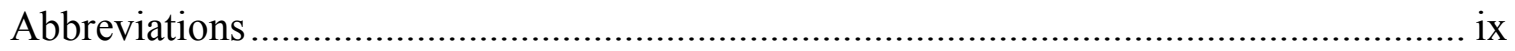

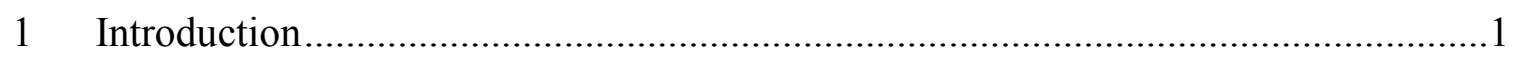

1.1 Background about climate change influence ..............................................

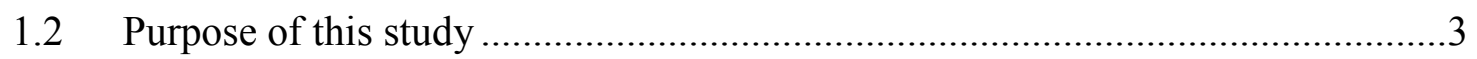

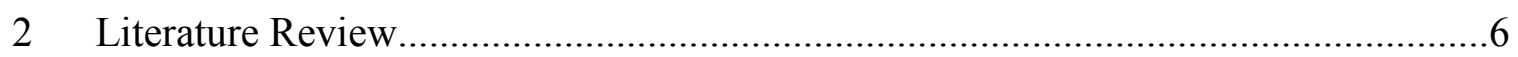

2.1 Climate change impact on temperature and precipitation respectively................6

2.2 Researches on the interdependence between temperature and precipitation ........7

2.3 Copula application in different areas .......................................................

2.4 Multi model ensemble and bootstrap sampling............................................

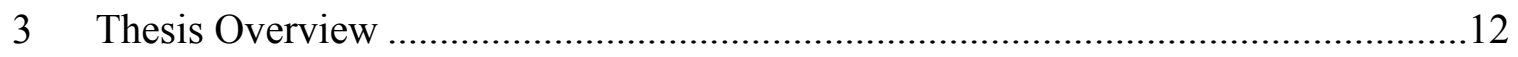

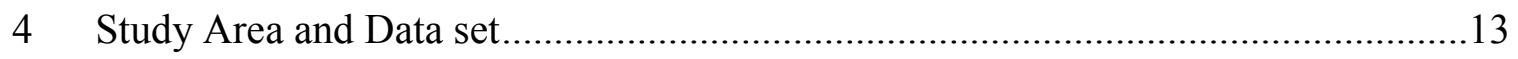

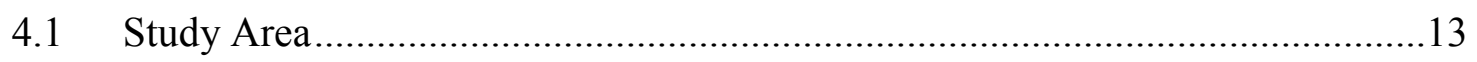

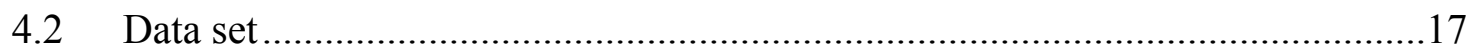

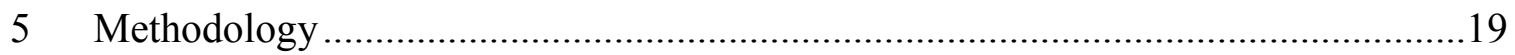


5.1 Bootstrap Sampling for multi models ensemble

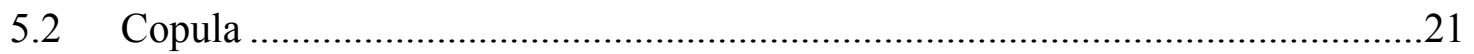

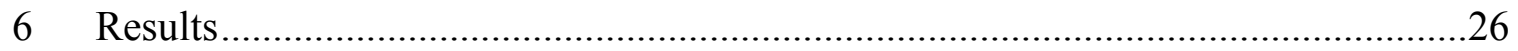

6.1 Verification of bootstrap sampling in multi model ensemble ..........................26

6.2 Copula based joint relationship between temperature and precipitation.............33

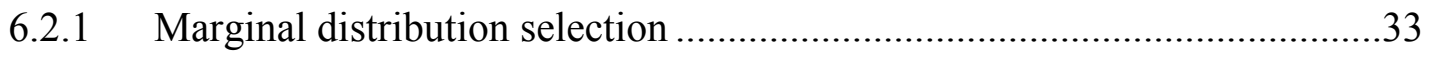

6.2.2 Goodness-of-fit test for Copula ...........................................................46

6.3 Future joint trends of temperature and precipitation ...................................53

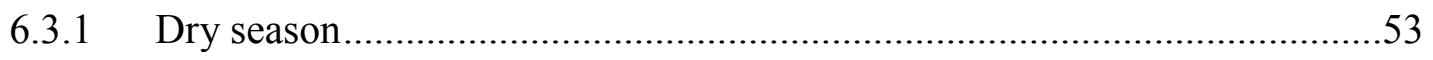

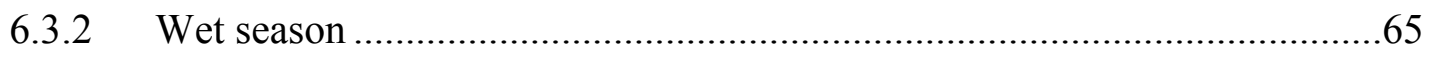

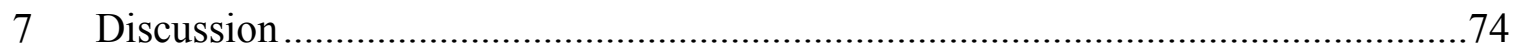

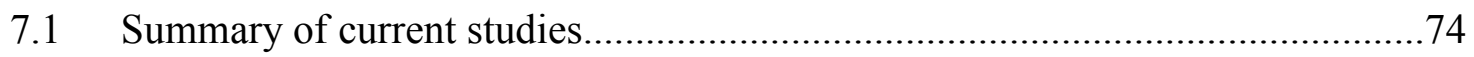

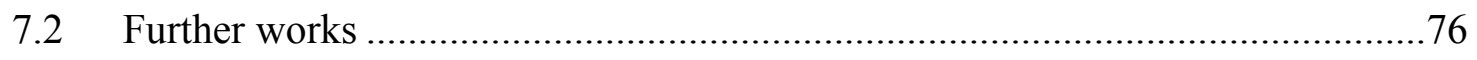

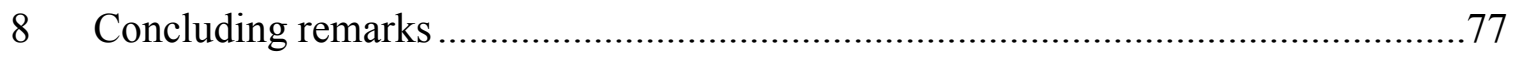

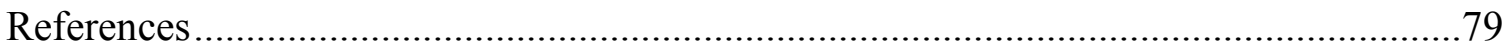




\section{List of Tables}

Table 1 Description of different sub-basins delineated and used in this study (Refer to Figure 1 for details on geographical locations of each) .............................................. 16

Table 2 GCM Models used in this study and their characteristics. All the models used were statistically downscaled using BCSD technique for entire CRB for RCP 4.5 in future period (2070-2099) 168

Table 3 Best marginal distributions selection for precipitation and temperature in dry and wet season respectively. The selection is separately made for historical and future data over all 10 sub basins of CRB (Distributions with least AIC values are chosen amongst the accepted distributions, indicated by bold below for each basin/season/variable). ...

Table 4 Best Copula selection in historical and future periods over all 10 sub basins of CRB (Preferred copula is with greatest p-value) in dry seasons. Values in bold are the selected Copula for respective period for joint distribution of temperature and precipitation.

Table 5 Best Copula selection in historical and future periods over all 10 sub basins of CRB (Preferred copula is with greatest p-value) in wet seasons. Values in bold are the selected Copula for respective period for joint distribution of temperature and precipitation 51 


\section{List of Figures}

Figure 1 Columbia River Basin and its 10 sub basins 15

Figure 2 Mean absolute value (MAE) for bootstrap sampled multi-model ensemble and original GCMs ensemble data sets in the historical period against observation data for precipitation (A- Dry Season and B-Wet Season) and temperature (C- Dry Season and DWet Season). 27

Figure 3 Frequency based histograms of precipitation seasonal average data sets in dry season for original GCMs and bootstrap sampled multi-model ensemble over the historical period (1970-1999) in 10 sub basins of CRB. The pink color represents the original GCMs dataset and the blue color represents the bootstrap sampled multi-model ensemble dataset.

Figure 4 Frequency based histograms of precipitation seasonal average data sets in wet season for original GCMs and bootstrap sampled multi-model ensemble over the historical period (1970-1999) in 10 sub basins of CRB. The pink color represents the original GCMs dataset and the blue color represents the bootstrap sampled multi-model ensemble dataset.

Figure 5 Frequency based histograms of temperature seasonal average data sets in dry season for original GCMs and bootstrap sampled multi-model ensemble over the historical period (1970-1999) in 10 sub basins of CRB. The pink color represents the original GCMs dataset and the blue color represents the bootstrap sampled multi-model ensemble dataset.

Figure 6 Frequency based histograms of temperature seasonal average data sets in wet season for original GCMs and bootstrap sampled multi-model ensemble over the historical period (1970-1999) in 10 sub basins of CRB. The pink color represents the original GCMs dataset and the blue color represents the bootstrap sampled multi-model ensemble datase 
Figure 7 Frequency based histograms of temperature seasonal average data sets in dry seasons of original ensemble and bootstrap sampling ensemble over the future period (2070-2099) in 10 sub basins of CRB. The pink color represents the original ensemble dataset and the blue color represents the bootstrap sampling ensemble dataset. 36

Figure 8 Frequency based histograms of precipitation seasonal average data sets in dry seasons of original ensemble and bootstrap sampling ensemble over the future period (2070-2099) in 10 sub basins of CRB. The pink color represents the original ensemble dataset and the blue color represents the bootstrap sampling ensemble dataset. 37

Figure 9 Frequency based histograms of temperature seasonal average data sets in wet seasons of original ensemble and bootstrap sampling ensemble over the future period (2070-2099) in 10 sub basins of CRB. The pink color represents the original ensemble dataset and the blue color represents the bootstrap sampling ensemble dataset. 38

Figure 10 Frequency based histograms of precipitation seasonal average data sets in wet seasons of original ensemble and bootstrap sampling ensemble over the future period (2070-2099) in 10 sub basins of CRB. The pink color represents the original ensemble dataset and the blue color represents the bootstrap sampling ensemble dataset. 39

Figure 11 Comparison of joint Cumulative Distribution Functions (CDFs) of temperature and precipitation, using multi-model ensemble, for dry season over the 10 sub basins of CRB. The solid lines represent the future period (2070-2099) and the dash lines represent the historical period (1970-1999). Color of the line indicates the probability of values for temperature and precipitation. The probabilities associated with each color line refer to figure color bar 55

Figure 12 Spatial locations of 10 sub basins' 5 categories in CRB for dry season. The color of outline indicates the associated category, as right-hand side legend shown. 56

Figure 13 Likelihood of precipitation ranges given a particular temperature in future data (2070-2099) during dry season in each of the 10 sub-basins in CRB. Conditional Probability density Function of precipitation against certain temperature is plotted and 
scaled for probability (0 to 1 ), for visualization purpose (red color- most likelihood and blue color- least likelihood). The conditional probability density associated with each color line refers to this figure color bar.

Figure 14 Comparison of joint Cumulative Distribution Functions (CDFs) of temperature and precipitation, using multi-model ensemble, for wet season over the $10 \mathrm{sub}$ basins of CRB. The solid lines represent the future period (2070-2099) and the dash lines represent the historical period (1970-1999). Color of the line indicates the probability of values for temperature and precipitation. The probabilities associated with each color line refer to figure color bar 66

Figure 15 Spatial locations of 10 sub basins' 5 categories in CRB for wet season. The color of outline indicates the associated category, as right-hand side legend shown.

Figure 16 Likelihood of precipitation ranges given a particular temperature in future data (2070-2099) during wet season in each of the 10 sub-basins in CRB. Conditional Probability density Function of precipitation against certain temperature is plotted and scaled for probability ( 0 to 1 ), for visualization purpose (red color- most likelihood and blue color- least likelihood). The conditional probability density associated with each color line refers to this figure color bar. 


\section{Abbreviations}

$\begin{array}{ll}\text { PDFs } & \text { Probability Distribution Functions } \\ \text { GCMs } & \text { Global Climate Models } \\ \text { BCSD } & \text { Bias Correction Spatial Downscaling } \\ \text { MAE } & \text { Mean Absolute Error } \\ \text { CRB } & \text { Columbia River Basin } \\ \text { cj } & \text { Chief Joseph } \\ \text { cor } & \text { Corra Linn } \\ \text { dalles } & \text { The Dalles } \\ \text { ib } & \text { Ice Harbor } \\ \text { mica } & \text { Mica } \\ \text { oxbow } & \text { Oxbow } \\ \text { pr } & \text { Priest Rapids } \\ \text { rev } & \text { Revelstoke } \\ \text { sul } & \text { TW Sullivan } \\ \text { wan } & \text { Waneta }\end{array}$




\section{Introduction}

\subsection{Background about climate change influence}

Many global services are closely related/dependent on climate of the region e.g. agriculture, water, ecosystem, and energy, amongst others. Climate change, resulting from increasing emission of carbon dioxide, will threaten these services by increase in temperature, changes in the amount and intensity of precipitation, among others, and thus affecting variability of climatic variables (IPCC 2007, IPCC 2013).

Agriculture strongly relies on specific climate condition. Warm temperature will cause many crops to grow fast. High $\mathrm{CO}_{2}$ level will increase the yield of crops. However, to understand the overall effect of climate on agriculture is much more difficult. Warm temperature will benefit crops in some area, but if warm temperature exceeds the optimal level, the yield will reduce. More extreme temperature and precipitation will harm the growth of crops. Extreme events, especially floods and drought, will directly reduce the crop yield. For example, in 2008, the Mississipi experienced a flood just before the harvest period for many crops, causing an estimated loss of 8 billion for farmers (Karl et al, 2009). Drought along with warmer temperature and less precipitation will threaten the water supplies for the crop irrigation, which will directly reduce the production of crops.

Water is important to human. Reliable and clean water supply is necessary to sustain our health. Climate change is likely to shrink the supply of water and simultaneously extend the demand for it. For example, many areas of the United States, especially the west, currently face the water shortage issue. The amount of water in this area is already limited and demand will continue to rise with the growth in population. In addition, the west has 
faced less rainfall over the last 50 years, as well as increase in the severity and length of the drought. (Karl et al. 2009). Furthermore, we also need water for other purposes, such as energy production, agriculture, navigation, recreation. Many of these uses will put more pressure on the availability of the water supply. As for water quality issue, it can be already seen in areas with excessive precipitation. Heavy precipitation will increase not only the amount of runoff into lake, stream and other water bodies, but also will wash sediment, pollutants, trash, animal waste and other materials into water supplies. Overall, our water supplies will become unsafe and unusable.

Climate change plays an important role on the ecosystem, which will lead to the changes of the habitat and range of species. Take an aquatic species as an example, warm air temperature will directly raise the water body temperature. Warmer water temperature will harm the aquatic organisms that only live in cold water environment, such as salmon and trout. In addition, warmer water temperature will also expand the range of non-native species, allowing them to move to the places that previously have cold environment. Such migration will break the balance among species living in these areas. The population of native-species often decrease as the non-native species appear as prey and competence. (Backlunk et al. 2008). Combined with other factors, like excessive precipitation, which will bring adverse impact on water quality, these factors will exacerbate the problems on the aquatic ecosystem.

Energy production also highly depends on climate and changes in climatic variables are very likely to increase the risk of energy supply issue. Warmer temperature in the winter create more precipitation as rain fall rather than snow. In addition, warmer temperature will 
cause snow to melt earlier in the year and thus affecting spring flow to streams. For example, some areas in United States, particularly the Northwest, use water to produce energy by hydropower. The amount of energy generated through hydropower will reduce if climate change results in low stream flow in this area.

The climate of the 21 st century will very likely be quite different from the climate we observed in the past. The changes will continue to be large in the future period with increasing carbon dioxide emissions. Analyzing and quantifying the signal of climate change will be much in demand considering the above sectors, which are highly relating to the sustainability and human living.

\subsection{Purpose of this study}

Temperature and precipitation are two main climatic variables, changes in these is highly indicative of climate change, and it is difficult to simulate rainfall and temperature simultaneously due to the interdependence (correlation) between them. On the other hand, as we discussed above, cumulative effects of these two have influenced various services. Typically most of the research have focused on study of temperature and precipitation independently. Interdependence between temperature and precipitation is somewhat neglected topic in the literature. However, there is obvious physical relationship between temperature and precipitation; warm temperature will increase the rate of evaporation into atmosphere and in turn the capacity of atmosphere to hold water, leading to excessive precipitation in few areas and droughts in others. In this study, Copula is applied to develop the joint distribution of temperature and precipitation since it allows us to model the joint multivariate distributions easily by estimating the marginal distributions of variables and 
their correspondence separately. In addition, Copula has been widely used in different areas to simulate the interdependence among variables (Zhang and Singh 2007; Salvadori and De Michele 2006; Kao and Govindaraju 2008; Favre et al. 2004, Zhang and Singh 2007; Salvadri and De Michele 2010; Shiau 2006; Dupuis 2007; Kao and Govindaraju 2010; Wong et al. 2010; Madadgar and Moradkhani 2011; Madadgar and Moradkhani 2013; Madadgar and Moradkhani 2013; Risley, J. et al. 2011), including drought analysis, rainfall analysis, flood analysis etc. Through this study, we are employing Copula to develop the joint distribution of temperature and precipitation and ultimately filling the void of negligence of climate change impact using interdependence of the two variables. The results will further provide more useful and comprehensive information to various service sectors of this region, like water resource, agriculture, ecosystem, energy to adapt their managements in facing future climate change.

The study is conducted over Columbia River Basins (CRB); the largest river in the Pacific Northwest region of North America. It drains an area of about $567000 \mathrm{~km}^{2}$ consisting of portions of seven states in the western USA (Washington, Oregon, Idaho, Montana, Wyoming, Nevada, and Utah), contributing to almost $85 \%$ of the basin and part of British Columbia, in western Canada ( $15 \%$ of the basin). Nearly two-thirds of precipitation occurs during half of the year (October-March) in CRB. The amount of precipitation declines from later spring to early fall with high pressure system dominating west, generally keeping the Northwest fairly dry. Contrasts in Pacific Northwest climate can be stark owing to the region's mountains, especially the Cascade mountain range. The Cascades create a barrier between the maritime climate influencing the west, where temperatures are generally mild 
year-round, and the continental climate influencing the east, with more sunshine and less precipitation (Littell et al. 2009). Historical climate variability has already been indicated to significantly alter mean and extreme hydro-climatic conditions of the Columbia River (Gershunov and Barnett, 1998; Mantua et al., 1997; Cayan et al., 1999, Leung et al. 2004). Temperature and precipitation changes resulting from climate change can significantly alter snowpack and stream flow in Columbia River (Leung and Wigmosta, 1999; Hamlet and Lettenmaier, 1999; Mote et al,. 1999; Leung et al. 2004; Halmstad, A. et al. 2012; Najafi M.R. and H. Moradkhani 2013; Najafi, M.R. and H. Moradkhani 2014) and in turn bring adverse impacts on agriculture, water resource, ecosystem and energy, especially within the rapid growth of economy and population in this region. Information produced by CRB climate change impact studies can therefore be helpful in providing options for various sectors to adapt to climate change. 


\section{Literature Review}

\subsection{Climate change impact on temperature and precipitation respectively}

It is difficult to simulate temperature and precipitation simultaneously due to their interdependence, researchers have focused their resources to study the (future) changes in temperature and precipitation separately across the world.. Piao et al. 2010 studied the projected change and trends of temperature and precipitation respectively under future climate change and assessed the impacts on water resource and agriculture in China. Feng et al. 2014 studied the change of temperature and precipitation separately over the global range based on 20 global climate models (GCMs) of the Coupled Model Inter-comparison project (CMIP5) and examined shifts in climate regimes over the global land area. Wuebbles et al. (2014) studied the climate extremes in the contiguous United States using CMIP5 dataset. Future climate and impact studies based in USA are also conducted by many researchers including (Leung et al. 2004; Brunsell et al. 2010; Moradkhani H. et al. 2010; Jung, I. et al. 2011; Halmstad et al. 2012; Jung, I. et al. 2012; Pierce et al. 2013; Rana and Moradkhani. 2014- Submitted; Rana et al. 2015- submitted; among others). Leung et al. (2004) studied the impacts of climate change on water resource in the western U.S. using the National Center for Atmospheric Research/Department of Energy (NCAR/DOE) Parallel Climate Model (PCM) and their results indicated towards significant effects on water resources in the western U.S. Brunsell et al. (2010) studied seasonal trends in air temperature and precipitation patterns from 21 global climate models, under the Special Report on Emissions Scenarios A1B scenario used by Intergovernmental Panel of Climate Change (IPCC) in assessment report 4, for six grid cells representing Kansas. Results indicated that temperature is likely to warm in all seasons, with the largest trends of the 
order of $0.04{ }^{\circ} \mathrm{C} /$ year in summer and fall. Precipitation is likely to increase slightly in winter and decrease in summer and fall. Halmstad et al. (2012) analyzed precipitation extremes in Willamette River Basin, USA with 12 different combinations of General Circulation Model (GCM)-regional climate model (RCM). The extreme value analysis results showed significant differences between models runs for both historical and future periods with considerable spatial variability in precipitation extremes. Pierce et al. (2012) used 16 GCMs with two statistical downscaling techniques and three nested dynamical regional climate models to develop probabilistic projections of temperature and precipitation changes over California by the 2060 s.

\subsection{Researches on the interdependence between temperature and precipitation}

As listed in the above section, most of research considers the change of temperature and precipitation separately (Leung et al. 2004; Brunsell et al. 2010; Najafi, M. et al. 2011 Halmstad et al. 2012; Pierce et al. 2013; Feng et al. 2014; Wuebbles et al. 2014;). Their interdependence is somewhat neglected topic in the literature on climate change impact studies (Buishand et al. 1999). Attention should be directed towards the combined effects of temperature and precipitation changes and associated impacts. Limited studies have looked into this aspect, e.g., Zhao et al. 1992 studied the correlation between monthly total precipitation and monthly mean temperature at nearly 1000 stations in the contiguous United States. Over most of the United States, summer precipitation and temperature were negatively correlated, which indicates that warm summers tended to be drier. Buishand et al. 1999 studied dependence of precipitation and temperature at Florence and Livorno and their results indicated a marked increase in the mean wet-day precipitation amount with 
increasing temperature (Buishand et al. 1999). Temporal relationships between the two variables have been studied by Rajeevan et al. (1998) (monthly basis) and Huang et al. (2009) (annual basis). Collins and Knight (2007) studied the possibility of ensembles and probabilistic projections for prediction of climate change. Tebaldi et al. (2007) established the joint projections of future temperature and precipitation trends and changes by applying a Bayesian hierarchical model to the simulated date sets from general circulation models. In this study, after establishing the correlation between temperature and precipitation, we will focus on the joint changes of temperature and precipitation under climate change impact in CRB.

\subsection{Copula application in different areas}

Statistical methods for probabilistic projections have been applied since the joint behavior of two or more correlated variables has been established in the distant past. Hydrologic and climatological variables are usually correlated to each other and thus statistical methods could be used to explain interdependence. In literature, over past years, Copula has been widely used to develop the joint distribution for various applications; including rainfall analysis (Zhang and Singh 2007; Salvadori and De Michele 2006; Kao and Govindaraju 2008), flood analyses(Favre et al. 2004, Zhang and Singh 2007; Salvadri and De Michele 2010), drought analyses (Shiau 2006; Dupuis 2007; Kao and Govindaraju 2010; Wong et al. 2010; Madadgar and Moradkhani 2011; Madadgar and Moradkhani 2013). Madadgar et al. (2013) employed Copula to develop the conditional distribution for post processing of hydrologic forecast and results indicated that using Copula could efficiently improve the stream flow predictions, reduce the uncertainty and increase the reliability of forecast. 
Recently, Madadgar et al. (2014) improved Bayesian Model Averaging (BMA) by inserting Copula for hydrologic forecasts and results demonstrated that predictive distributions are more accurate, reliable, and more confident with small uncertainty after Cop-BMA. In respect to temperature and rainfall interdependence, Schölzel et al. (2008) used a simple statistical model based on the Copula approach. They found that cold periods were accompanied by small precipitation amounts. Recently, Cong et al. (2012) applied Copula to develop the joint distribution between them in historical data and consequently studied their interdependence in historical period. Copula has advantage in joining variables with diverse correlation and dependence structure since it develops the joint distribution based on the variables' marginal distributions, which are not restricted to any parametric distribution (like Gaussian distribution). Based on this advantage, Copula is applied to develop the joint relationship between temperature and precipitation in this study.

\subsection{Multi model ensemble and bootstrap sampling}

Global Climate Models (GCM) can be used to obtain the projections of climate variables, such as temperature and precipitation and in turn help us to analyze the climate change impact in the future period. A large number of GCMs have been provided so far. Advantages of using multi-model ensemble instead of single scenario/projection from 1 GCM have been pointed out in various studies previously (Krishnamurti, Kishtawal et al. 2000; Raftery et al. 2005; Duan et al. 2007, Tebaldi and Knutti 2007, Duan and Phillips 2010, Sillmann, Kharin et al. 2013; Samadi S.Z. et al. 2013). Multi-model ensemble provides an alternative to improve projections, in terms of reduction of spread from large 
datasets of climate projections, requires less computation capacity, and improves accuracy in model predictions. It takes different models' strengths into consideration, and is able to capture various aspects of the prediction processes, and thus more reliable simulations and consequently less uncertainty. Various studies on multi-model ensemble have been conducted with different techniques (e.g. Giorgi and Mearns 2002, Knutti et al. 2010, Feng et al. 2014). Even though several advanced methods have been proposed to combine multimodel ensemble (e.g. Duan and Phillips 2010; Sillmann, Kharin et al. 2013), research have indicated that ensemble mean outperforms all or most of the individual ensemble (e.g. Tebaldi and Knutti 2007; Knutti et al. 2010). It has the advantages of simplification, efficiency, and computationally less demanding. Additionally, there is empirical evidence from various areas that multi models average performs better in prediction or behaves more favorably to observations than any single model (Knutti et al 2010, Thomson et al. 2006). Examples include predictions of the El Niño-Southern Oscillation (ENSO), health, agriculture, sea level pressure (SLP) (Palmer et al. 2005, Thomson et al. 2006, Cantelaube and Terres 2005, Gillett et al. 2005, Knutti et al 2010).

In order to consider the variability and confidence level of ensemble mean as well as the strength of multi models combination, ensemble mean using bootstrap sampling will be applied to pre process our multi-model ensembles. The bootstrap sampling method was published by Bradley Efron in "Bootstrap methods: another look at the jackknife (1979)" (Efron 1979). Bootstrap sampling procedure will be applicable to the below situations: when the theoretical distribution of a statistic of interest is complicated or unknown; when 
the sample size is insufficient for straightforward statistical inference and when power calculations have to be performed, and a small pilot sample is available (Ader et al. 2008). 


\section{Thesis Overview}

In the present study, we have tried to establish probabilistic future (copula based) with multi-model ensemble (bootstrap sampling). We have established joint distribution between temperature and precipitation climate variables in historical dataset (1970-1999) using Copula, owing to its wider application in literature and other advantages. The method is applied over 10 sub-basins in Columbia River Basin (CRB) using multi-model ensemble of 10 Global Climate Models (GCMs) downscaled products from CMIP5 daily dataset. The multi-model ensemble Probability Density Functions (PDFs) of both precipitation and temperature are evaluated for dry (dry i.e. April-September) and wet (i.e. October-March) periods in historical data. The joint PDFs are then used to evaluate the trends over subbasins in future multi-model ensemble scenario period (2070-2099) along with estimation of the likely occurring of the given change. The study is organized in following manner: Introduction section 1 is followed by Section 2 literature review. Section 3 describes thesis overview. Section 4 introduces study area and data used. Section 5 lists methodology (multi-model ensemble and joint distribution) applied for analysis. Section 6 (results) presents multi-model ensemble product and for application of Copula in studying the joint change of temperature and precipitation. Section 7 deals with discussion of obtained results. Section 8 provides concluding remarks. 


\section{Study Area and Data set}

\subsection{Study Area}

This study aims to analyze the multi-model ensemble climate projections over Columbia River Basin (CRB) (Figure 1, adopted from Rana et al. 2015), in the northwestern region of USA, using a probabilistic joint distribution. The Columbia River is the largest river in the Pacific Northwest region of North America. It drains an area of about $567000 \mathrm{~km}^{2}$ consisting of portions of seven states in the western USA (Washington, Oregon, Idaho, Montana, Wyoming, Nevada, and Utah), contributing to almost $85 \%$ of the basin and part of British Columbia, in western Canada ( $15 \%$ of the basin). The climate varies from moist, maritime conditions in the western parts of the basin to semi-arid and arid conditions in the south-eastern part with topography playing an important role on precipitation within the basin. Mean annual precipitation varies from as much as $2500 \mathrm{~mm} /$ year along the crest of the Washington Cascades, to between 1000 and $1800 \mathrm{~mm} /$ year in the northern Rocky Mountains, the west slope of the continental divide in western Montana, and the Canadian portion of the basin. The driest parts of the basin, with about 200 to $400 \mathrm{~mm}$ of annual precipitation, lie on the Columbia Plateau in Washington and the Snake River Plain in Idaho. The river's annual discharge rate fluctuates with precipitation and ranges from $120000 \mathrm{cfs}$ (cubic feet per second) in a low water year to $260000 \mathrm{cfs}$ in a high water year. The Columbia has ten major tributaries: the Kootenay, Okanagan, Wenatchee, Spokane, Yakima, Snake, Deschutes, Willamette, Cowlitz, and Lewis rivers.

Accordingly, based on user interest from various stakeholders in the study area and hydrological/climatological regimes, the 10 specified sub-basins (Figure 1) are delineated using 30 arc-second data DEM from National Elevation Dataset (available at 
http://ned.usgs.gov/), resampled at $1 / 16^{0}$ for consistency with the climate variables resolution in the study. The delineation was based on the flow accumulation and direction maps for 10 specific stream flow location points in the CRB to include/support planning at geographic scales ranging from relatively small river basins (Mica Basin) to main-stem planning studies (The Dalles Basin) for the CRB as a whole. The 10 sub-basin delineated are namely, brackets represent their name used during this entire study, The Dalles (dalles), TW Sullivan (sul), Priest Rapids (pr), Ice Harbor (ib), Oxbox (oxbow), Chief Joseph (cj), Waneta (wan), Corra Linn (cor), Revelstoke (rev), and Mica (mica) (Table1). This strategy would further assist in for hydrological model calibration for the sub-basins in the study area. 


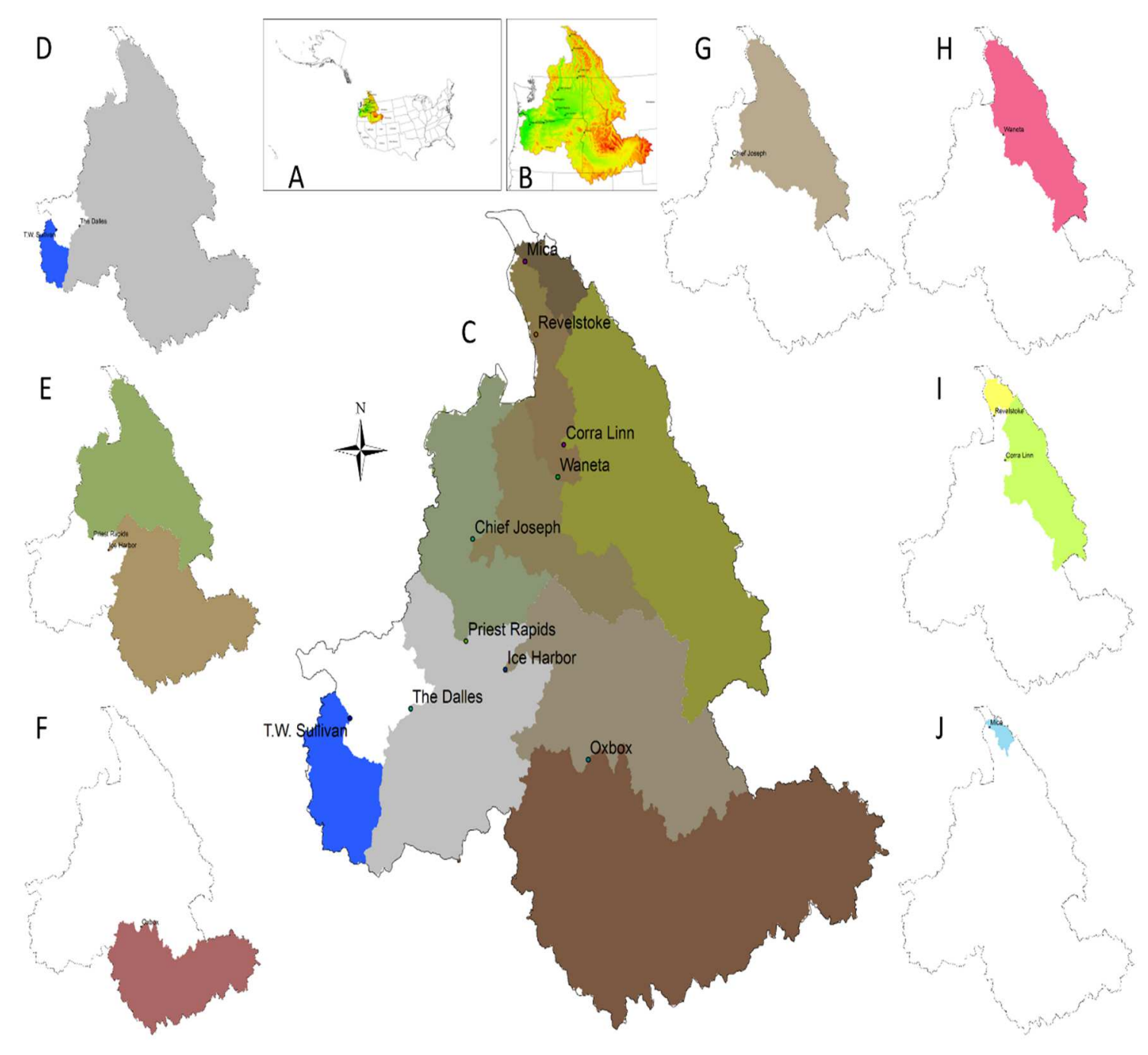

Figure 1 Columbia River Basin and its 10 sub basins 
Table 1 Description of different sub-basins delineated and used in this study (Refer to Figure 1 for details on geographical locations of each)

\begin{tabular}{|c|c|c|c|c|c|c|}
\hline S.No. & $\begin{array}{c}\text { Sub-basin } \\
\text { name }\end{array}$ & $\begin{array}{c}\text { Representative } \\
\text { Name }\end{array}$ & Area $\left(\mathbf{1 0 0 0 \mathbf { k m } ^ { \mathbf { 2 } } \mathbf { ) }}\right.$ & $\begin{array}{c}\text { Avg. Annual P } \\
(\mathbf{m m})\end{array}$ & $\begin{array}{c}\text { Avg. Annual } \\
\text { TMax }\left({ }^{\mathbf{0}} \mathbf{C}\right)\end{array}$ & $\begin{array}{c}\text { Avg. Annual } \\
\left.\text { TMin } \mathbf{(}^{\mathbf{0}} \mathbf{C}\right)\end{array}$ \\
\hline 1 & Chief Joseph & cj & 193.6 & 1024 & 9 & -3 \\
\hline 2 & Corra Linn & cor & 121.7 & 1188 & 7.4 & -4.3 \\
\hline 3 & The Dalles & dalles & 614.3 & 684 & 12.2 & -1.7 \\
\hline 4 & Ice Harbor & ib & 278.5 & 578 & 13.4 & -1.7 \\
\hline 5 & Mica & mica & 8.4 & 1164 & 6 & -5.3 \\
\hline 6 & Oxbow & oxbow & 187 & 493 & 13.7 & -2 \\
\hline 7 & Priest Rapids & pr & 245.2 & 915 & 9.8 & -2.3 \\
\hline 8 & Revelstoke & rev & 13.4 & 1189 & 6 & -5.1 \\
\hline 9 & TW Sullivan & sul & 24.6 & 1661 & 13.9 & 2.1 \\
\hline 10 & Waneta & wan & 151.9 & 1132 & 7.9 & -4 \\
\hline
\end{tabular}




\subsection{Data set}

In the present study, statistically downscaled climate data for 10 Global Climate Models (GCMs) from CMIP5 dataset over Columbia River Basin was used for all the analysis. They were all downscaled using the Bias correction and spatial downscaling (BCSD) (Rana et. al. 2014-Submitted). The analysis of multi-modelling techniques was done on historical data, 1970-1999, whereas scenario RCP 4.5 is considered for analysis of climatic parameters in future data period 2070-2099. Daily records of precipitation (P) and near surface temperature $(\mathrm{T}$ ) in the study region (Figure 1) were collected for $10 \mathrm{GCMs}$ (Table 1) of the CMIP5 data (Taylor et al. 2012). Readers are referred to Taylor et al. 2012 and its references for details about the scenarios and CMIP5 dataset. Details of the models, institution, GCM resolution and scenario used are provided in table 2, along with total other information used in the present study. Observational data (Livneh et. al. 2013) for precipitation $(\mathrm{P})$, temperature minimum (TMin) and temperature maximum (TMax) at gridded spatial resolution of $1 / 16^{0}$ is used for evaluation of particular multi-modelling method in the historical data period (1970-1999), as same was used for downscaling BCSD data. Therefore, the spatial and temporal resolution is same and comparative analysis is done for a multi-model method BCSD data set. 
Table 2 GCM Models used in this study and their characteristics. All the models used were statistically downscaled using BCSD technique for entire CRB for RCP 4.5 in future period (2070-2099)

\begin{tabular}{|c|c|c|c|c|}
\hline S.No. & Model & Center & $\begin{array}{c}\text { Atm. } \\
\text { Resolution } \\
\text { (Lon x Lat) }\end{array}$ & $\begin{array}{c}\text { Vertical } \\
\text { levels in } \\
\text { Atm. }\end{array}$ \\
\hline 1 & BCC-CSM1-1 & Beijing Climate Center, China Meteorological Administration & $2.8 \times 2.8$ & 26 \\
\hline 2 & CanESM2 & Canadian Centre for Climate Modeling and Analysis & $2.8 \times 2.8$ & 35 \\
\hline 3 & CCSM4 & National Center of Atmospheric Research, USA & $1.25 \times 0.94$ & 26 \\
\hline 4 & GFDL-ESM2G & NOAA Geophysical Fluid Dynamics Laboratory, USA & $2.5 \times 2.0$ & 48 \\
\hline 5 & GFDL-ESM2M & NOAA Geophysical Fluid Dynamics Laboratory, USA & $2.5 \times 2.0$ & 48 \\
\hline 6 & inmcm4 & Institute for Numerical Mathematics, Russia & $2.0 \times 1.5$ & 21 \\
\hline 7 & IPSL-CM5A-LR & Institut Pierre Simon Laplace, France & $3.75 \times 1.8$ & 39 \\
\hline 8 & IPSL-CM5A-MR & Institut Pierre Simon Laplace, France & $2.5 \times 1.25$ & 39 \\
\hline 9 & IPSL-CM5B-LR & Institut Pierre Simon Laplace, France & $3.75 \times 1.8$ & 39 \\
\hline 10 & MIROC5 & $\begin{array}{c}\text { Atmosphere and Ocean Research Institute (The University of } \\
\text { Tokyo), National Institute for Environmental Studies, and } \\
\text { Japan Agency for Marine-Earth Science and Technology }\end{array}$ & $1.4 \times 1.4$ & 40 \\
\hline
\end{tabular}




\section{Methodology}

\subsection{Bootstrap Sampling for multi models ensemble}

Before deducing marginal distributions of climatic variables (temperature and precipitation), we ought to select the most suitable theoretical distributions. In case of climate change scenarios, it is advisable to do so on ensemble of simulations to be able to quantify uncertainty in climate in a probabilistic way. Advantages of using multi-model ensemble instead of single scenario/projection from $1 \mathrm{GCM}$ have been pointed out in various studies (Krishnamurti et al 2000, Raftery et al. 2005, Duan et al. 2007, Tebaldi et al. 2007, Knutti et al. 2010, Duan and Phillips 2010, Sillmann et al. 2013, Shahrbanou et al. 2014). Here we will apply ensemble mean using bootstrap sampling to pre-process our multi-model GCM simulations in historical period (1970-1999). The same approach would be applied to future dataset (2070-2099) for multi-model ensemble, on satisfactory application in historical dataset, to analyze the trends of changes in temperature and precipitation as compared to historical ones.

The basic idea of bootstrap sampling is to infer the estimates or statistics, like mean and variance, about population from sample datasets. It is simply random sampling from population with replacement based on the desired statistics by users (means in this case and thus reduction of variance). For bootstrap sampling, the existence sample represents "population" (10 GCM projections) and resample data set (multi-model ensemble) is regarded as sampling from "population", which enables us to measure the quality of inference (mean) from resample data to "population". Furthermore, bootstrap sampling can provide with the typical distribution, uncertainty and confidence level inherent in the 
estimation of statistics and avoids a single estimation from the only original sample without confidence level. Suppose we had a sample with $x_{1}, x_{2}, \cdots, x_{n} \mathrm{n}$ points. For this dataset, we are interested in the statistical estimation:

$$
s=S\left(x_{1}, x_{2}, \cdots, x_{n}\right)
$$

Where $s$ is the statistical estimation from sample; $S$ is statistical estimation function of the samples provided.

In the present study, bootstrap sampling method will be used to resample our dataset (temperature and precipitation of dry and wet seasons in yearly step) for 200 times and thus creating a new multi-model ensemble time series for the period for both the climatic variables. Each of these resamples is obtained by randomly sampling $n$ points from original sample $\left(x_{1}, x_{2}, \cdots, x_{n}\right)$ with replacement. In turn, each resample dataset will be constructed by $x_{1}^{*}, x_{2}^{*}, \cdots, x_{n}^{*} \mathrm{n}$ points. It is quite likely that some of the original sample elements are selected more than once but others are omitted, which is the intention behind bootstrap sampling to resample large times in order to take all the elements into consideration. Mathematically, we will be able to compute its statistical estimation:

$$
s_{i}^{*}=S\left(x_{i 1}^{*}, x_{i 2}^{*}, \cdots, x_{i n}^{*}\right)
$$

Where $\mathrm{i}=1, \cdots \mathrm{N}, \mathrm{N}$ is the total number of resamples and i represents each resample. $x_{i 1}^{*}, x_{i 2}^{*}, \cdots, x_{i n}^{*}$ represent randomly sampled $\mathrm{n}$ points from original sample set. $S$ is statistical estimation function, which is the mean of resample. In addition to a set of statistical estimation $s_{i}^{*}$ constructed, a distribution of statistical estimations $s^{*}$ will be 
obtained and in turn be used to approximate the distribution of the actual statistical estimation (s). The statistical estimation in consideration for the study is representation of mean of the population for each time step (year). Thus, the resampled dataset is representative of the mean of $10 \mathrm{GCM}$ simulations at that time step (year) and the procedure is repeated for each year for entire period both in historical and future data as well as dry and wet seasons.

\subsection{Copula}

Various methods can be deployed to establish the joint projections/distribution, Copula being one such statistical method. Its advantages includes, not limited to, ability to join several variables with diverse correlation and dependence structure. It develops the joint distribution by estimating the marginal distributions of variables and their correspondence separately, which are not restricted to any parametric distribution (e.g. Gaussian distribution). Copula is a statistical procedure to join multivariate distribution functions by their marginal distribution functions uniform (Nelson 2007). The method has received of great interest lately and have been applied widely in hydrological and climatological studies, as discussed in introduction section. The physical relationship (interdependence/correlation) between temperature and precipitation will determine the inherent relationship between these two climatological variables. The interdependence of these two climatic variables using Copula have not been extensively investigated (Scholzel and Friederichs 2008; Cong et al. 2012). In the present study, we have investigated the same using five parametric copula families (discussed below) to establish correlation between the two variables. We have established the joint distribution of temperature and 
precipitation to study the changes in trends and probabilities of future multi-model ensemble scenario in respect to historical multi-model ensemble scenario, for all 10 subbasin. The analysis is performed in dry (April-September) and wet (October-March) season across CRB. Thus, the changes across sub-basin are studied with joint distribution and probabilities instead of considering them independently.

Mathematically, assume a pair of random variables $\mathrm{X}$ and $\mathrm{Y}$, with cumulative distribution functions $(\mathrm{CDFs}) \quad F(x)=P(X \leq x)$ and $\mathrm{G}(y)=P(Y \leq y)$, respectively, and a joint distribution of $H(x, y)=P(X \leq x, Y \leq y)$ are given. Each pair of $(\mathrm{x}, \mathrm{y})$ is associated with three numbers: $F(x), G(y)$, and $H(x, y)$ (each of these numbers falls in the range of $[0,1]$ ). To be specific, each pair (x,y) of real numbers associates with a point $((F(x), G(y))$, and in turn this ordered pair corresponds to a number $H(x, y)$ in $[0,1]$ (Nelson 2007).

The Copula a function to describe this correspondence, i.e. assigning the value in $[0,1]$ equal to the value of the joint distribution function $H(x, y)$, can be written as below function:

$$
H(x, y)=H\left(F^{-1}(u)\right),\left(G^{-1}(v)\right)=C(u, v)
$$

where $u$ and $v$ are equal to CDFs of $\mathrm{X}$ and Y respectively: $u=F(x), v=G(y)$, ranging from 0 to 1 (here $u$ and $v$ are strictly increasing functions); $\mathrm{C}$ is the Copula function; $F^{-1}$ and $G^{-1}$ are the inverse CDFs of X and $\mathrm{Y}$ respectively.

Sklar's theorem states that any multivariate joint distribution can be written in terms of cumulative distribution function of each variable and Copula is used to describe the 
dependence or any level of correlation between variables (Sklar 1959). Copula function satisfies the following properties:

a) The joint probability density function:

$$
\begin{gathered}
c(u, v)=\frac{\partial C(u, v)}{\partial u \partial v} \\
f(x, y)=\frac{\partial C(u, v)}{\partial u \partial v} * \frac{\partial u}{\partial x} * \frac{\partial v}{\partial y}=c(u, v) * f_{x}(x) * f_{y}(y)
\end{gathered}
$$

b) The conditional probability density function:

$$
f(x \mid y)=\frac{f(x, y)}{f(y)}=\frac{c(u, v) \times f_{x}(x) \times f_{y}(y)}{f_{y}(y)}=c(u, v) \cdot f_{x}(x)
$$

c) The boundary condition:

$$
\begin{gathered}
0 \leq C(u, v) \leq 1 \\
C(u=0, v)=C(u, v=0)=0 \\
C(u=1, v=1)=1 \\
C(u, v=1)=u
\end{gathered}
$$




$$
C(u=1, v)=v
$$

Here we just show two random variables situation, the joint distribution of multivariables has the same properties.

Here we have shown just show two random variables situation, the joint distribution of multiple variables has the same properties. There are many parametric copula families available, which usually have parameters that control the strength of dependence. Below are five copula functions that are used in the present study:

(1) Gaussian Copula:

$$
\begin{gathered}
C(u, v) \\
=\int_{-\infty}^{\emptyset^{-1}(u)} \int_{-\infty}^{\emptyset^{-1}(v)} \frac{1}{2 \pi\left(1-\rho^{2}\right)^{1 / 2}} \exp \left\{-\frac{x^{2}+y^{2}-2 \rho x y}{2\left(1-\rho^{2}\right)}\right\} d x d y \\
x, y \in R
\end{gathered}
$$

Where $\rho$ linear correlation coefficient and $\emptyset$ is standard normal cumulative distribution function

(2) T Copula:

$$
\begin{gathered}
C(u, v)=\int_{-\infty}^{t_{v}^{-1}(u)} \int_{-\infty}^{t_{v}^{-1}(v)} \frac{1}{2 \pi\left(1-\rho^{2}\right)^{1 / 2}} \exp \left\{1+\frac{x^{2}+y^{2}-2 \rho x y}{v\left(1-\rho^{2}\right)}\right\}^{-(v+2) / 2} d x d y \\
x, y \in R
\end{gathered}
$$

where $\rho$ linear correlation coefficient, $t_{v}$ is cumulative distribution function of $t$ distribution with $v$ degree of freedom

(3) Gumbel Copula: 


$$
C(u, v)=\exp \left\{-\left[(-\ln u)^{\theta}+(-\ln v)^{\theta}\right]^{1 / \theta}\right\}
$$

where $\theta$ measures dependency between $\mathrm{u}$ and $\mathrm{v}$

(4) Clayton Copula:

$$
C(u, v)=\left(u^{-\theta}+v^{-\theta}-1\right)^{-1 / \theta}
$$

where $\theta$ measures dependency between $\mathrm{u}$ and $\mathrm{v}$

(5) Frank Copula:

$$
C(u, v)=-\frac{1}{\theta} \ln \left[1+\frac{\left(e^{-\theta u}-1\right)\left(e^{-\theta v}-1\right)}{\left(e^{-\theta}-1\right)}\right]
$$

where $\theta$ measures dependency between $\mathrm{u}$ and $\mathrm{v}$

The joint distribution (of multi-model ensemble data) after Copula is then used to get probabilistic projections/scenarios for future and historical data which in-turn is used to study changes, trends and probabilities of those variables in future climate change scenario. 


\section{$6 \quad$ Results}

\subsection{Verification of bootstrap sampling in multi model ensemble}

We intended to generate multi-model ensemble to compute the mean statistics of models for combining the strength of each model; i.e. to get a series of mean values from a set of resample datasets instead of obtaining only one mean from single sample. Thus, estimates of mean statistics and variance would be tested in order to judge performance of multimodel ensemble scenario against 10 individual GCMs, both in historical and future data. For both historical and future data, the performance is tested in 2 different seasons, namely wet season (October to March) and dry season (April to September), for both precipitation and temperature variables. Thus seasonal averages for the 30 years period in consideration for multi-model ensemble was tested against the individual GCMs.

Mean absolute error (MAE) is calculated for the both of the original multi-model ensemble and multi-model ensemble with bootstrap sampling ensemble datasets regarding to the observation dataset from the same historical period:

$$
M A E=\frac{\sum_{t=1}^{T} \sum_{i=1}^{N}\left|\operatorname{Sim}_{t i}-O b s_{t}\right|}{N * T}
$$

Where $\mathrm{T}$ represents each year from the historical period and here $T=30 . \mathrm{N}$ is the total number of elements included in each year. For original ensemble dataset, $\mathrm{N}$ is equal to 10 and for the bootstrap sampling ensemble dataset, $\mathrm{N}$ is equal to $200 . \mathrm{Sim}_{t i}$ is the value of each ensemble member from each year and $O b s_{t}$ is the observation value of each year.

Figure 2 represents MAE values for precipitation and temperature in all sub-basins across CRB. It can be observed that bootstrap sampled multi-model ensemble outperforms the original multi-model ensemble against the observations in both season/climatic 
variables/Sub-basins. The percentages of MAE improvement averaged over 10 sub basins of CRB from bootstrap sampled ensemble compared to mean-original ensemble data sets is $14.56 \%$ for precipitation in dry season and $12.56 \%$ in wet seasons, whereas it is $19.29 \%$ and $18.15 \%$ for dry and wet season for temperature respectively. Thus it could be concluded that bootstrap sampled ensemble data sets have an advantage of combining multi models' strengths and result in decreasing the bias between simulations and observations than using original multi-model ensemble.

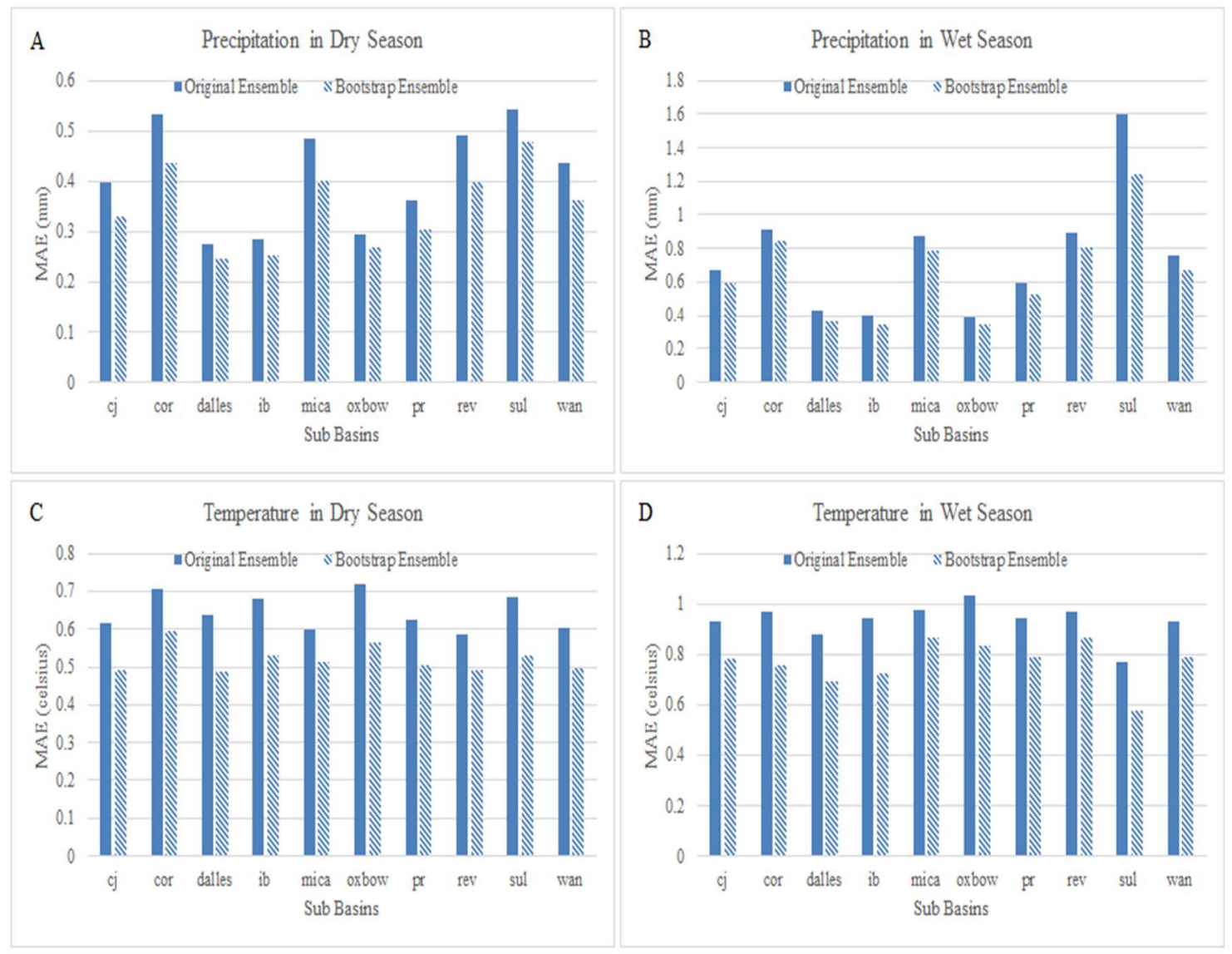

Figure 2 Mean absolute value (MAE) for bootstrap sampled multi-model ensemble and original GCMs ensemble data sets in the historical period against observation data for precipitation (ADry Season and B-Wet Season) and temperature (C- Dry Season and D-Wet Season). 
Further, frequency based histogram of bootstrap sampled multi-model ensemble is compared to $10 \mathrm{GCMs}$ in all 10 sub-basins of $\mathrm{CRB}$, to compare mean and variance statistics. Figure 3 and 4, represent the frequency based histograms of precipitation for bootstrap sampled multi-model ensemble against original GCMs ensemble in historical period (1970-1999) for dry and wet season respectively whereas figure 5 and 6 represents the same for temperature. It can be noted from Figure. 3, 4, 5, and 6 that histograms of bootstrap sampled ensemble are narrow in spread compared with original GCMs ensemble in all 10 sub basins in both season and variables in consideration. The narrow spread histograms of bootstrap sampled multi-model ensemble reduce the uncertainty/variance due to its shorter tails as compared to those of the histograms in original ensemble datasets, which in turn provides more accurate assumption of mean and variance of the dataset from 10 GCMs in consideration. 

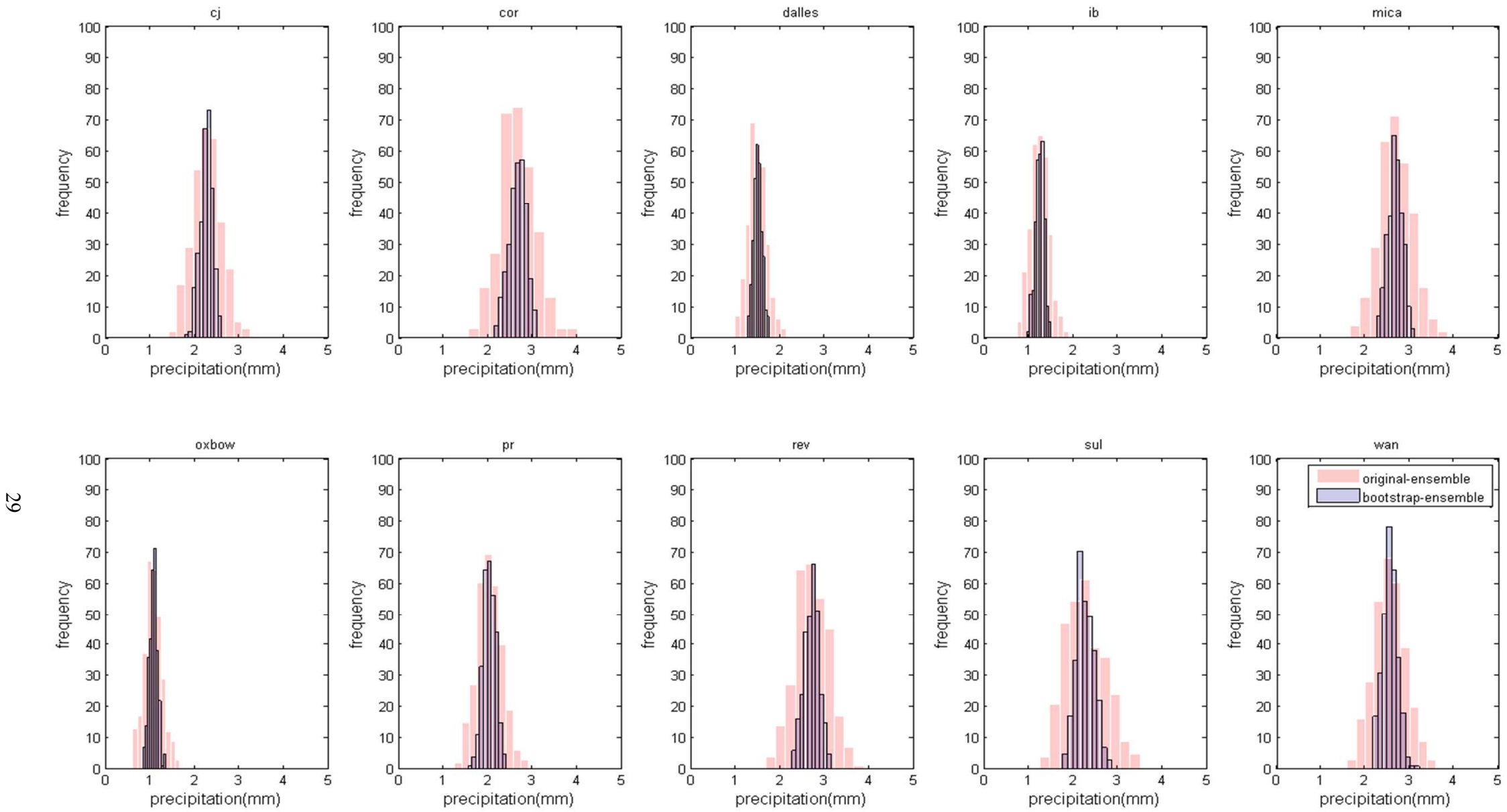

Figure 3 Frequency based histograms of precipitation seasonal average data sets in dry season for original GCMs and bootstrap sampled multimodel ensemble over the historical period (1970-1999) in 10 sub basins of CRB. The pink color represents the original GCMs dataset and the blue color represents the bootstrap sampled multi-model ensemble dataset. 

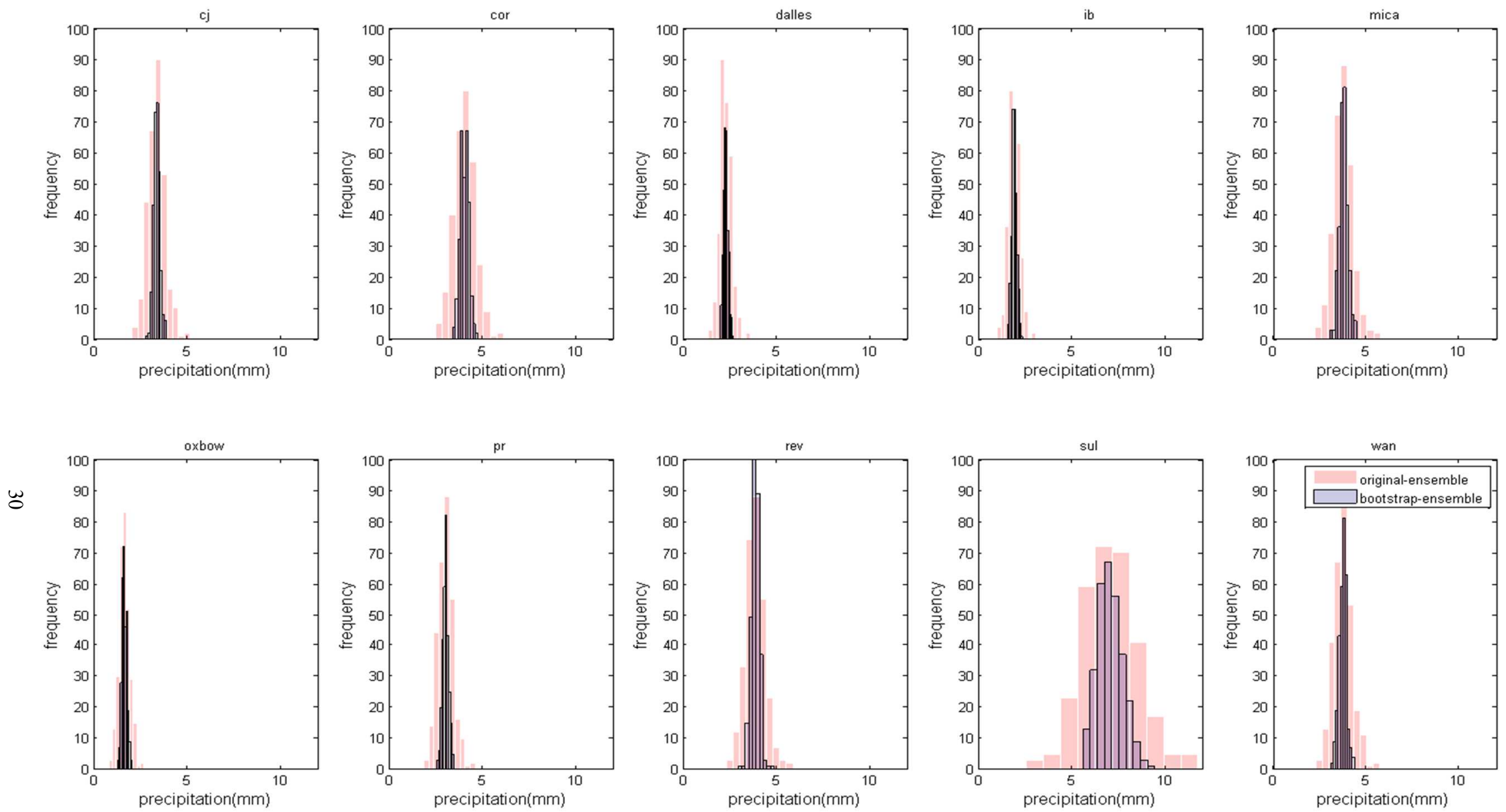

Figure 4 Frequency based histograms of precipitation seasonal average data sets in wet season for original GCMs and bootstrap sampled multimodel ensemble over the historical period (1970-1999) in 10 sub basins of CRB. The pink color represents the original GCMs dataset and the blue color represents the bootstrap sampled multi-model ensemble dataset. 


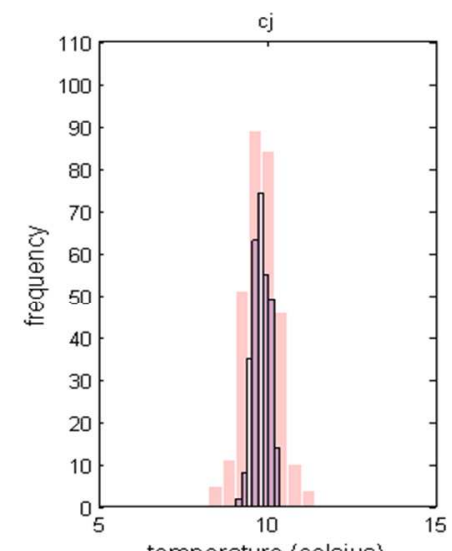

temperature (celsius)

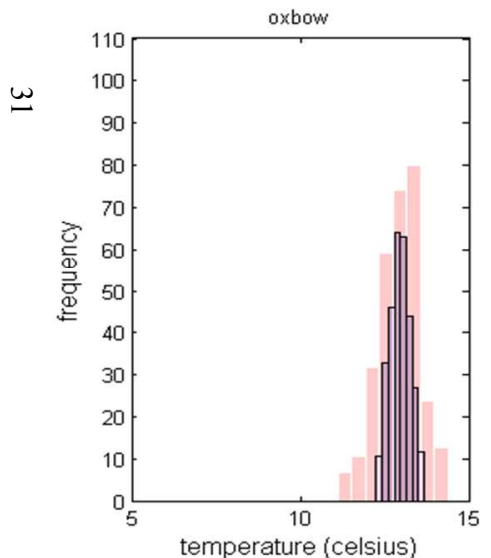

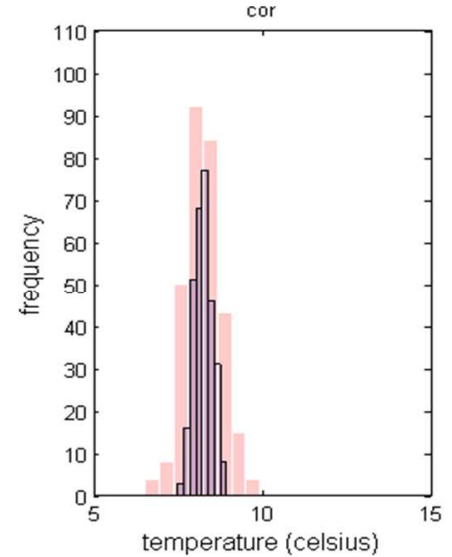

temperature (celsius)

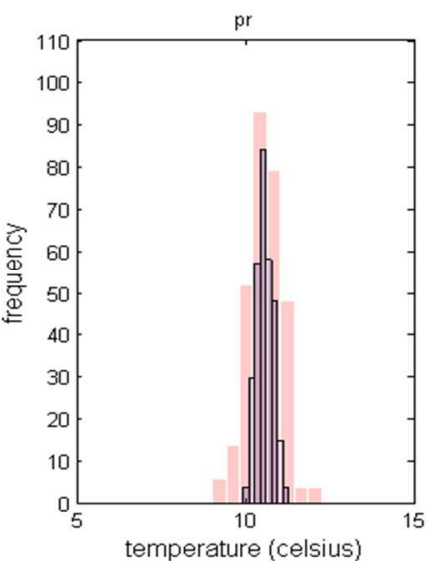

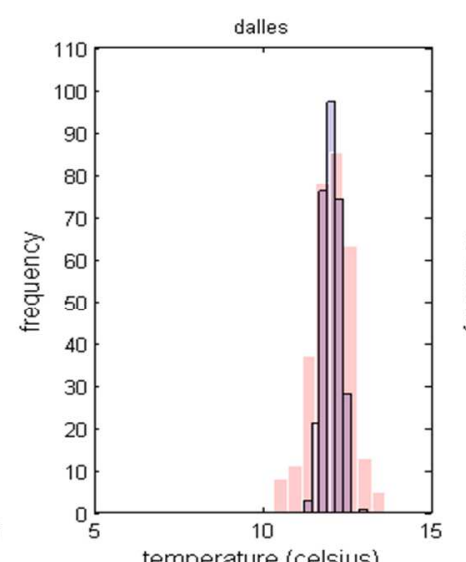

temperature (celsius)

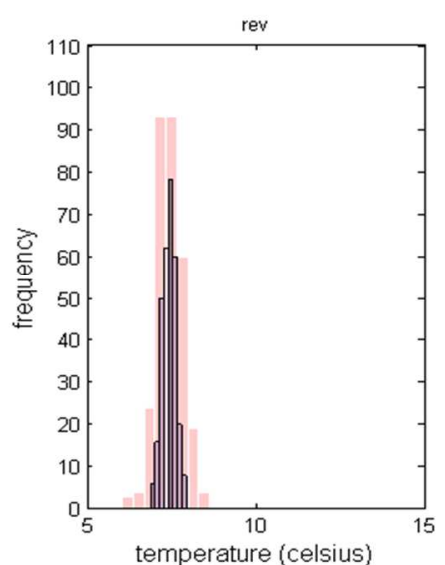

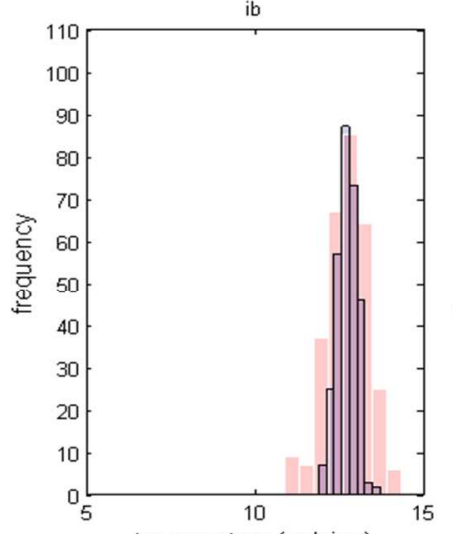

temperature (celsius)

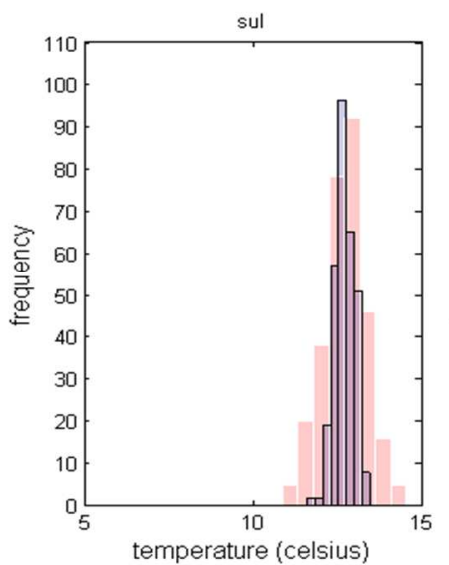

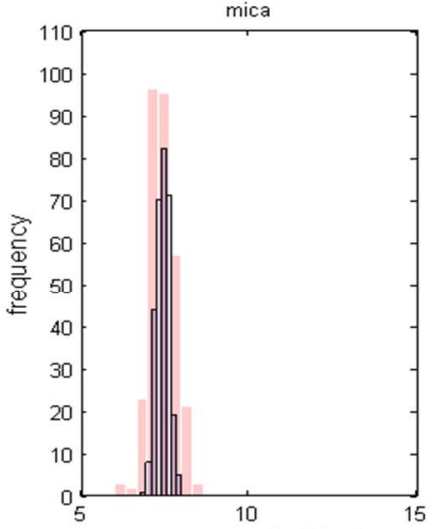

temperature (celsius)

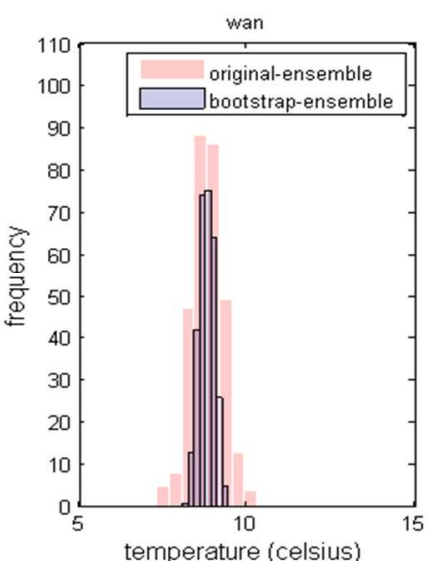

Figure 5 Frequency based histograms of temperature seasonal average data sets in dry season for original GCMs and bootstrap sampled multimodel ensemble over the historical period (1970-1999) in 10 sub basins of CRB. The pink color represents the original GCMs dataset and the blue color represents the bootstrap sampled multi-model ensemble dataset. 

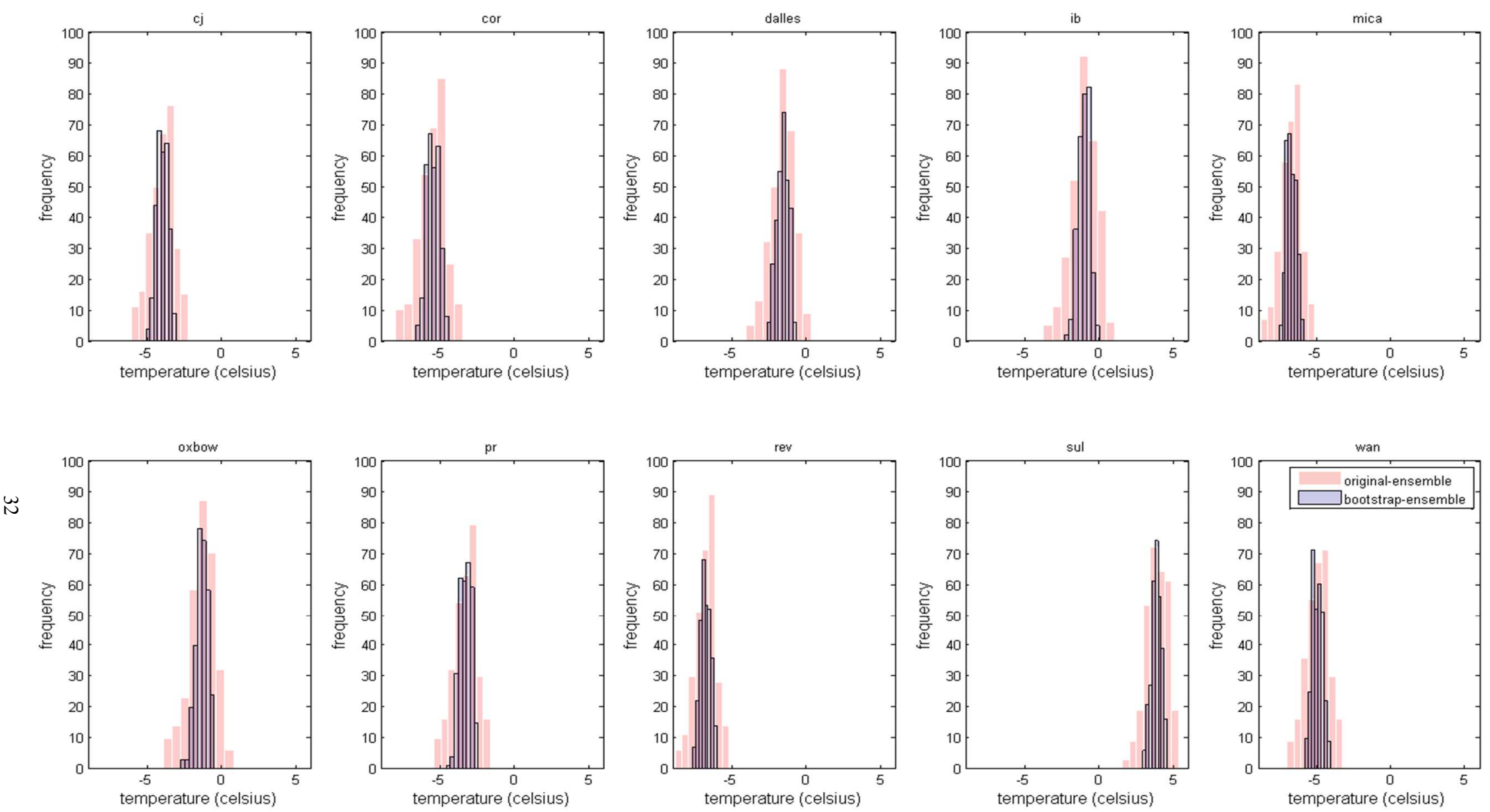

Figure 6 Frequency based histograms of temperature seasonal average data sets in wet season for original GCMs and bootstrap sampled multimodel ensemble over the historical period (1970-1999) in 10 sub basins of CRB. The pink color represents the original GCMs dataset and the blue color represents the bootstrap sampled multi-model ensemble datase 


\subsection{Copula based joint relationship between temperature and precipitation}

\subsubsection{Marginal distribution selection}

Since bootstrap sampled multi-model ensemble (herein called as multi-model ensemble) is found to be sufficient representation of the mean and variation of $10 \mathrm{GCMs}$ in both historical and future period's, thus application of Copula would be performed on the same. The joint distribution/projections of both temperature and precipitation variables is developed for both historical and future periods and both seasons.

Application of Copula starts with fitting the theoretical distributions to temperature and precipitation multi-model ensemble datasets. Seven distributions including Gamma, Generalized Extreme Value (GEV), Lognormal, Gaussian, Weibull, Gumbel, and Exponential distributions are fitted to temperature and precipitation in both dry and wet seasons; both for historical (1970-1999) and future period (2070-2099) respectively. This is performed separately for each of the sub-basins. The parameters of marginal distributions are estimated by Maximum Likelihood Estimation method. Kolmogorov-Smirnov (K-S) test based on hypothesis test is used to find the appropriate theoretical distributions according the $\mathrm{p}$-value at the selected significance level $\alpha=0.05$ (If $\mathrm{p}$-value is large than 0.05 , the ensemble dataset belongs to this reference theoretical distribution. Otherwise we will reject the null hypothesis that the dataset belongs to this reference theoretical distribution).

The Kolmogorov-Smirnov test (K-S test) is nonparametric test that will be used to choose the reference distribution suitable to the dataset. The K-S statistics quantifies the maximum 
distance between the empirical cumulative distribution function (CDF) of the dataset and the reference distribution's CDF.

$$
\mathrm{D}=\operatorname{Max}\{|F(x)-G(x)|\}
$$

where $\mathrm{F}(\mathrm{x})$ and $\mathrm{G}(\mathrm{x})$ are the empirical and reference CDFs, respectively. Here our null hypothesis that our dataset follows the reference distribution and the alternative hypothesis is that our dataset doesn't follow it. Based on the chosen significance level (like $\alpha=0.05$ ), the calculated $p$-value if larger than $\alpha$ then we accept our null hypothesis otherwise reject the null hypothesis.

Furthermore, Akaike Information Criterion (AIC) values are used to choose the best theoretical distribution from the approved theoretical distributions. Theoretical distribution with minimum AIC value is the best fitted one. (Madadgar et al. 2012 and Akaike et al. 1974 ).

Akaike information criterion (AIC) works with the trade-off between the goodness of fit of the model and the complexity of the model. For any statistical model, the AIC value is

$$
\mathrm{AIC}=2 \times \mathrm{k}-2 \times \ln (L)
$$

where $\mathrm{k}$ is the number of parameters in the model, and $\mathrm{L}$ is the maximized value of the likelihood function for the model. The minimum value of AIC indicates the most suitable statistical model. AIC value not only rewards the goodness-of-fit, but also penalizes the overfitting of the statistical model with increasing number of parameters. 
This selection is made separately for each of the sub-basin, season and climatic variables. Figures 78,9 and 10 represent the frequency based histograms of temperature and precipitation in future period for both dry and wet seasons respectively. Similar to the observations of historical period, the histograms of bootstrap sampled ensemble are narrow in spread compared with original GCMs ensemble in all 10 sub basins in both season and variables in consideration. Table 3 lists the marginal distribution selection results for each of the sub-basins separately. 

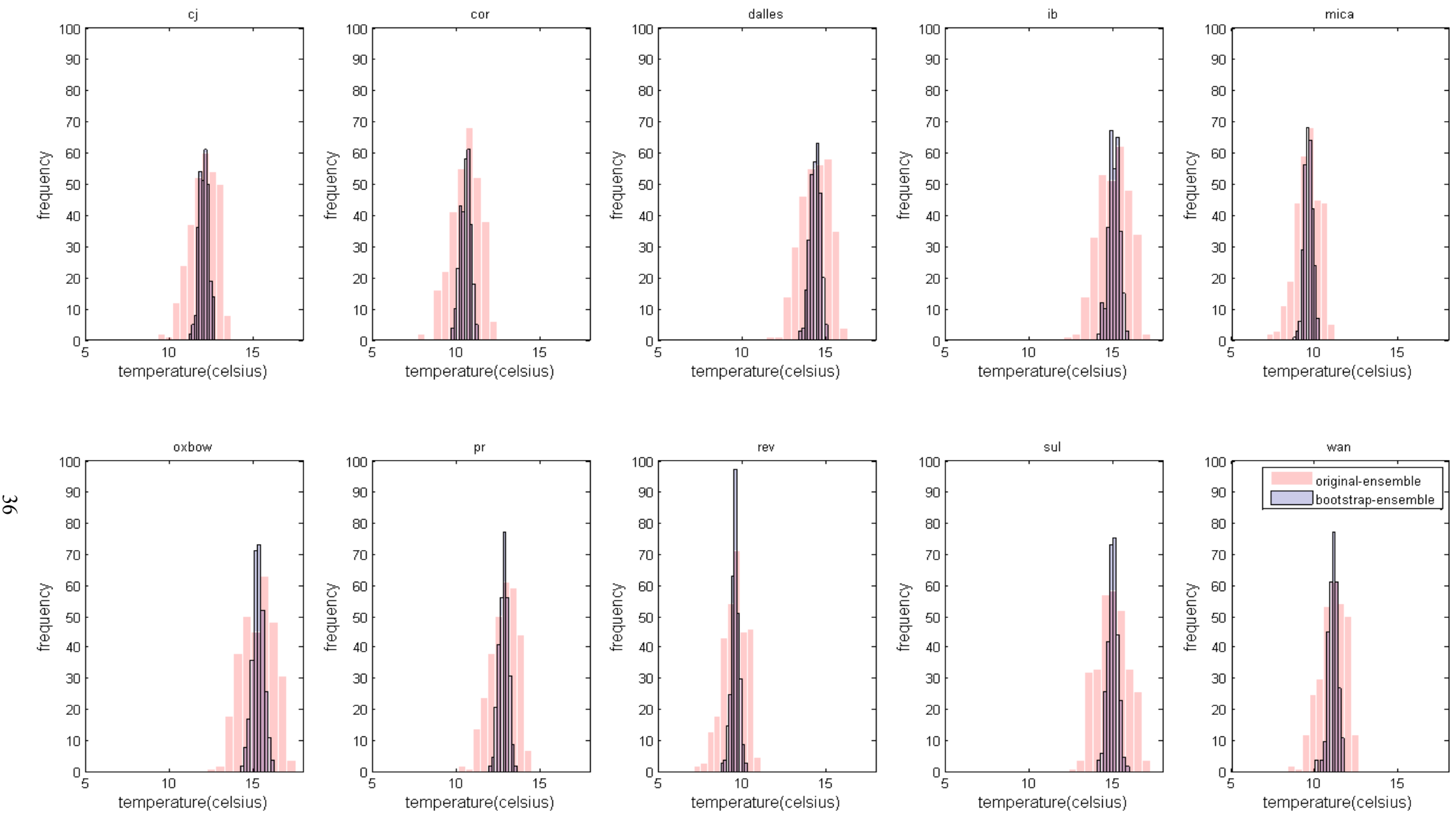

Figure 7 Frequency based histograms of temperature seasonal average data sets in dry seasons of original ensemble and bootstrap sampling ensemble over the future period (2070-2099) in 10 sub basins of CRB. The pink color represents the original ensemble dataset and the blue color represents the bootstrap sampling ensemble dataset. 

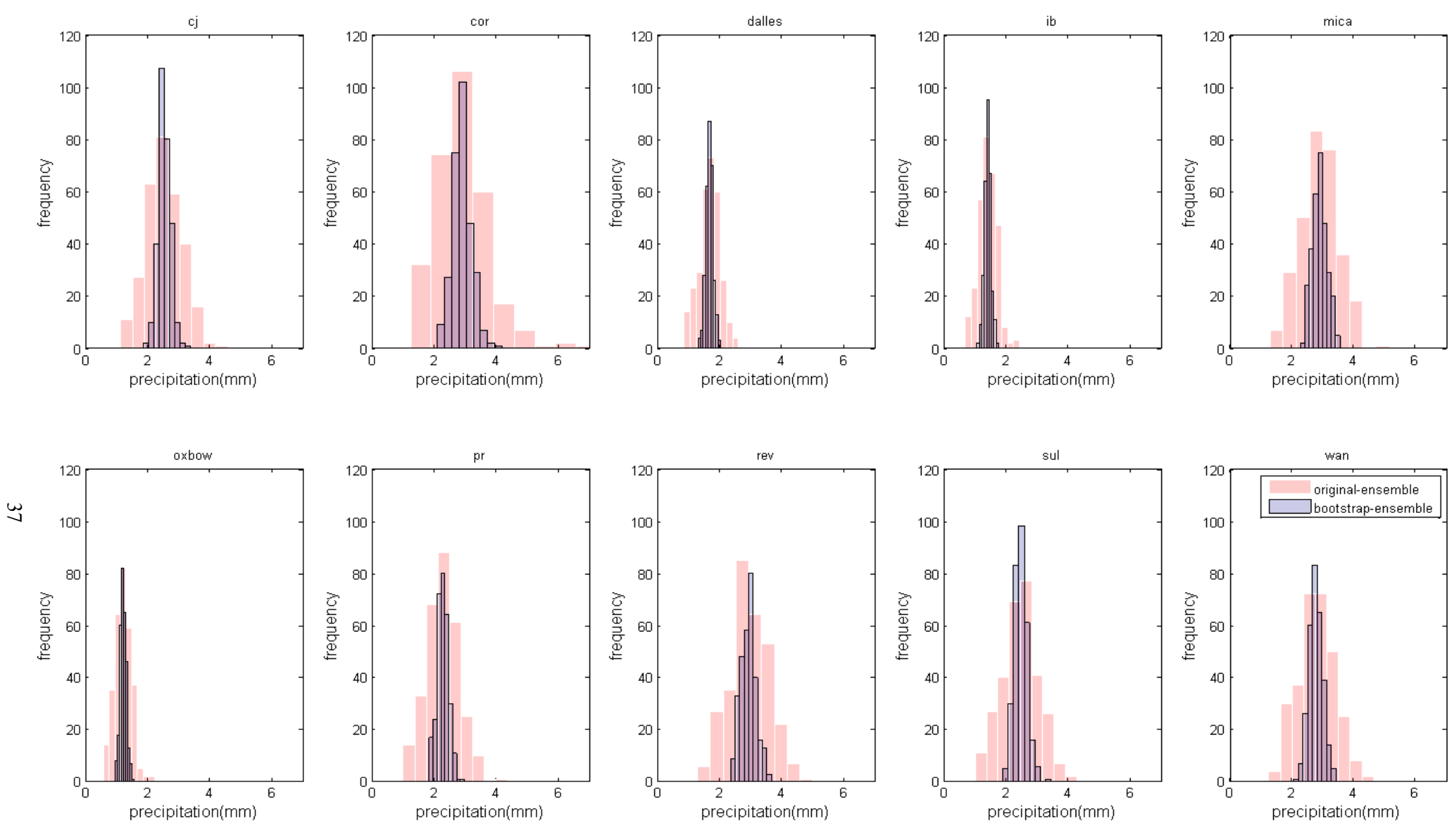

Figure 8 Frequency based histograms of precipitation seasonal average data sets in dry seasons of original ensemble and bootstrap sampling ensemble over the future period (2070-2099) in 10 sub basins of CRB. The pink color represents the original ensemble dataset and the blue color represents the bootstrap sampling ensemble dataset. 

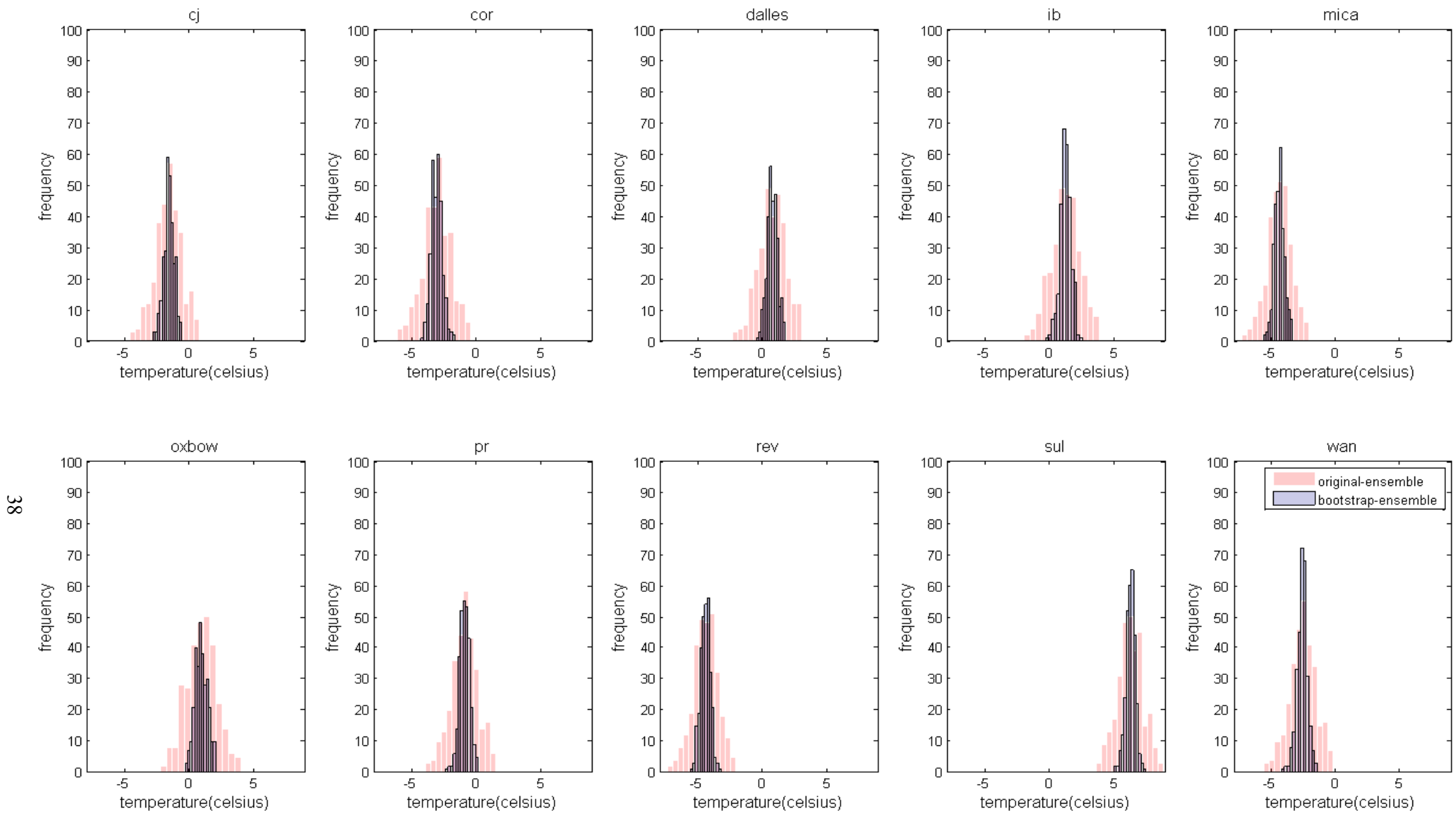

Figure 9 Frequency based histograms of temperature seasonal average data sets in wet seasons of original ensemble and bootstrap sampling ensemble over the future period (2070-2099) in $10 \mathrm{sub}$ basins of CRB. The pink color represents the original ensemble dataset and the blue color represents the bootstrap sampling ensemble dataset. 

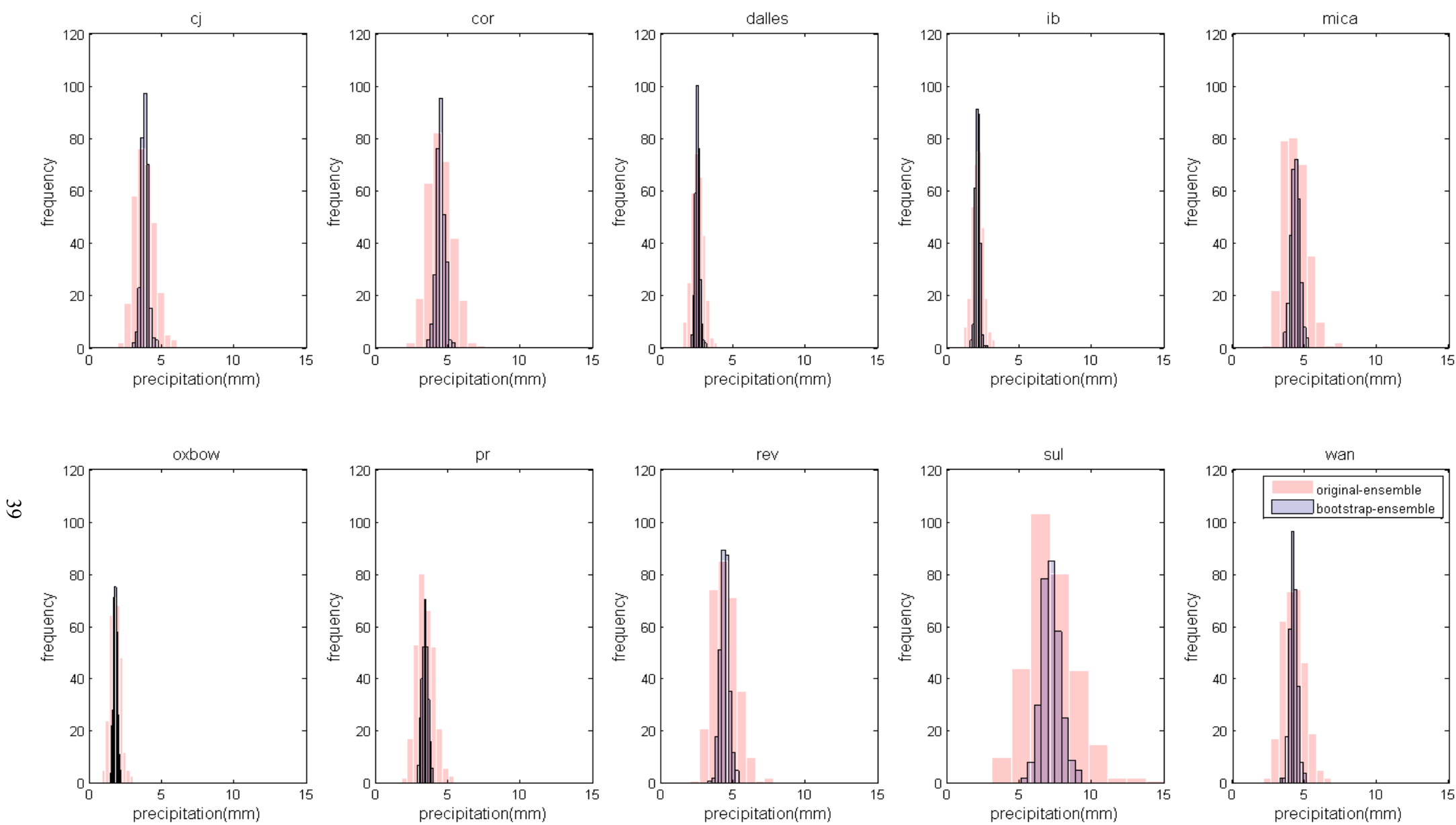

Figure 10 Frequency based histograms of precipitation seasonal average data sets in wet seasons of original ensemble and bootstrap sampling ensemble over the future period (2070-2099) in 10 sub basins of CRB. The pink color represents the original ensemble dataset and the blue color represents the bootstrap sampling ensemble dataset. 
Table 3 Best marginal distributions selection for precipitation and temperature in dry and wet season respectively. The selection is separately made for historical and future data over all 10 sub basins of CRB (Distributions with least AIC values are chosen amongst the accepted distributions, indicated by bold below for each basin/season/variable).

\begin{tabular}{|c|c|c|c|c|c|c|c|c|c|c|c|c|c|c|}
\hline \multirow{2}{*}{ Sub-Basin } & \multirow{2}{*}{ Period } & \multirow{2}{*}{$\begin{array}{l}\text { Distribution } \\
\text { / Season }\end{array}$} & \multicolumn{3}{|c|}{ Dry Season- P } & \multicolumn{3}{|c|}{ Dry Season- T } & \multicolumn{3}{|c|}{ Wet Season- P } & \multicolumn{3}{|c|}{ Wet Season- T } \\
\hline & & & $\mathrm{p}$-value & Hypothe. & $\mathrm{AIC}$ & $\begin{array}{c}\mathrm{p}- \\
\text { value }\end{array}$ & Hypothe. & AIC & $\begin{array}{c}\mathrm{p}- \\
\text { value }\end{array}$ & Hypothe. & AIC & $\begin{array}{c}\mathrm{p}- \\
\text { value }\end{array}$ & Hypothe. & $\mathrm{AIC}$ \\
\hline \multirow{12}{*}{ Chief Joseph } & \multirow{6}{*}{ Historical } & Gamma & 0.30 & Accept & 38.15 & 0.75 & Accept & 64.36 & 0.97 & Accept & 65.75 & $\mathrm{NaN}$ & $\mathrm{NaN}$ & $\mathrm{NaN}$ \\
\hline & & GEV & 0.74 & Accept & 36.77 & 0.78 & Accept & 66.44 & 0.95 & Accept & 67.51 & 0.98 & Accept & 87.30 \\
\hline & & Lognormal & 0.26 & Accept & 39.58 & 0.77 & Accept & 64.28 & 0.97 & Accept & 65.95 & $\mathrm{NaN}$ & $\mathrm{NaN}$ & $\mathrm{NaN}$ \\
\hline & & Gaussian & 0.46 & Accept & 36.25 & 0.66 & Accept & 64.74 & 0.85 & Accept & 66.49 & 0.64 & Accept & 89.64 \\
\hline & & Gumbel & 0.63 & Accept & 36.25 & 0.22 & Accept & 73.25 & 0.45 & Accept & 72.20 & 0.95 & Accept & 86.29 \\
\hline & & Exp & 0.00 & Reject & 110.94 & 0.00 & Reject & 199.10 & 0.00 & Reject & 132.29 & $\mathrm{NaN}$ & $\mathrm{NaN}$ & $\mathrm{NaN}$ \\
\hline & \multirow{6}{*}{ Future } & Gamma & 0.62 & Accept & 503.45 & 0.40 & Accept & 721.38 & 0.90 & Accept & 611.24 & $\mathrm{NaN}$ & $\mathrm{NaN}$ & $\mathrm{NaN}$ \\
\hline & & GEV & 0.87 & Accept & 503.67 & 0.85 & Accept & 698.05 & 0.95 & Accept & 613.26 & 0.84 & Accept & 869.68 \\
\hline & & Lognormal & 0.25 & Accept & 513.04 & 0.35 & Accept & 725.43 & 0.76 & Accept & 612.76 & $\mathrm{NaN}$ & $\mathrm{NaN}$ & $\mathrm{NaN}$ \\
\hline & & Gaussian & 0.90 & Accept & 499.26 & 0.42 & Accept & 714.50 & 0.32 & Accept & 617.62 & 0.86 & Accept & 870.57 \\
\hline & & Gumbel & 0.04 & Reject & 563.30 & 0.61 & Accept & 705.18 & 0.01 & Reject & 698.16 & 0.05 & Reject & 894.25 \\
\hline & & Exp & 0.00 & Reject & 1156.38 & 0.00 & Reject & 2094.78 & 0.00 & Reject & 1403.92 & $\mathrm{NaN}$ & $\mathrm{NaN}$ & $\mathrm{NaN}$ \\
\hline \multirow{7}{*}{ Corra Linn } & \multirow{7}{*}{ Historical } & Gamma & 0.37 & Accept & 55.49 & 0.88 & Accept & 74.78 & 0.42 & Accept & 81.06 & $\mathrm{NaN}$ & $\mathrm{NaN}$ & $\mathrm{NaN}$ \\
\hline & & GEV & 0.70 & Accept & 55.40 & 0.97 & Accept & 76.46 & 0.49 & Accept & 82.81 & 0.96 & Accept & 89.33 \\
\hline & & Lognormal & 0.27 & Accept & 57.35 & 0.93 & Accept & 74.54 & 0.56 & Accept & 81.01 & $\mathrm{NaN}$ & $\mathrm{NaN}$ & $\mathrm{NaN}$ \\
\hline & & Gaussian & 0.65 & Accept & 53.35 & 0.81 & Accept & 75.62 & 0.22 & Accept & 82.62 & 0.76 & Accept & 90.01 \\
\hline & & Weibull & 0.72 & Accept & 52.99 & 0.52 & Accept & 81.86 & 0.18 & Accept & 83.65 & $\mathrm{NaN}$ & $\mathrm{NaN}$ & $\mathrm{NaN}$ \\
\hline & & Gumbel & 0.42 & Accept & 56.00 & 0.37 & Accept & 85.70 & 0.08 & Accept & 89.20 & 0.98 & Accept & 88.43 \\
\hline & & Exp & 0.00 & Reject & 118.33 & 0.00 & Reject & 189.57 & 0.00 & Reject & 140.65 & $\mathrm{NaN}$ & $\mathrm{NaN}$ & $\mathrm{NaN}$ \\
\hline
\end{tabular}




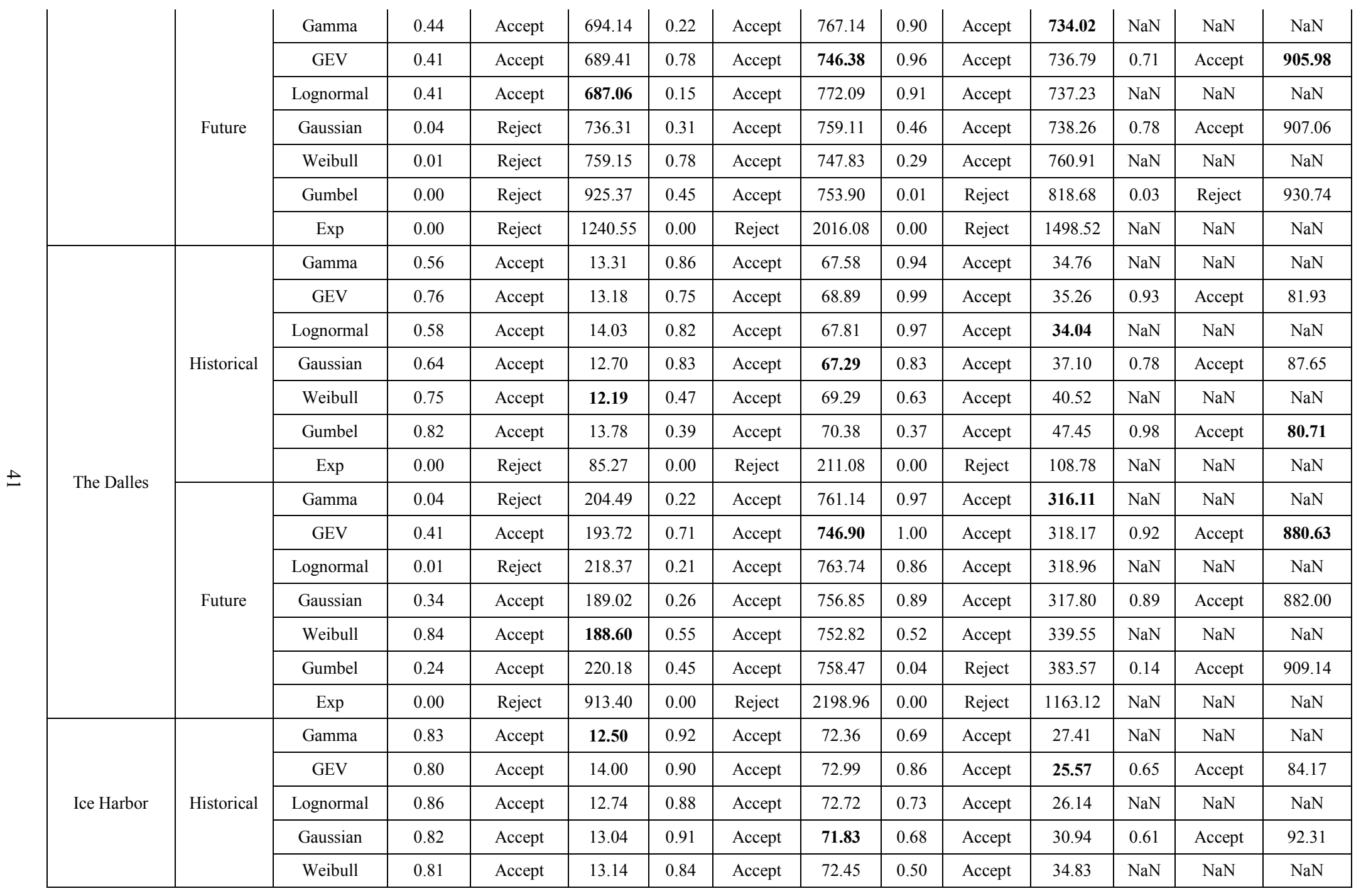




\begin{tabular}{|c|c|c|c|c|c|c|c|c|c|c|c|c|c|c|}
\hline & & Gumbel & 0.74 & Accept & 16.44 & 0.79 & Accept & 73.32 & 0.21 & Accept & 43.29 & 0.95 & Accept & 82.86 \\
\hline & & Exp & 0.00 & Reject & 74.21 & 0.00 & Reject & 214.20 & 0.00 & Reject & 98.60 & $\mathrm{NaN}$ & $\mathrm{NaN}$ & $\mathrm{NaN}$ \\
\hline & \multirow{6}{*}{ Future } & Gamma & 0.44 & Accept & 112.73 & 0.34 & Accept & 802.66 & 0.82 & Accept & 260.98 & $\mathrm{NaN}$ & $\mathrm{NaN}$ & $\mathrm{NaN}$ \\
\hline & & Lognormal & 0.19 & Accept & 123.75 & 0.28 & Accept & 804.70 & 0.59 & Accept & 265.61 & $\mathrm{NaN}$ & $\mathrm{NaN}$ & $\mathrm{NaN}$ \\
\hline & & Gaussian & 0.75 & Accept & 104.87 & 0.40 & Accept & 799.51 & 0.93 & Accept & 261.61 & 0.76 & Accept & 920.31 \\
\hline & & Weibull & 0.59 & Accept & 116.44 & 0.29 & Accept & 802.35 & 0.28 & Accept & 282.81 & $\mathrm{NaN}$ & $\mathrm{NaN}$ & $\mathrm{NaN}$ \\
\hline & & Gumbel & 0.05 & Reject & 172.63 & 0.27 & Accept & 809.27 & 0.02 & Reject & 333.24 & 0.12 & Accept & 953.93 \\
\hline & & Exp & 0.00 & Reject & 807.12 & 0.00 & Reject & 2229.01 & 0.00 & Reject & 1053.53 & $\mathrm{NaN}$ & $\mathrm{NaN}$ & $\mathrm{NaN}$ \\
\hline \multirow{13}{*}{ Mica } & \multirow{6}{*}{ Historical } & Gamma & 0.63 & Accept & 53.07 & 0.78 & Accept & 63.87 & 0.59 & Accept & 90.85 & $\mathrm{NaN}$ & $\mathrm{NaN}$ & $\mathrm{NaN}$ \\
\hline & & GEV & 0.83 & Accept & 52.95 & 0.89 & Accept & 65.37 & 0.57 & Accept & 87.05 & 0.99 & Accept & 93.66 \\
\hline & & Lognormal & 0.49 & Accept & 54.99 & 0.83 & Accept & 63.74 & 0.38 & Accept & 94.59 & $\mathrm{NaN}$ & $\mathrm{NaN}$ & $\mathrm{NaN}$ \\
\hline & & Gaussian & 0.88 & Accept & 50.82 & 0.68 & Accept & 64.38 & 0.86 & Accept & 86.55 & 0.67 & Accept & 96.41 \\
\hline & & Gumbel & 0.54 & Accept & 54.02 & 0.34 & Accept & 71.05 & 0.38 & Accept & 87.14 & 0.98 & Accept & 92.21 \\
\hline & & Exp & 0.00 & Reject & 121.65 & 0.00 & Reject & 182.32 & 0.00 & Reject & 138.66 & $\mathrm{NaN}$ & $\mathrm{NaN}$ & $\mathrm{NaN}$ \\
\hline & & Gamma & 0.53 & Accept & 580.37 & 0.40 & Accept & 662.34 & 0.87 & Accept & 714.37 & $\mathrm{NaN}$ & $\mathrm{NaN}$ & $\mathrm{NaN}$ \\
\hline & & GEV & 0.67 & Accept & 578.22 & 0.99 & Accept & 643.56 & 0.97 & Accept & 716.68 & 0.82 & Accept & 820.73 \\
\hline & & Lognormal & 0.21 & Accept & 592.26 & 0.32 & Accept & 667.14 & 0.92 & Accept & 714.53 & $\mathrm{NaN}$ & $\mathrm{NaN}$ & $\mathrm{NaN}$ \\
\hline & Future & Gaussian & 0.90 & Accept & 571.66 & 0.64 & Accept & 654.51 & 0.57 & Accept & 725.00 & 0.92 & Accept & 820.31 \\
\hline & & Weibull & 0.63 & Accept & 577.93 & 0.46 & Accept & 645.90 & 0.08 & Accept & 755.58 & $\mathrm{NaN}$ & $\mathrm{NaN}$ & $\mathrm{NaN}$ \\
\hline & & Gumbel & 0.06 & Accept & 626.23 & 0.23 & Accept & 652.75 & 0.00 & Reject & 828.19 & 0.08 & Accept & 847.34 \\
\hline & & Exp & 0.00 & Reject & 1239.08 & 0.00 & Reject & 1956.20 & 0.00 & Reject & 1476.33 & $\mathrm{NaN}$ & $\mathrm{NaN}$ & $\mathrm{NaN}$ \\
\hline & & Gamma & 0.71 & Accept & 15.22 & 0.91 & Accept & 75.90 & 0.55 & Accept & 25.85 & $\mathrm{NaN}$ & $\mathrm{NaN}$ & $\mathrm{NaN}$ \\
\hline Oxbow & Historical & GEV & 0.78 & Accept & 16.84 & 0.90 & Accept & 76.18 & 0.94 & Accept & 21.74 & 0.72 & Accept & 91.27 \\
\hline & & Lognormal & 0.69 & Accept & 15.65 & 0.88 & Accept & 76.30 & 0.67 & Accept & 24.12 & $\mathrm{NaN}$ & $\mathrm{NaN}$ & $\mathrm{NaN}$ \\
\hline
\end{tabular}




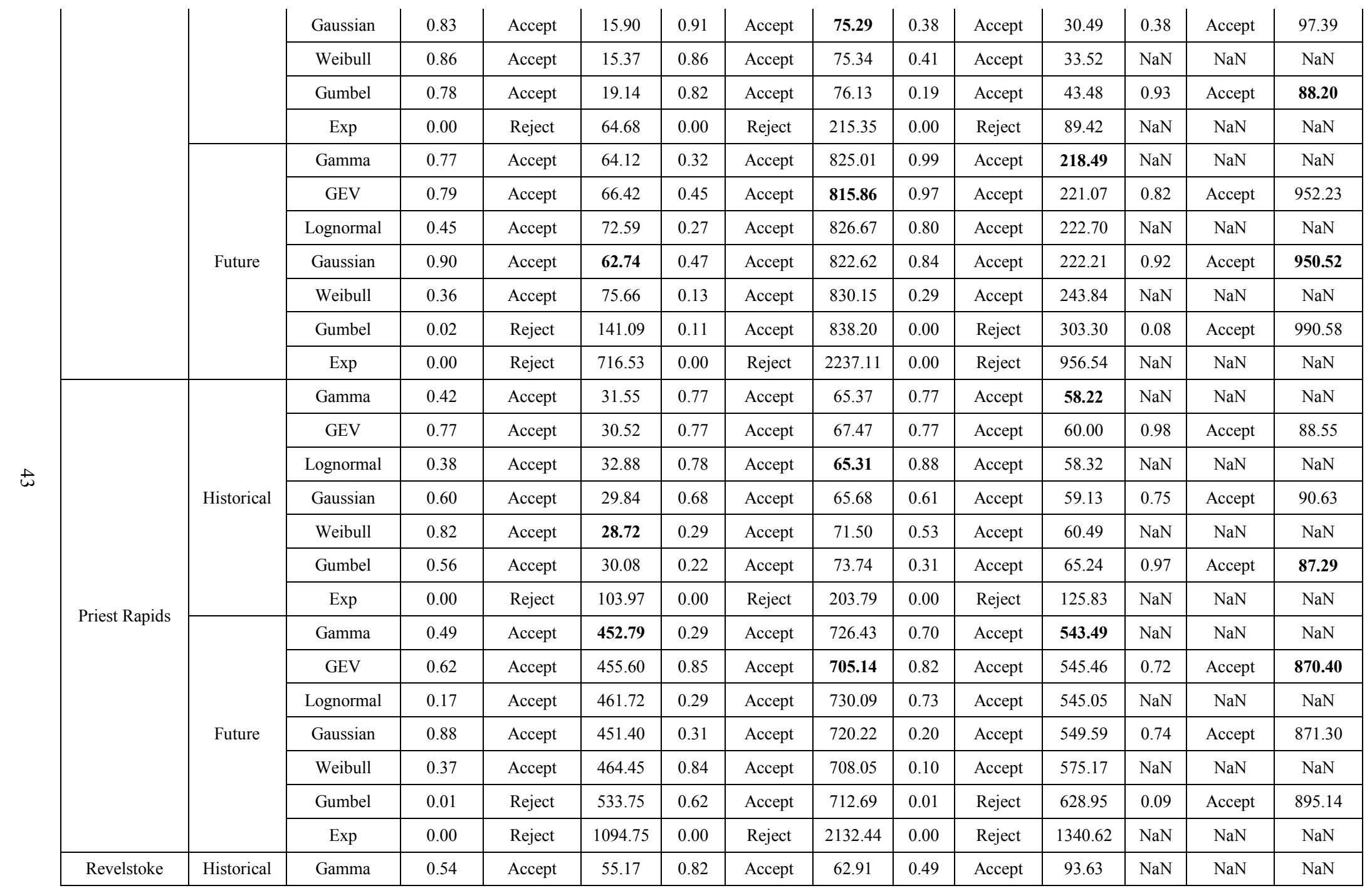




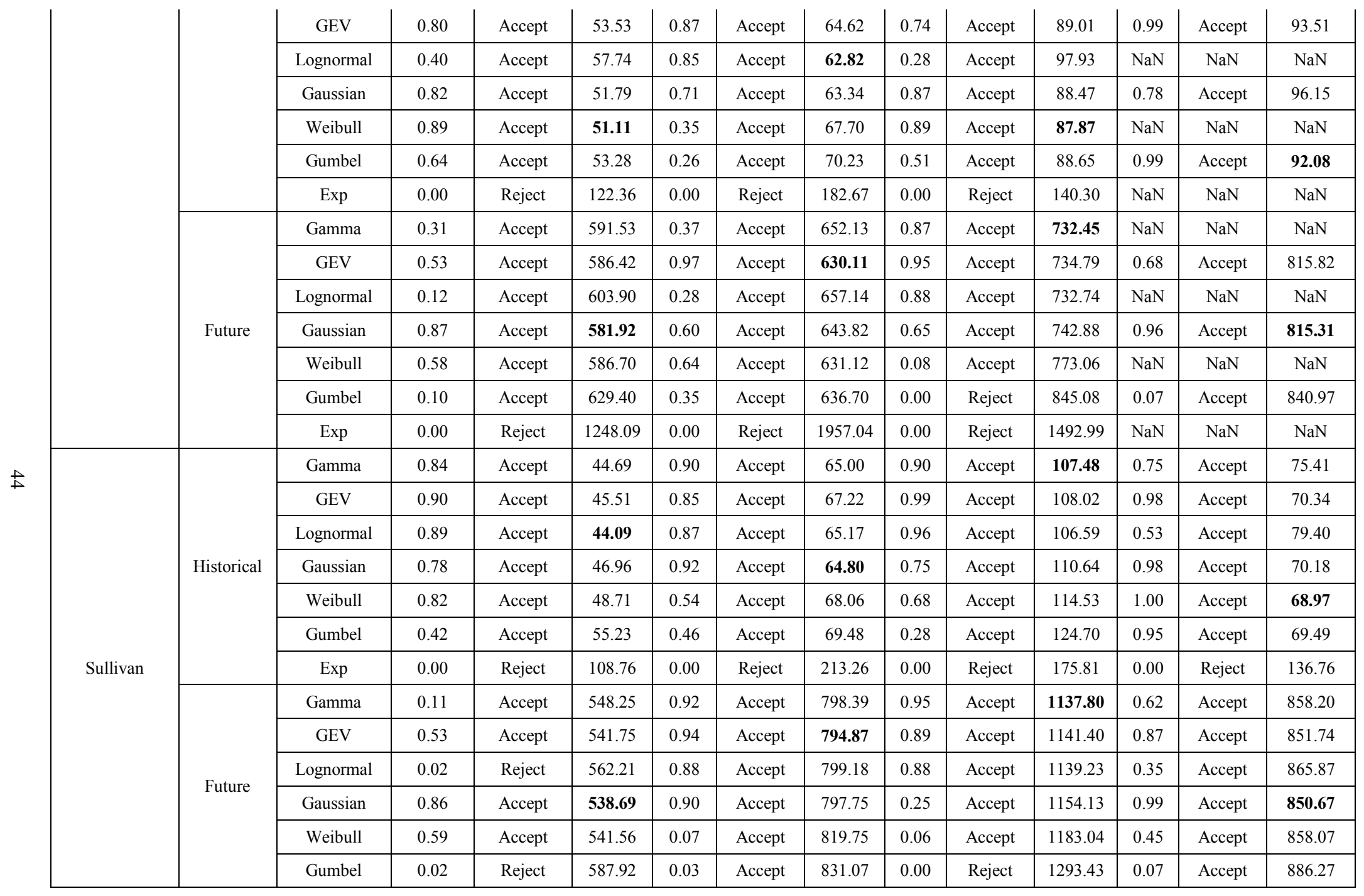




\begin{tabular}{|c|c|c|c|c|c|c|c|c|c|c|c|c|c|c|}
\hline & & Exp & 0.00 & Reject & 1141.02 & 0.00 & Reject & 2226.17 & 0.00 & Reject & 1782.91 & 0.00 & Reject & 1701.21 \\
\hline \multirow{14}{*}{ Waneta } & \multirow{7}{*}{ Historical } & Gamma & 0.65 & Accept & 44.85 & 0.93 & Accept & 63.05 & 0.95 & Accept & 73.98 & $\mathrm{NaN}$ & $\mathrm{NaN}$ & $\mathrm{NaN}$ \\
\hline & & GEV & 0.84 & Accept & 43.02 & 0.94 & Accept & 64.99 & 0.91 & Accept & 75.50 & 0.97 & Accept & 87.66 \\
\hline & & Lognormal & 0.56 & Accept & 46.45 & 0.93 & Accept & 62.92 & 0.97 & Accept & 74.49 & $\mathrm{NaN}$ & $\mathrm{NaN}$ & $\mathrm{NaN}$ \\
\hline & & Gaussian & 0.86 & Accept & 42.69 & 0.85 & Accept & 63.55 & 0.83 & Accept & 74.27 & 0.54 & Accept & 89.98 \\
\hline & & Weibull & 0.92 & Accept & 41.34 & 0.43 & Accept & 69.77 & 0.63 & Accept & 74.95 & $\mathrm{NaN}$ & $\mathrm{NaN}$ & $\mathrm{NaN}$ \\
\hline & & Gumbel & 0.69 & Accept & 42.51 & 0.33 & Accept & 72.59 & 0.32 & Accept & 78.98 & 0.98 & Accept & 86.65 \\
\hline & & Exp & 0.00 & Reject & 117.62 & 0.00 & Reject & 192.60 & 0.00 & Reject & 137.72 & $\mathrm{NaN}$ & $\mathrm{NaN}$ & $\mathrm{NaN}$ \\
\hline & \multirow{7}{*}{ Future } & Gamma & 0.65 & Accept & 555.23 & 0.33 & Accept & 711.30 & 0.94 & Accept & 673.34 & $\mathrm{NaN}$ & $\mathrm{NaN}$ & $\mathrm{NaN}$ \\
\hline & & GEV & 0.96 & Accept & 550.47 & 0.84 & Accept & 685.88 & 0.97 & Accept & 675.57 & 0.89 & Accept & 866.68 \\
\hline & & Lognormal & 0.34 & Accept & 565.82 & 0.26 & Accept & 715.81 & 0.84 & Accept & 674.65 & $\mathrm{NaN}$ & $\mathrm{NaN}$ & $\mathrm{NaN}$ \\
\hline & & Gaussian & 0.90 & Accept & 548.23 & 0.45 & Accept & 703.71 & 0.43 & Accept & 680.35 & 0.96 & Accept & 867.75 \\
\hline & & Weibull & 0.82 & Accept & \begin{tabular}{|l|l|}
553.14 \\
\end{tabular} & 0.61 & Accept & 689.18 & 0.18 & Accept & 707.07 & $\mathrm{NaN}$ & $\mathrm{NaN}$ & $\mathrm{NaN}$ \\
\hline & & Gumbel & 0.08 & Accept & 594.75 & 0.49 & Accept & 693.70 & 0.00 & Reject & 764.68 & 0.08 & Accept & 891.06 \\
\hline & & Exp & 0.00 & Reject & 1215.12 & 0.00 & Reject & 2042.28 & 0.00 & Reject & 1461.80 & $\mathrm{NaN}$ & $\mathrm{NaN}$ & $\mathrm{NaN}$ \\
\hline
\end{tabular}




\subsubsection{Goodness-of-fit test for Copula}

The cumulative distribution functions (CDFs) of temperature and precipitation are linked with copula. As discussed in methodology section, we have employed five copula functions for the same, namely Gaussian and T Copulas from Elliptical copulas; and Gumbel, Clayton and Frank from Archimedean copulas. Goodness-of-fit (GOF) test is employed to access the Copula function which describes the relationship between temperature and precipitation. GOF is based on the statistics relating the distance between the empirical and theoretical Copulas. Eventually, the parametric bootstrap procedure was employed to estimate the Cramér-von Mises statistics $(\mathrm{Sn})$ and the related p-value in order to choose the best copula function (Genest and Rémillard, 2008, Madadgar et al. 2014). If the variable's dataset fits to the parametric Copula, representing null hypothesis, $\left(H_{0}: C_{n} \in C_{\theta_{n}}\right)$, with pvalue greater than the significance level $\alpha=0.05$, then null hypothesis is accepted; otherwise rejected.

In terms of these five theoretical copula function, we are going to select the most suitable Copula to stand for datasets. Naturally, goodness-of-fit test tends to measure the distance between empirical and theoretical Copulas. Genest and Remllillard (2008) implemented a bootstrapping process to obtain the Cramer-von Mise of distance and K-S statistics as the measures of distance between the empirical and parametric copulas.

$$
S_{n}=\int_{u} \Delta C_{n}(u)^{2} d C_{n}(u)
$$

Where $S_{n}$ is Cramer-von Mise statistics, and $\Delta C_{n}(u)$ is expressed as: 


$$
\Delta C_{n}(u)=\sqrt{n}\left(C_{n}-C_{\theta_{n}}\right)
$$

Where $C_{n}$ is the empirical copula with a sample size $\mathrm{n}$, and $C_{\theta_{n}}$ is the theoretical copula estimated for a sample size of n. Here the null hypothesis is that the empirical Copula $C_{n}$ belongs to this theoretical copula. If our p-value obtained from bootstrap sampling is larger than the significance level $(\alpha)$, then we will accept our null hypothesis. Otherwise we will reject it and support our alternative hypothesis that $C_{n}$ doesn't belong to this theoretical Copula.

Therefore, among a group of Copula, the one with the greatest $\mathrm{p}$-value is preferred. Table 4 and 5 represent the statistics for choosing best copula to represent the relationship between temperature and precipitation in dry and wet seasons. Copula selection is done on seasonal data sets for all sub-basins in both historical and future period. One copula selection is performed, the same copulas are used to evaluate the changes on seasonal basis in future multi-model ensemble data and observed multi-model ensemble data. It can be observed from Table 4 that in historical dataset for dry season, T Copula is selected in 4 sub-basins followed by Frank (3), Gaussian (2) and Clayton (1). Whereas, in future dataset, $\mathrm{T}$ copula is describing the relationship between temperature and precipitation in 7 subbasins, Frank, Gaussian and Clayton are chosen in 1 sub-basin each. Gumbel Copula is not found appropriate to describe the temperature and precipitation relationships in any of the data periods. There is no co-relation between the size and location of the sub-basin and the chosen copula (the relationship between temperature and precipitation is not related to size 
and location of the sub-basin in CRB). The same phenomenon will be observed in wet seasons in both historical and future period. 
Table 4 Best Copula selection in historical and future periods over all 10 sub basins of CRB (Preferred copula is with greatest p-value) in dry seasons. Values in bold are the selected Copula for respective period for joint distribution of temperature and precipitation.

\begin{tabular}{|c|c|c|c|c|c|c|c|}
\hline Sub-Basin & Copula & Statistics & Guassian & $\mathbf{T}$ & Clayton & Gumbel & Frank \\
\hline \multirow{4}{*}{ Chief Joseph } & \multirow{2}{*}{$\begin{array}{c}\text { Historical } \\
\text { Period }\end{array}$} & p-value & 0.975 & 0.965 & 0.965 & 0.896 & 0.995 \\
\hline & & $S n$ & 0.019 & 0.018 & 0.015 & 0.023 & 0.020 \\
\hline & \multirow{2}{*}{$\begin{array}{l}\text { Future } \\
\text { Period }\end{array}$} & p-value & 0.064 & 0.114 & $\mathrm{NaN}$ & $\mathrm{NaN}$ & 0.025 \\
\hline & & $S n$ & 0.051 & 0.041 & $\mathrm{NaN}$ & $\mathrm{NaN}$ & 0.044 \\
\hline \multirow{4}{*}{ Corra Linn } & \multirow{2}{*}{$\begin{array}{l}\text { Historical } \\
\text { Period }\end{array}$} & p-value & 0.748 & 0.797 & $\mathrm{NaN}$ & $\mathrm{NaN}$ & 0.797 \\
\hline & & $S n$ & 0.032 & 0.028 & $\mathrm{NaN}$ & $\mathrm{NaN}$ & 0.028 \\
\hline & \multirow{2}{*}{$\begin{array}{l}\text { Future } \\
\text { Period }\end{array}$} & p-value & 0.035 & 0.163 & $\mathrm{NaN}$ & $\mathrm{NaN}$ & 0.025 \\
\hline & & $S n$ & 0.044 & 0.041 & $\mathrm{NaN}$ & $\mathrm{NaN}$ & 0.044 \\
\hline \multirow{4}{*}{ The Dalles } & \multirow{2}{*}{$\begin{array}{l}\text { Historical } \\
\text { Period }\end{array}$} & p-value & 0.272 & 0.411 & $\mathrm{NaN}$ & $\mathrm{NaN}$ & 0.312 \\
\hline & & $S n$ & 0.044 & 0.038 & $\mathrm{NaN}$ & $\mathrm{NaN}$ & 0.039 \\
\hline & \multirow{2}{*}{$\begin{array}{l}\text { Future } \\
\text { Period }\end{array}$} & p-value & 0.046 & 0.050 & 0.111 & 0.047 & 0.050 \\
\hline & & $S n$ & 0.062 & 0.049 & 0.136 & 0.054 & 0.052 \\
\hline \multirow{4}{*}{ Ice Harbor } & \multirow{2}{*}{$\begin{array}{l}\text { Historical } \\
\text { Period }\end{array}$} & $p$-value & 0.629 & 0.579 & $\mathrm{NaN}$ & $\mathrm{NaN}$ & 0.450 \\
\hline & & $S n$ & 0.035 & 0.035 & $\mathrm{NaN}$ & $\mathrm{NaN}$ & 0.035 \\
\hline & \multirow{2}{*}{$\begin{array}{l}\text { Future } \\
\text { Period }\end{array}$} & p-value & 0.252 & 0.391 & $\mathrm{NaN}$ & $\mathrm{NaN}$ & 0.153 \\
\hline & & $S n$ & 0.038 & 0.032 & $\mathrm{NaN}$ & $\mathrm{NaN}$ & 0.034 \\
\hline \multirow{4}{*}{ Mica } & \multirow{2}{*}{$\begin{array}{l}\text { Historical } \\
\text { Period }\end{array}$} & p-value & 0.262 & 0.738 & $\mathbf{0 . 7 7 7}$ & 0.173 & 0.411 \\
\hline & & $S n$ & 0.037 & 0.025 & 0.022 & 0.041 & 0.034 \\
\hline & \multirow{2}{*}{$\begin{array}{l}\text { Future } \\
\text { Period }\end{array}$} & p-value & 0.066 & 0.065 & 0.025 & 0.005 & 0.068 \\
\hline & & $S n$ & 0.071 & 0.061 & 0.082 & 0.057 & 0.061 \\
\hline \multirow{4}{*}{ Oxbow } & \multirow{2}{*}{$\begin{array}{l}\text { Historical } \\
\text { Period }\end{array}$} & p-value & 0.738 & 0.559 & $\mathrm{NaN}$ & $\mathrm{NaN}$ & 0.658 \\
\hline & & $S n$ & 0.031 & 0.034 & $\mathrm{NaN}$ & $\mathrm{NaN}$ & 0.033 \\
\hline & \multirow{2}{*}{$\begin{array}{l}\text { Future } \\
\text { Period }\end{array}$} & $p$-value & 0.153 & 0.144 & $\mathrm{NaN}$ & $\mathrm{NaN}$ & 0.045 \\
\hline & & $S n$ & 0.043 & 0.042 & $\mathrm{NaN}$ & $\mathrm{NaN}$ & 0.043 \\
\hline \multirow{4}{*}{$\begin{array}{l}\text { Priest } \\
\text { Rapids }\end{array}$} & \multirow{2}{*}{$\begin{array}{c}\text { Historical } \\
\text { Period }\end{array}$} & p-value & 0.906 & 0.837 & 0.837 & 0.807 & 0.946 \\
\hline & & $S n$ & 0.024 & 0.024 & 0.020 & 0.026 & 0.024 \\
\hline & \multirow{2}{*}{$\begin{array}{l}\text { Future } \\
\text { Period }\end{array}$} & p-value & 0.045 & 0.074 & $\mathrm{NaN}$ & $\mathrm{NaN}$ & 0.025 \\
\hline & & $S n$ & 0.089 & 0.073 & $\mathrm{NaN}$ & $\mathrm{NaN}$ & 0.081 \\
\hline \multirow{4}{*}{ Revelstoke } & \multirow{2}{*}{$\begin{array}{c}\text { Historical } \\
\text { Period }\end{array}$} & p-value & 0.153 & 0.688 & 0.520 & 0.153 & 0.322 \\
\hline & & $S n$ & 0.041 & 0.027 & 0.028 & 0.043 & 0.038 \\
\hline & \multirow{2}{*}{$\begin{array}{l}\text { Future } \\
\text { Period }\end{array}$} & p-value & 0.658 & 0.698 & $\mathrm{NaN}$ & $\mathrm{NaN}$ & 0.579 \\
\hline & & $S n$ & 0.028 & 0.025 & $\mathrm{NaN}$ & $\mathrm{NaN}$ & 0.025 \\
\hline \multirow{3}{*}{ TW Sullivan } & \multirow{3}{*}{$\begin{array}{l}\text { Historical } \\
\text { Period }\end{array}$} & p-value & 0.252 & 0.292 & $\mathrm{NaN}$ & $\mathrm{NaN}$ & 0.252 \\
\hline & & $\mathrm{Sn}$ & 0.048 & 0.045 & $\mathrm{NaN}$ & $\mathrm{NaN}$ & 0.045 \\
\hline & & $\mathrm{p}$-value & 0.074 & 0.203 & $\mathrm{NaN}$ & $\mathrm{NaN}$ & 0.094 \\
\hline
\end{tabular}




\begin{tabular}{|c|c|c|c|c|c|c|c|}
\hline & $\begin{array}{l}\text { Future } \\
\text { Period }\end{array}$ & $\mathrm{Sn}$ & 0.051 & 0.036 & $\mathrm{NaN}$ & $\mathrm{NaN}$ & 0.038 \\
\hline \multirow{4}{*}{ Waneta } & \multirow{2}{*}{$\begin{array}{c}\text { Historical } \\
\text { Period }\end{array}$} & p-value & 0.748 & 0.876 & 0.827 & 0.876 & 0.896 \\
\hline & & $\mathrm{Sn}$ & 0.026 & 0.023 & 0.019 & 0.026 & 0.026 \\
\hline & \multirow{2}{*}{$\begin{array}{l}\text { Future } \\
\text { Period }\end{array}$} & $\mathrm{p}$-value & 0.292 & 0.718 & $\mathrm{NaN}$ & $\mathrm{NaN}$ & 0.550 \\
\hline & & $\mathrm{Sn}$ & 0.034 & 0.024 & $\mathrm{NaN}$ & $\mathrm{NaN}$ & 0.026 \\
\hline
\end{tabular}


Table 5 Best Copula selection in historical and future periods over all 10 sub basins of CRB (Preferred copula is with greatest p-value) in wet seasons. Values in bold are the selected Copula for respective period for joint distribution of temperature and precipitation

\begin{tabular}{|c|c|c|c|c|c|c|c|}
\hline Sub-Basin & Copula & Statistics & Guassian & $\mathbf{T}$ & Clayton & Gumbel & Frank \\
\hline \multirow{4}{*}{$\begin{array}{l}\text { Chief } \\
\text { Joseph }\end{array}$} & \multirow{2}{*}{$\begin{array}{c}\text { Historical } \\
\text { Period }\end{array}$} & p-value & 0.866 & 0.470 & $\mathrm{NaN}$ & $\mathrm{NaN}$ & 0.550 \\
\hline & & $S n$ & 0.034 & 0.044 & $\mathrm{NaN}$ & $\mathrm{NaN}$ & 0.038 \\
\hline & \multirow{2}{*}{$\begin{array}{l}\text { Future } \\
\text { Period }\end{array}$} & $p$-value & 0.490 & 0.649 & $\mathrm{NaN}$ & 0.381 & 0.421 \\
\hline & & $S n$ & 0.027 & 0.025 & $\mathrm{NaN}$ & 0.032 & 0.030 \\
\hline \multirow{4}{*}{ Corra Linn } & \multirow{2}{*}{$\begin{array}{l}\text { Historical } \\
\text { Period }\end{array}$} & p-value & 0.500 & 0.411 & $\mathrm{NaN}$ & $\mathrm{NaN}$ & 0.282 \\
\hline & & $S n$ & 0.047 & 0.048 & $\mathrm{NaN}$ & $\mathrm{NaN}$ & 0.044 \\
\hline & \multirow{2}{*}{$\begin{array}{l}\text { Future } \\
\text { Period }\end{array}$} & p-value & 0.827 & 0.688 & 0.639 & 0.658 & 0.748 \\
\hline & & $S n$ & 0.017 & 0.021 & 0.023 & 0.021 & 0.021 \\
\hline \multirow{4}{*}{ The Dalles } & \multirow{2}{*}{$\begin{array}{c}\text { Historical } \\
\text { Period }\end{array}$} & $p$-value & 0.698 & 0.411 & $\mathrm{NaN}$ & $\mathrm{NaN}$ & 0.411 \\
\hline & & $S n$ & 0.033 & 0.035 & $\mathrm{NaN}$ & $\mathrm{NaN}$ & 0.034 \\
\hline & \multirow{2}{*}{$\begin{array}{l}\text { Future } \\
\text { Period }\end{array}$} & $p$-value & 0.045 & 0.045 & 0.005 & 0.203 & 0.124 \\
\hline & & $S n$ & 0.047 & 0.048 & 0.089 & 0.033 & 0.040 \\
\hline \multirow{4}{*}{ Ice Harbor } & \multirow{2}{*}{$\begin{array}{l}\text { Historical } \\
\text { Period }\end{array}$} & p-value & 0.827 & 0.569 & $\mathrm{NaN}$ & $\mathrm{NaN}$ & 0.589 \\
\hline & & $S n$ & 0.041 & 0.045 & $\mathrm{NaN}$ & $\mathrm{NaN}$ & 0.041 \\
\hline & \multirow{2}{*}{$\begin{array}{l}\text { Future } \\
\text { Period }\end{array}$} & $p$-value & 0.114 & 0.163 & $\mathrm{NaN}$ & $\mathrm{NaN}$ & 0.084 \\
\hline & & $S n$ & 0.041 & 0.041 & $\mathrm{NaN}$ & $\mathrm{NaN}$ & 0.039 \\
\hline \multirow{4}{*}{ Mica } & \multirow{2}{*}{$\begin{array}{l}\text { Historical } \\
\text { Period }\end{array}$} & p-value & 0.193 & 0.332 & $\mathrm{NaN}$ & $\mathrm{NaN}$ & 0.094 \\
\hline & & $S n$ & 0.053 & 0.047 & $\mathrm{NaN}$ & $\mathrm{NaN}$ & 0.050 \\
\hline & \multirow{2}{*}{$\begin{array}{l}\text { Future } \\
\text { Period }\end{array}$} & $p$-value & 0.787 & 0.688 & 0.233 & 0.609 & $\mathbf{0 . 8 4 7}$ \\
\hline & & $S n$ & 0.018 & 0.018 & 0.033 & 0.024 & 0.018 \\
\hline \multirow{4}{*}{ Oxbow } & \multirow{2}{*}{$\begin{array}{l}\text { Historical } \\
\text { Period }\end{array}$} & $p$-value & 0.490 & 0.470 & $\mathrm{NaN}$ & $\mathrm{NaN}$ & 0.460 \\
\hline & & $S n$ & 0.044 & 0.038 & $\mathrm{NaN}$ & $\mathrm{NaN}$ & 0.039 \\
\hline & \multirow{2}{*}{$\begin{array}{l}\text { Future } \\
\text { Period }\end{array}$} & $p$-value & 0.104 & 0.025 & $\mathrm{NaN}$ & $\mathrm{NaN}$ & 0.065 \\
\hline & & $S n$ & 0.043 & 0.050 & $\mathrm{NaN}$ & $\mathrm{NaN}$ & 0.047 \\
\hline \multirow{4}{*}{$\begin{array}{l}\text { Priest } \\
\text { Rapids }\end{array}$} & \multirow{2}{*}{$\begin{array}{l}\text { Historical } \\
\text { Period }\end{array}$} & $p$-value & 0.777 & 0.401 & $\mathrm{NaN}$ & $\mathrm{NaN}$ & 0.401 \\
\hline & & $S n$ & 0.035 & 0.044 & $\mathrm{NaN}$ & $\mathrm{NaN}$ & 0.038 \\
\hline & \multirow{2}{*}{$\begin{array}{l}\text { Future } \\
\text { Period }\end{array}$} & $p$-value & 0.074 & 0.015 & 0.005 & 0.233 & 0.064 \\
\hline & & $S n$ & 0.037 & 0.047 & 0.076 & 0.031 & 0.040 \\
\hline \multirow{4}{*}{ Revelstoke } & \multirow{2}{*}{$\begin{array}{l}\text { Historical } \\
\text { Period }\end{array}$} & $p$-value & 0.272 & 0.321 & $\mathrm{NaN}$ & $\mathrm{NaN}$ & 0.124 \\
\hline & & $S n$ & 0.056 & 0.047 & $\mathrm{NaN}$ & $\mathrm{NaN}$ & 0.050 \\
\hline & \multirow{2}{*}{$\begin{array}{l}\text { Future } \\
\text { Period }\end{array}$} & $p$-value & 0.361 & 0.431 & $\mathrm{NaN}$ & $\mathrm{NaN}$ & 0.371 \\
\hline & & $S n$ & 0.028 & 0.028 & $\mathrm{NaN}$ & $\mathrm{NaN}$ & 0.029 \\
\hline \multirow{2}{*}{$\begin{array}{c}\text { TW } \\
\text { Sullivan }\end{array}$} & \multirow{2}{*}{$\begin{array}{l}\text { Historical } \\
\text { Period }\end{array}$} & p-value & 0.391 & 0.530 & $\mathrm{NaN}$ & $\mathrm{NaN}$ & 0.361 \\
\hline & & $\mathrm{Sn}$ & 0.039 & 0.038 & $\mathrm{NaN}$ & $\mathrm{NaN}$ & 0.040 \\
\hline
\end{tabular}




\begin{tabular}{|c|c|c|c|c|c|c|c|}
\hline & Future & $\mathrm{p}$-value & 0.065 & 0.025 & $\mathrm{NaN}$ & $\mathrm{NaN}$ & 0.015 \\
\hline & Period & $\mathrm{Sn}$ & 0.056 & 0.052 & $\mathrm{NaN}$ & $\mathrm{NaN}$ & 0.053 \\
\hline \multirow{4}{*}{ Waneta } & \multirow{2}{*}{$\begin{array}{c}\text { Historical } \\
\text { Period }\end{array}$} & $\mathrm{p}$-value & 0.668 & 0.658 & $\mathrm{NaN}$ & $\mathrm{NaN}$ & 0.431 \\
\hline & & $\mathrm{Sn}$ & 0.040 & 0.037 & $\mathrm{NaN}$ & $\mathrm{NaN}$ & 0.038 \\
\hline & \multirow{2}{*}{$\begin{array}{l}\text { Future } \\
\text { Period }\end{array}$} & p-value & 0.282 & 0.203 & 0.015 & 0.441 & 0.153 \\
\hline & & $\mathrm{Sn}$ & 0.028 & 0.032 & 0.057 & 0.026 & 0.032 \\
\hline
\end{tabular}




\subsection{Future joint trends of temperature and precipitation}

The following section would deal with trends in multi-model ensemble future dataset as compared to multi-model ensemble historical dataset from combined distribution of temperature and precipitation. We would also be evaluating the future probabilities of precipitation and temperature based on their joint distribution. This would be done separately for dry and wet season and for all the sub-basin.

\subsubsection{Dry season}

Trends and changes in joint distribution of temperature and precipitation: Figure 11 represents the changes and trends with joint distribution of temperature and precipitation for all the 10 sub basins in CRB in dry season for both historical and future periods based on their joint CDFs. Copula based relationship (CDFs) of temperature and precipitation are depicted for 10 sub-basins. For each of the sub-basin, e.g. first sub-plot top left (Chief Joseph Sub-basin), the solid lines represent the future period (2070-2099) and the dash lines represent the historical period (1970-1999) with color of the line indicating the probability associated with each color (refer to figure color bar). In all of the sub-basin it was noted from Figure 11 that the trends are positive in future scenario for both the climatic variables. There is variation amongst the sub-basins for degree of that change from historical values. Similar observations about the trends and changes were reported by Rana et. al. 2015. It can also be observed that every sub-basin has its own change characteristics i.e. change in precipitation as compared to temperature for particular sub-basin. Since temperature as climatic variable is believed to be better predicted than precipitation and also some sub basins have similar temperature ranges (based on geographical location, 
Fig.1), we would categorize them (Sub-basin) into 5 classes, according to temperature ranges for further evaluation of trends and changes. Same categorization would be followed in wet season as well for comparison. The classification of this $10 \mathrm{sub}$ basins are also displayed in Figure 11. For example, category 1 includes T.W. Sullivan, Oxbow and Ice Harbor, which have highest dry season average temperature; category 5 includes Mica and Revelstoke, which have lowest dry season average temperature. The locations of this 5 categories' sub basins are also shown in the map, referring to Figure 12. 


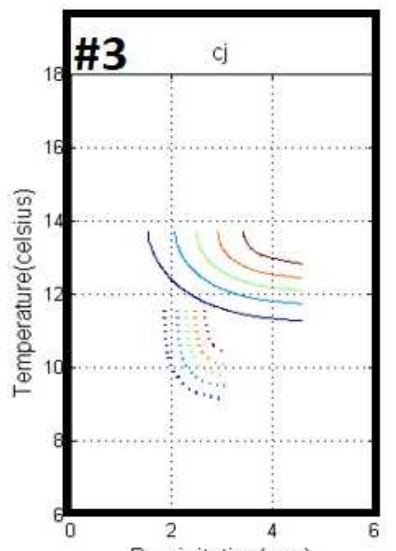

Precipitation(mm)

un

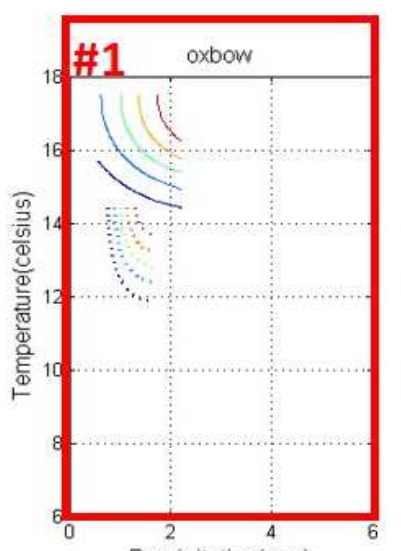

Precipitation(mm)
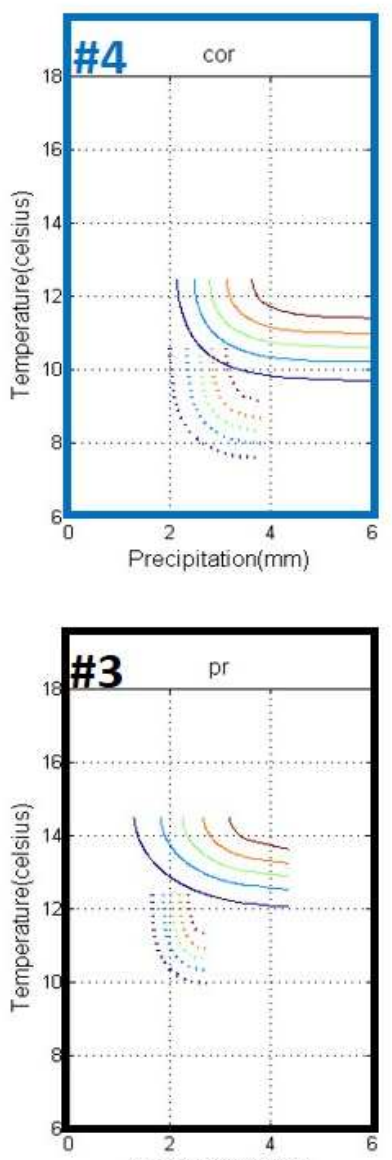

Precipitation(mm)

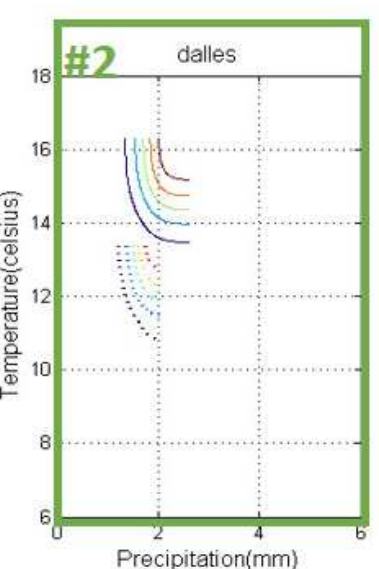

Precipitation(mm)

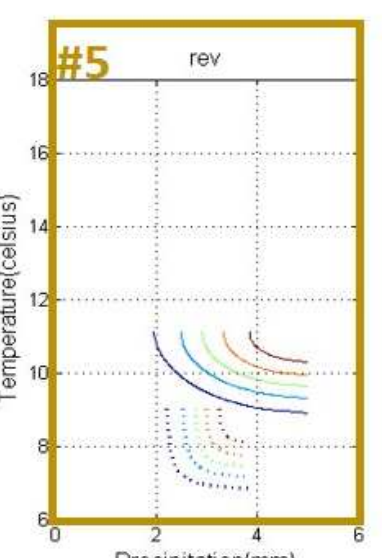

Precipitation $(\mathrm{mm})$

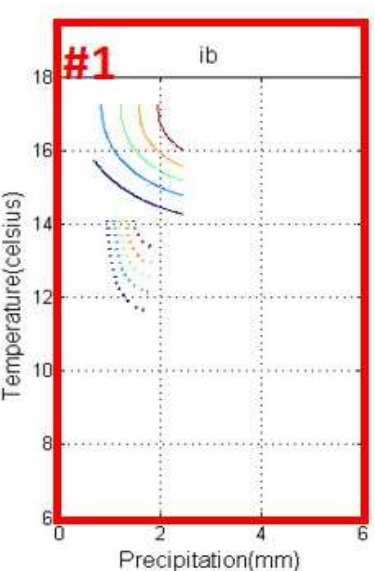

Precipitation(mm)

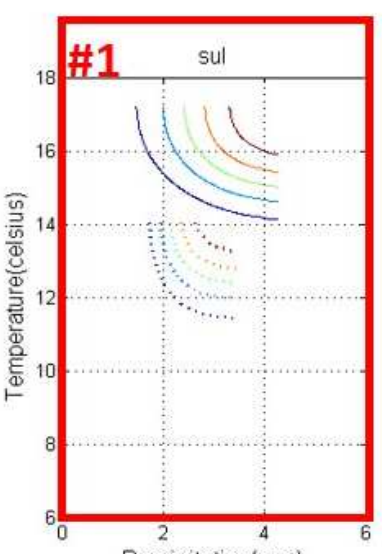

Precipitation(mm)

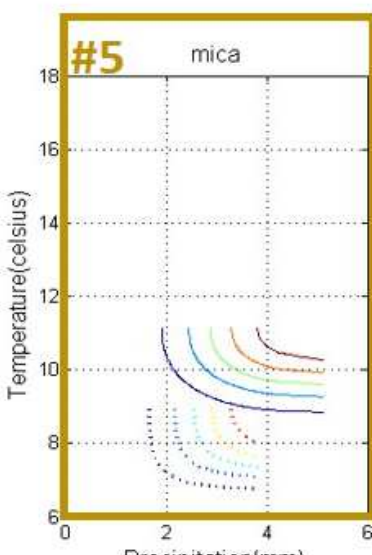

Precipitation(mm)

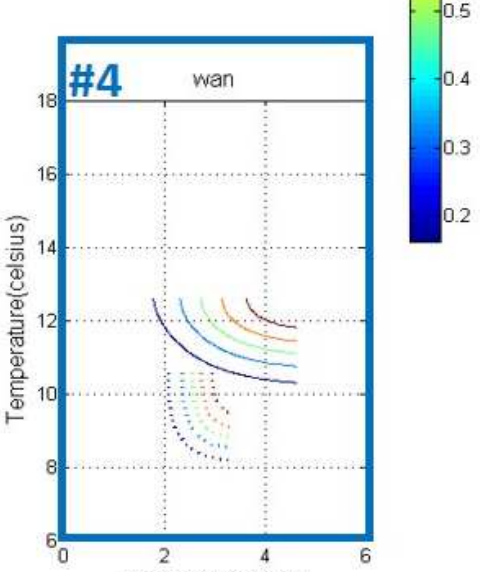

Precipitation ( $\mathrm{mm}$ )

Figure 11 Comparison of joint Cumulative Distribution Functions (CDFs) of temperature and precipitation, using multi-model ensemble, for dry season over the $10 \mathrm{sub}$ basins of CRB. The solid lines represent the future period (2070-2099) and the dash lines represent the historical period (1970-1999). Color of the line indicates the probability of values for temperature and precipitation. The probabilities associated with each color line refer to figure color bar. 


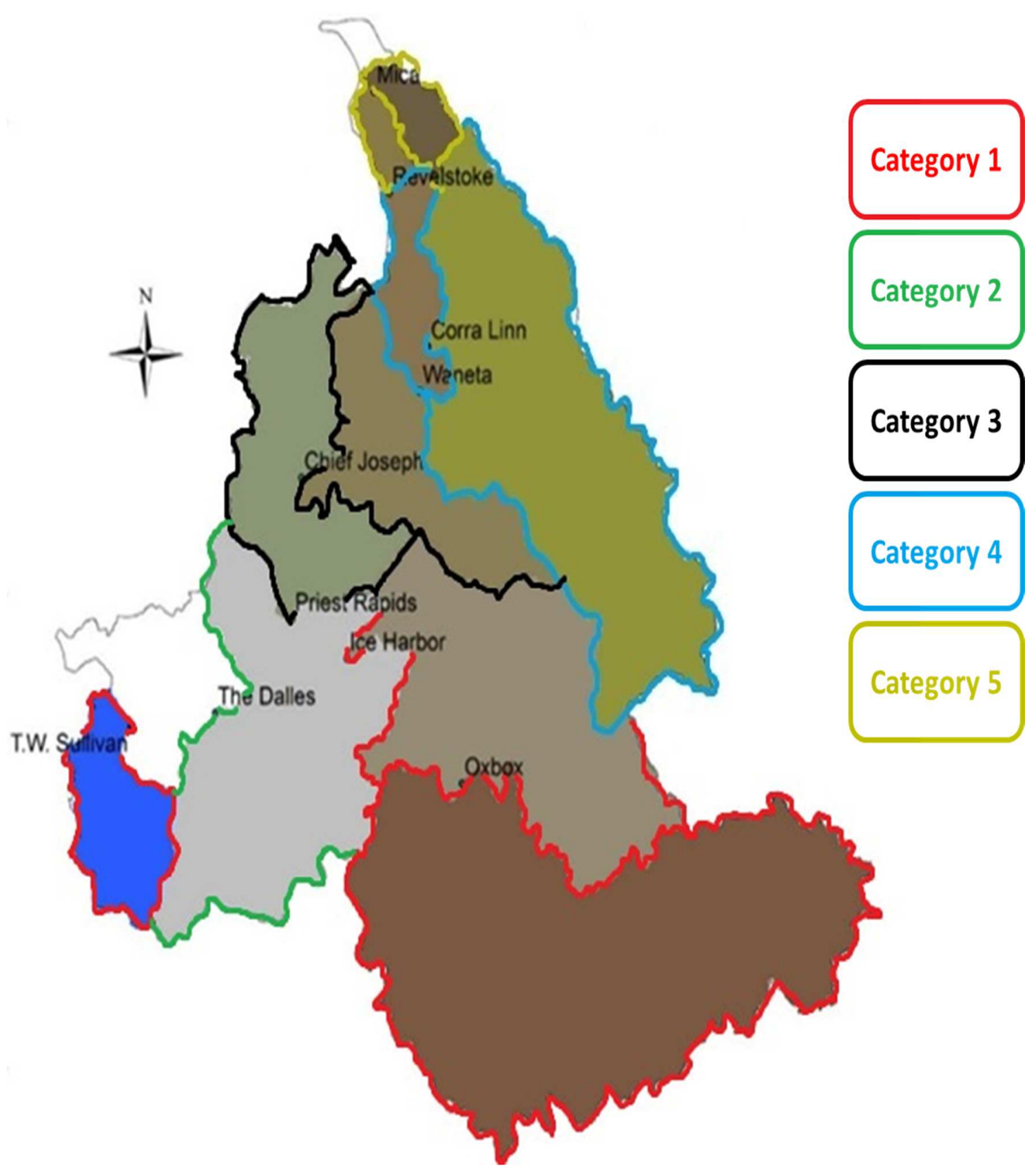

Figure 12 Spatial locations of 10 sub basins' 5 categories in CRB for dry season. The color of outline indicates the associated category, as right-hand side legend shown. 


\section{Category 1 (sub-basins with highest temperature ranges):}

Ice Harbor, Oxbow and TW Sulliwan are the sub-basins with highest seasonal average temperatures among all the sub basins in dry season. For historical period (1970-1999), temperature ranges among these three basins vary around between 11 to $14^{\circ} \mathrm{C}$; however, for future period (2070-2099), temperatures vary around between 14 to $18{ }^{\circ} \mathrm{C}$, predicting. The lowest seasonal average temperature rises $3{ }^{\circ} \mathrm{C}$ and the highest seasonal average temperature rises $4{ }^{\circ} \mathrm{C}$ in the dry seasons of future period compared to historical one.

In terms of precipitation, Ice Harbor and Oxbow share similar characteristics, both of these sub-basins have relatively high temperature but less amount of precipitation. Seasonal average precipitation for these two sub basins in dry seasons ranges from $1-2 \mathrm{~mm}$ in the historical period. Joint CDFs of temperature and precipitation in the historical period have sharper slope with temperature axis, indicating sharp and higher changes in temperature with small/negligible changes in precipitation. Geographical location of these sub-basins in $\mathrm{CRB}$, southwest of $\mathrm{CRB}$, where Cascade mountain range creates a barrier from receiving much precipitation is primary reason behind low precipitation and higher temperature ranges. This also corresponds to observations in the area. In the future period, the joint CDFs of temperature and precipitation shows a positive and upward trends in temperature. Even slope is relatively flat, change in temperature is still much higher than that in precipitation in the future period. Additionally, the ranges of precipitation in these two subbasins only have changed slightly from $0.5-2.5 \mathrm{~mm}(0.5 \mathrm{~mm}$ increase from historical). It could be conclusively said that these two sub basins will potentially experience drought in the future scenario, with sharp rising temperatures. 
TW Sulliwan sub basin has relatively high temperature, similar to the above two sub basins, but also has quite high precipitation in the range of $1.5-3.5 \mathrm{~mm}$, for the historical period with similar slope inclination towards temperature. In the future period, in addition to moving upward (positive trend), the joint CDF hints towards increase in ranges of precipitation $(1-4.5 \mathrm{~mm})$ and flatter slope to both variables. Temperature and precipitation changes are more synchronized in future scenario with former affecting later with more likelihood. TW Sullivan sub-basin receives relatively high precipitation in the CRB along with highest temperature due to its southwestern location close to ocean. The sub-basin will potentially be wetter and warmer in future scenario compared to Ice Harbor and Oxbow sub basins.

\section{Category 2 (sub-basins with second high temperature range):}

Dalles sub basin has the second highest seasonal average temperature in dry season with historical temperature range around $10.5-13.5^{\circ} \mathrm{C}$, whereas temperatures vary from 13.5 $16.5^{\circ} \mathrm{C}$ in future period. The lowest and highest seasonal average temperature rises $3{ }^{\circ} \mathrm{C}$ in the dry seasons of future period compared to the historical period.

As per precipitation, Dalles share similar characteristics as two above sub-basins (Ice Harbor and Oxbow). Dalles has relatively high temperature but less precipitation with seasonal average of $1-2 \mathrm{~mm}$. Joint CDFs of temperature and precipitation, in the historical period, exhibit similar behavior as the above mentioned sub-basins (sharper slope to temperature) indicating the change range of temperature is wider than that of precipitation. In the future period, the joint $\mathrm{CDFs}$ of temperature and precipitation is predicting positive and upward in comparison to historical one with slight change in ranges of seasonal 
average precipitation $(1.5-2.5 \mathrm{~mm}, \sim 0.5 \mathrm{~mm}$ increase). This sub-basin is also indicating that the temperature rise would be sharper than in precipitation, for future scenario, in dry season, this may also be attributed to very large size of the basin (covering most parts of $\mathrm{CRB}$ and thus depicting the overall scenario in $\mathrm{CRB}$ ).

\section{Category 3 (sub-basins with medium temperature ranges):}

Chief Joseph and Priest Rapids sub-basins have medium seasonal average temperatures in dry seasons among all the sub basins. For Chief Joseph, in the historical period, seasonal average temperature ranges from $9-11.5^{\circ} \mathrm{C}$, and in the future period, seasonal average temperatures vary around from $11-14{ }^{\circ} \mathrm{C}$. Thus, the lowest seasonal average temperature in the dry season rises $2{ }^{\circ} \mathrm{C}$ and the highest seasonal average temperature rises around 2.5 ${ }^{\circ} \mathrm{C}$. For Priest Rapids basin, in the historical period, temperature ranges from $10-12.5{ }^{\circ} \mathrm{C}$, whereas it varies from $12-14.5^{\circ} \mathrm{C}$ in future scenario indicating $2{ }^{\circ} \mathrm{C}$ rise in both the lowest and highest average temperature values.

For precipitation, both the sub-basins exhibit the same ranges of $1.5-3 \mathrm{~mm}$ in the historical dataset which shows a sharp rise of range to $1-4.5 \mathrm{~mm}$ in future scenario. Joint CDFs of temperature and precipitation is similar to above noted features in all sub-basins (sharp slope inclined towards temperature) in historical data. Whereas, the joint CDFs, for future

period, is more inclined towards precipitation i.e. more precipitation change as compared to temperature changes. This indicates that the two sub-basins would be warmer and wetter as compared to historical scenario.

\section{Category 4 (sub basins with second lowest temperature ranges):}


Corra Linn and Waneta have the second lowest seasonal average temperatures in dry season. For Corra Linn basin, in the historical period, seasonal average temperatures ranges from $7.5-10.5{ }^{\circ} \mathrm{C}$ and $9.5-12.5{ }^{\circ} \mathrm{C}$ for future period. Both the lowest and highest average temperatures in the area is indicating towards $2{ }^{\circ} \mathrm{C}$ rise. For Waneta basin, in the historical period, temperature ranges from $8-10.5^{\circ} \mathrm{C}$ and $10-12.5^{\circ} \mathrm{C}$ for future data. The rise in lowest and highest temperature exhibit similar range as Corra Linn $\left(2{ }^{\circ} \mathrm{C}\right)$.

As per precipitation, both the sub-basin provides similar variations as compared to temperature in historical period (Slope inclined towards temperature). Ranges for Corra Linn varies from $2-4 \mathrm{~mm}$ and that for Waneta is $2-3 \mathrm{~mm}$, in historical data. Joint CDFs, depicting changes and trends, hints towards positive and upward trends but with varying degree for both the sub-basins. The changes in precipitation are more profound for Corra Linn sub-basin ranging from $2-6 \mathrm{~mm}(\sim 2 \mathrm{~mm}$ increase)with the joint distribution slope inclined highly towards precipitation i.e. changes in precipitation would be higher with every degree change in temperature. Whereas, in case of Waneta, the changes are positive (ranges from $1.5-4.5 \mathrm{~mm}, \sim 1.5 \mathrm{~mm}$ increase) but the slope is not as skewed towards precipitation as was in Corra Linn. The CDFs for Waneta suggests equal changes in both climatic variables. This, it can be conclusively deduced that both the sub-basins would be warmer and wetter with Corra Linn projecting higher precipitation amounts, in future scenario.

\section{Category 5 (sub basins with lowest temperature ranges):}

Mica and Revelstoke sub-basins have the lowest seasonal average temperatures in dry seasons. For Mica basin, in the historical period, temperature ranges from $6.5-9^{\circ} \mathrm{C}$ and 9 - 
$11{ }^{\circ} \mathrm{C}$ in the future period. The lowest average temperatures rise is around $2.5^{\circ} \mathrm{C}$ and the highest temperature rise is $3{ }^{\circ} \mathrm{C}$. For Revelstoke sub-basin, in the historical period, temperature ranges from $7-9{ }^{\circ} \mathrm{C}$ and $9-11^{\circ} \mathrm{C}$ in the future period with $2{ }^{\circ} \mathrm{C}$ rise in both the lowest and highest average temperature.

Mica and Revelstoke are smallest sub-basins with lowest temperatures, located in the far north of CRB. In historical period, precipitation ranges of Mica sub-basin is $1.5-4 \mathrm{~mm}$ and that of Revelstoke sub-basin is $2-4 \mathrm{~mm}$, with similar slope distribution in joint CDFs for temperature and precipitation. For the future period, both of Mica and Revelstoke subbasins indicate a positive and upward changes, as was case in all sub-basins. The slope of joint CDFs is becoming flatter and inclined towards precipitation (more so the case in Mica than in Revelstoke). Although precipitation change range in both the sub-basin is $2-5 \mathrm{~mm}$ but Mica is predicted to show more increase in precipitation with every degree rise in temperature in future scenario and thus wetter and warmer than historical ones.

Overall, we can deduce that categories close together i.e. similar spatial distribution (geographic space) and seasonal average temperature, in dry season, will have positive change temperature which is relatively decreasing from north to south of CRB. Sub basins in category 1 and category 2 with high seasonal average temperature in dry season are located in southern CRB exhibit higher increases in temperatures, around 3 to $3.5^{\circ} \mathrm{C}$. Category 3 to Category 5, which are located from center to north of CRB will have less increasing in temperature, around $2{ }^{\circ} \mathrm{C}$. Precipitation change will vary in all the $10 \mathrm{sub}$ basins with increase of temperature. The north part of CRB, category 4 and 5 will have more increase of precipitation, around 1.5 to $2 \mathrm{~mm}$, with increasing temperature. The south 
part of CRB, category 1 to 3, may have less increase of precipitation, or even decrease in precipitation, with increasing temperature.

\section{Probabilities of joint distribution of temperature and precipitation in future scenario:}

Figure 13 represents the likeness of two variables with joint distribution for all the $10 \mathrm{sub}$ basins in CRB in dry season for future period based on their joint CDFs. For each of the sub-basin, e.g. first sub-plot top left (Chief Joseph Sub-basin), a series of conditional probability density functions (PDFs) of precipitation ranges given a particular temperature in future data (2070-2099) during dry season are plotted and scaled from 0 to 1 (based on the mode of each conditional PDFs)for visualization purpose. Red color represents most likely occurring and blue color least likely occurring of amount of precipitation given a particular temperature in future scenario.

Thus it can be said that the areas with dark blue colors indicate the tails of the precipitation conditional PDF, at given temperature, which shows the least likely occurring precipitation given certain temperature and vice-versa in case of red color. Therefore, if given temperatures are expected, precipitation magnitudes associated with the red areas (closely surrounding the mode of the condition PDFs of precipitation given temperature) are most likely to happen.

From Fig. 10 it can be noted that 7 out of the 10 sub-basins (namely Chief Joseph, Ice Harbor, Oxbow, Priest Rapids, Revelstoke, TW Sullivan and Waneta) depicts a negative relationship between the most likely occurrence of precipitation with temperature i.e. the amount of precipitation in dry season is decreasing with increasing temperature for most likelihood scenarios. The geographic locations of these 7 sub-basins do not show any 
obvious pattern. It also indicates that the temperature is more dominant variable in the joint probabilities and is in inverse relation to precipitation in dry season. Thus, during this season we can expect higher temperatures and drier conditions in future scenario (as already pointed out that temperatures are increasing in future scenario and thus precipitation would relatively be lower increase). It should be pointed out that there is increase in amount and intensity of both variables in future scenario but their interdependence is varied in different sub-basins.

For 2 sub-basins i.e. Dalles and Mica, the most likely occurrence of precipitation at a given temperature is constant. This indicates that the precipitation increase is constant in these sub-basins irrespective of increase in temperature. Thus, the expected increase (discussed above) in precipitation would be independent of increase in temperature. In case of Corra Linn, the precipitation doesn't show any specific patterns. For higher temperatures (more than $9^{\circ} \mathrm{C}$ ) the precipitation amounts are relatively constant whereas the probabilities of precipitation are very varied for lower temperatures. The precipitation amount (likelihood of getting that - red color) is depicting both increase and decrease with temperatures from $7-9^{\circ} \mathrm{C}$, with wider ranges towards the lower temperatures. The inverse relationship across most of the sub-basin could be related to water holding capacity of clouds with particular temperatures and vice-versa. 

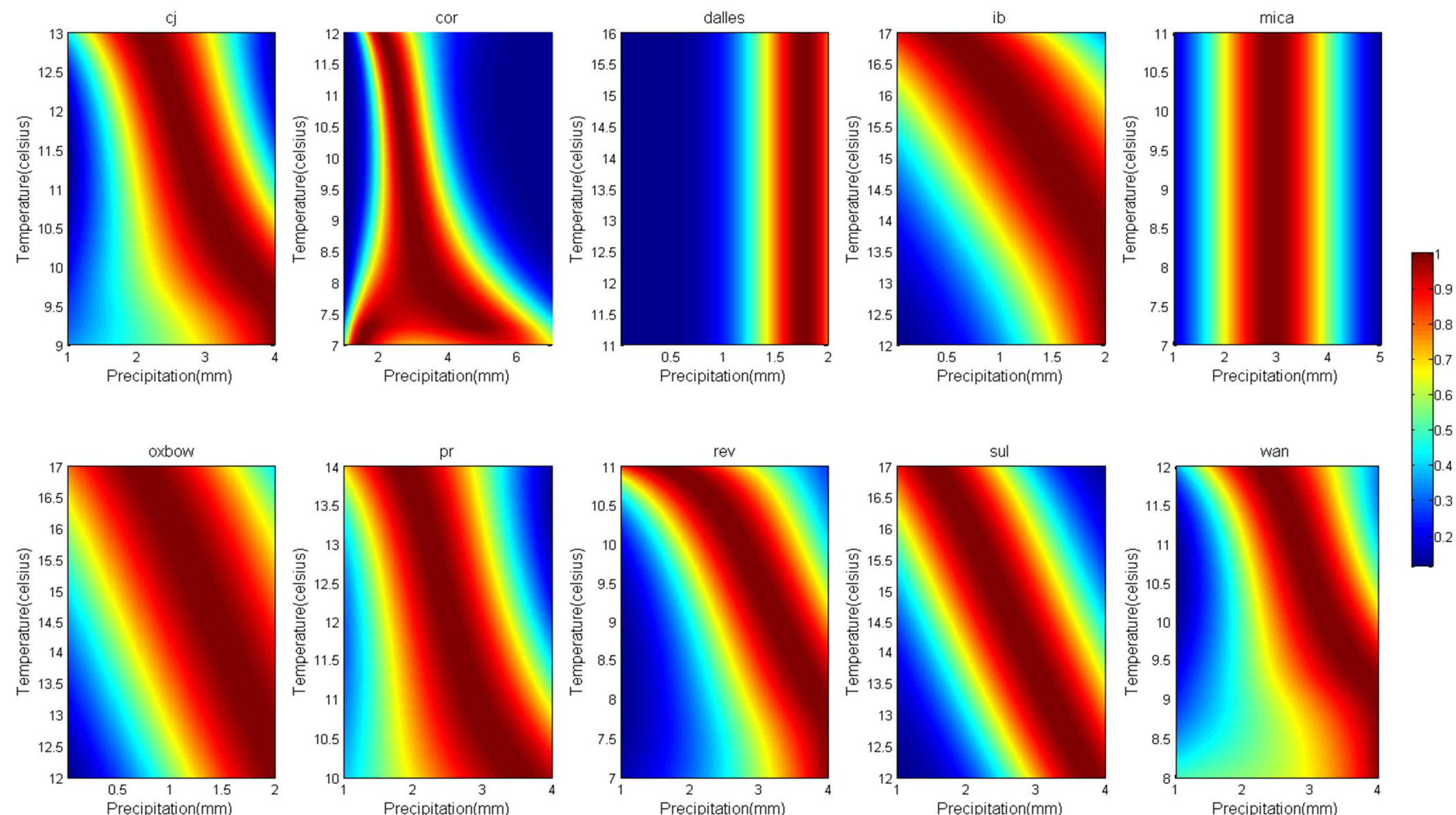

\&
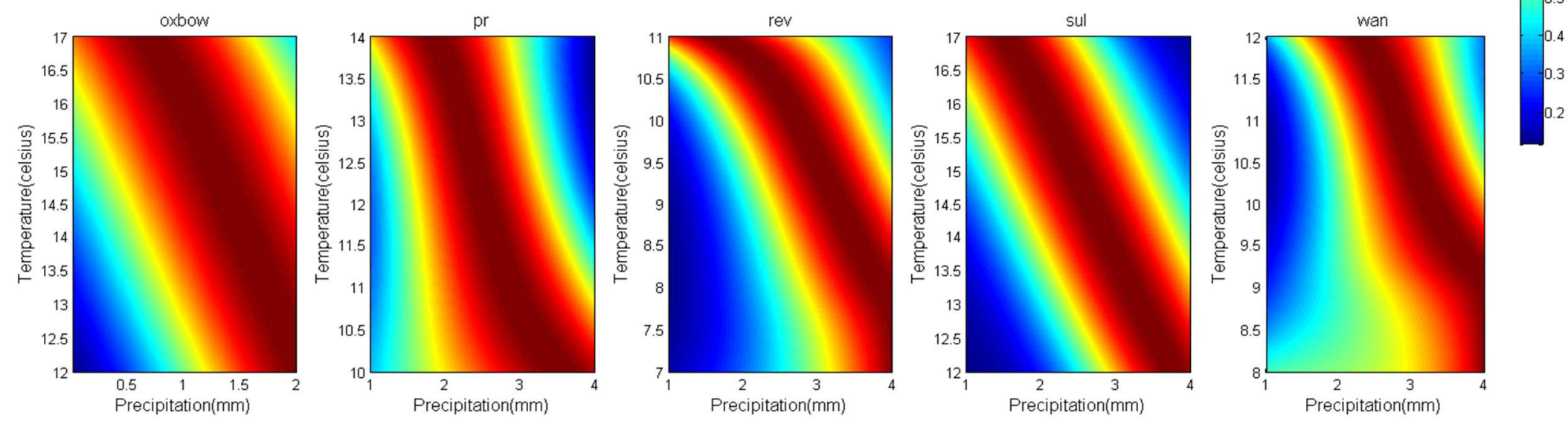

Figure 13 Likelihood of precipitation ranges given a particular temperature in future data (2070-2099) during dry season in each of the 10 subbasins in CRB. Conditional Probability density Function of precipitation against certain temperature is plotted and scaled for probability ( 0 to

1), for visualization purpose (red color- most likelihood and blue color- least likelihood). The conditional probability density associated with each color line refers to this figure color bar. 


\subsubsection{Wet season}

Trends and changes in joint distribution of temperature and precipitation: Figure 14 represents the changes and trends with joint distribution of temperature and precipitation for all the 10 sub basins in CRB in wet season for both historical and future periods based on their joint CDFs. The figure presented here is similar to Figure 11. For each of the subbasin, e.g. first sub-plot top left (Chief Joseph Sub-basin), the solid lines represent the future period (2070-2099) and the dash lines represent the historical period (1970-1999) with color of the line indicating the probability associated with each color. Similar observations as Figure 11 can be made in Figure 14 in reference to trends and changes in future scenario i.e. positive and upwards changes and trends in both variables. There is variation amongst the sub-basins for degree of that change from historical values. Similarly, for comparison within sub-basin same categorization of temperature is studied in wet season as well (not necessarily same sub-basins would fall in same category). Figure 14 will indicate 10 sub basins' 5 categories in terms of wet seasonal average precipitation range as well. Category 1 here includes T.W.Sullivan, which has highest seasonal average temperature in wet season. Category includes Mica and Revelstoke, which have lowest seasonal average temperature in wet season. Figure 15 presents these 5 categories' spatial locations in the map. 

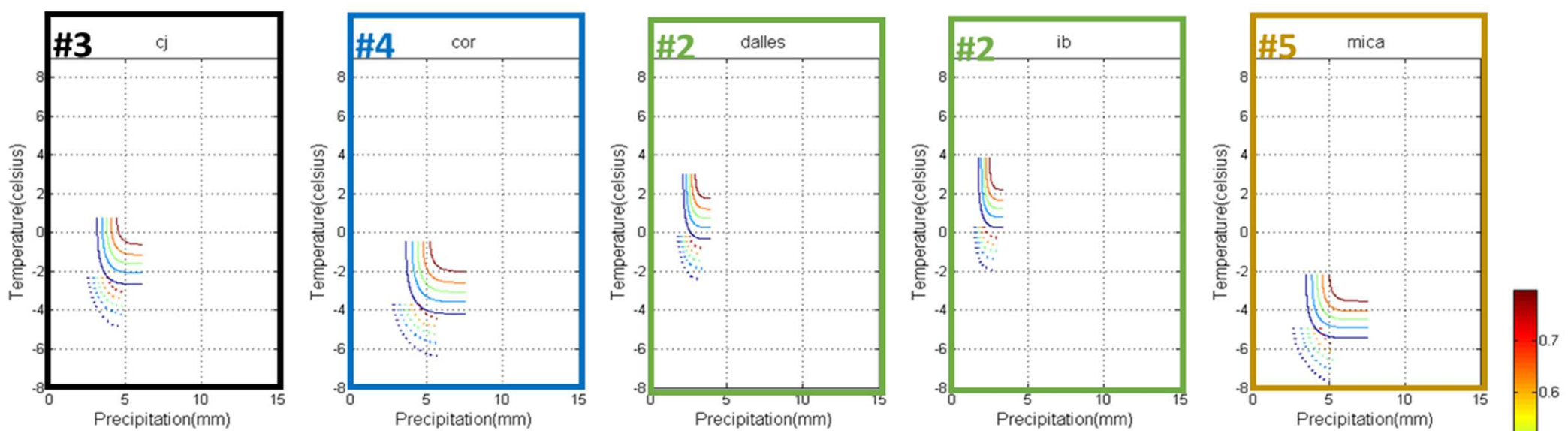

8
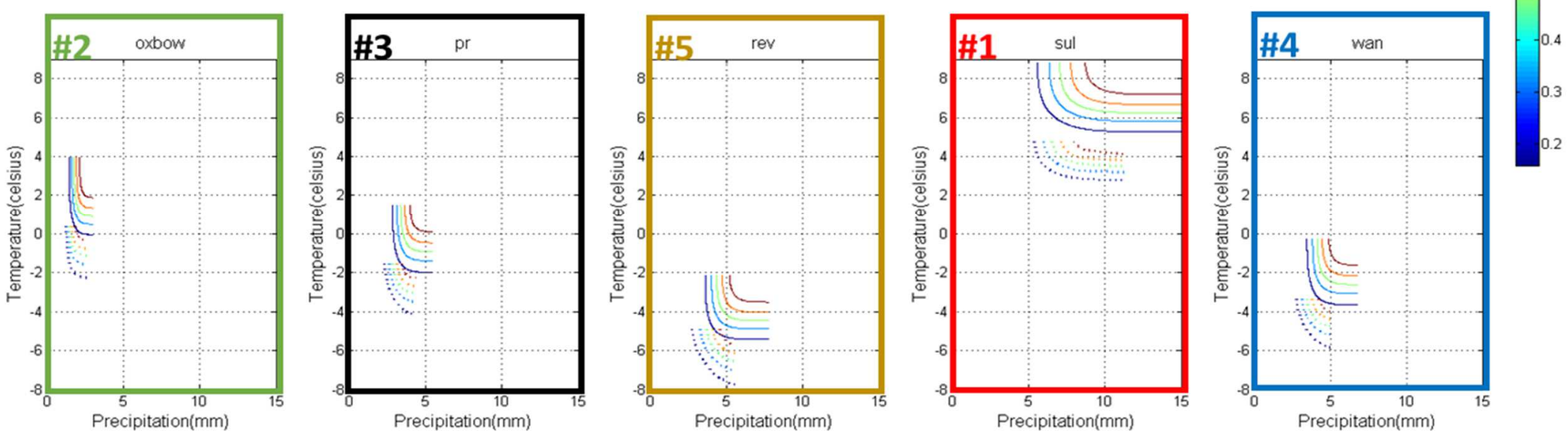

Figure 14 Comparison of joint Cumulative Distribution Functions (CDFs) of temperature and precipitation, using multi-model ensemble, for wet season over the $10 \mathrm{sub}$ basins of CRB. The solid lines represent the future period (2070-2099) and the dash lines represent the historical period (1970-1999). Color of the line indicates the probability of values for temperature and precipitation. The probabilities associated with each color line refer to figure color bar. 


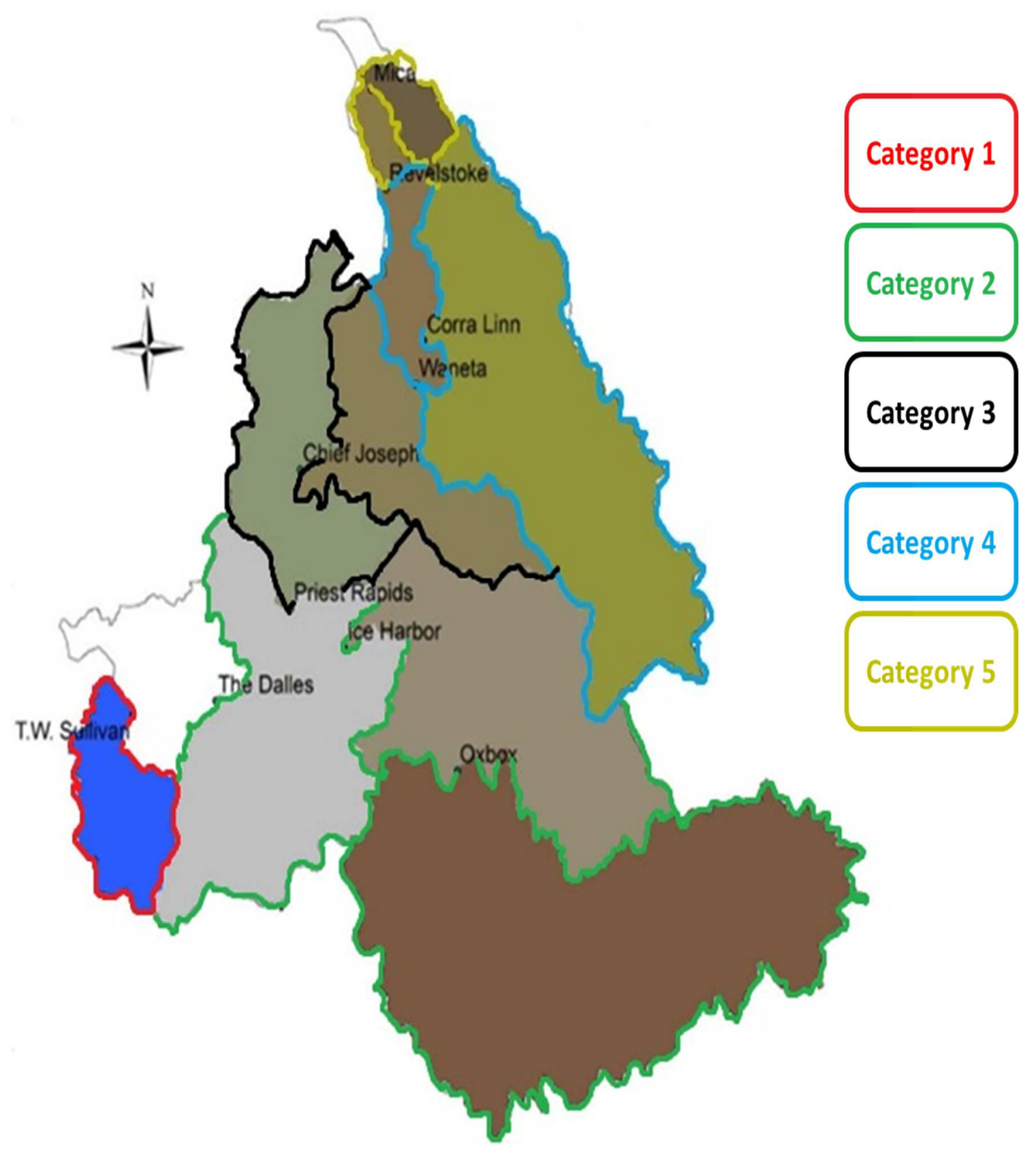

Figure 15 Spatial locations of 10 sub basins' 5 categories in CRB for wet season. The color of outline indicates the associated category, as right-hand side legend shown. 


\section{Category 1 (sub basins with highest temperature ranges):}

TW Sullivan depicts the highest seasonal average temperatures among all the sub basins in wet seasons which is $3-5^{\circ} \mathrm{C}$ for the historical period (1970-1999) and $5.5-9{ }^{\circ} \mathrm{C}$ for future period. There is rise of $2.5{ }^{\circ} \mathrm{C}$ and $4{ }^{\circ} \mathrm{C}$ in lowest and highest temperature respectively for the future scenario. In addition, TW Sullivan sub-basin has maximum amount of average seasonal precipitation among all of the 10 sub basins in the wet seasons of historical period ranging from $5-12 \mathrm{~mm}$ whereas it increases to $5-15 \mathrm{~mm}$ in future scenario. The slope of joint $\mathrm{CDF}$ is not changing in the historical and future data but the ranges (upwards increase) are becoming higher. The slope is more inclined towards precipitation and thus indicating higher changes of precipitation amounts than temperature. The sub-basin depicts the likely possibility of higher precipitation along with rising temperature events in future period. Increased intensity of precipitation would lead to the high possibility of flood in the area.

\section{Category 2 (sub basins with second highest temperature ranges):}

Dalles, Ice Harbor and Oxbow sub-basins have second high seasonal average temperatures in wet seasons ranging from -2 to $0.5^{\circ} \mathrm{C}$ in the historical period (1970-1999), however, for the future period (2070-2099), temperatures vary around from $0-4{ }^{\circ} \mathrm{C}$ for Ice Harbor and Oxbow sub-basins and from -0.5 to $3{ }^{\circ} \mathrm{C}$ for Dalles sub-basin. For Ice Harbor and Oxbow sub-basins, the rise in lowest and highest seasonal average temperature is $2^{\circ} \mathrm{C}$ and $3.5^{\circ} \mathrm{C}$ respectively, whereas for Dalles it is $1.5^{\circ} \mathrm{C}$ and $2.5{ }^{\circ} \mathrm{C}$ respectively. All these 3 sub-basins share similar characteristics i.e. they have relatively high temperature but lower amounts of precipitation. Seasonal average precipitation for Dalles and Ice Harbor sub-basins ranges from $2-3 \mathrm{~mm}$ and for Oxbow it is $1-2 \mathrm{~mm}$, with around $0.5 \mathrm{~mm}$ increase in future for all 
three. The joint CDFs of temperature and precipitation for all of these three, both in historical and future periods, have sharper slope to temperature axis indicating that the changes in range of temperature is higher than that of precipitation. In the future period, the joint CDFs of temperature and precipitation is depicting a positive change but still higher changes in temperature than in precipitation.

\section{Category 3 (sub basins with medium temperature ranges):}

Chief Joseph and Priest Rapids have medium seasonal average temperatures, with Chief Joseph historical temperatures ranging $-5{ }^{\circ} \mathrm{C}$ to $-2{ }^{\circ} \mathrm{C}$, and -3 to $1{ }^{\circ} \mathrm{C}$ for future, whereas Priest Rapids historical temperature ranges from -4 to $-1.5^{\circ} \mathrm{C}$, and -2 to $1.5^{\circ} \mathrm{C}$ for future. The changes/rise in lowest and highest average temperature for both the sub-basin is $2{ }^{\circ} \mathrm{C}$ and $3{ }^{\circ} \mathrm{C}$ respectively. For Precipitation, Chief Joseph have $2.5-5 \mathrm{~mm}$ range in historical period (1-2mm increase in future) and Priest Rapids have $2.5-4.5 \mathrm{~mm}$ range in same period ( $\sim 1 \mathrm{~mm}$ increase in future). The joint change trends (CDFs) of temperature and precipitation are quite similar to the sub-basins discussed in category 2 of wet season i.e. for both subbasins changes in temperature are more pronounced than in precipitation for both historical and future period. For future period, the CDFs indicate a higher rise in temperature ranges with slight increase in precipitation ranges. It hints towards a similar fate of these subbasins in future as was for category 2 wet season but with lower temperatures than those three sub-basin in category 2. Thus, in future scenario, the temperature rise dominates the precipitation rise.

\section{Category 4 (sub basins with second lowest temperature ranges):}


Corra Linn and Waneta belongs to category of sub-basins with second lowest seasonal average temperatures in wet seasons. For Corra Linn, in the historical period, seasonal average temperatures ranges from $-6{ }^{\circ} \mathrm{C}$ to $-4{ }^{\circ} \mathrm{C}$ whereas for the future period the ranges are $-4{ }^{\circ} \mathrm{C}$ to $0{ }^{\circ} \mathrm{C}$. The lowest seasonal average temperature rises $2{ }^{\circ} \mathrm{C}$ and the highest seasonal average temperatures rises $4{ }^{\circ} \mathrm{C}$ in Corra Linn. For Wan basin, the historical temperature ranges are from -6 to $-3.5^{\circ} \mathrm{C}$; and future temperatures vary from -4 to $0{ }^{\circ} \mathrm{C}$ depicting $2{ }^{\circ} \mathrm{C}$ and $3.5^{\circ} \mathrm{C}$ rise in lowest and highest temperatures. Historical precipitation ranges for Corra Linn are 2.5-6mm and $2.5-5 \mathrm{~mm}$ for Waneta which increases to $4-7.5 \mathrm{~mm}$ and 3.5-6.5 in future for the two sub-basins respectively. The joint change trends of temperature and precipitation in both the historical and future periods are similar in both of these two sub basins. The CDFs depict similar behavior as category 2 and 3 for wet season i.e. higher increase in temperature ranges than in precipitation values. Thus, wetter and warmer scenario should be expected in future.

\section{Category 5 (sub basins with lowest temperature):}

Mica and Revelstoke sub-basins have the lowest seasonal average temperatures in wet seasons, located in the far north of CRB. For both Mica and Revelstoke, in the historical period, temperature ranges from -8 to $-5{ }^{\circ} \mathrm{C}$ and -5.5 to $-2{ }^{\circ} \mathrm{C}$ in the future period. The lowest average temperatures rise $2.5^{\circ} \mathrm{C}$ and the highest temperature rises $3{ }^{\circ} \mathrm{C}$ in the wet seasons of future period. In historical period, precipitation ranges of both Mica and Revelstoke are $2.5-5 \mathrm{~mm}$ which increase to $3-7.5 \mathrm{~mm}$ in future scenario. Both sub-basins depict similar properties of joint changes of precipitation and temperature in the historical and future periods indicating towards higher precipitation accompanied with increasing 
temperature events in future as compared to historical. The joint CDFs are different from all the categories discussed in wet season and is not inclined to any of the climatic variables. The positive changes in precipitation are accompanied with similar degree of positive changes in temperature, as depicted from joint CDFs in future scenario.

Overall, the categories for wet season are almost same to the ones for dry seasons, except categories 1 and 2. Seasonal average temperature in wet seasons will be increasing in all of the 10 sub basins in the future period. Except category 5 , will increase $2.5^{\circ} \mathrm{C}$ on average. The rest categories will increase $3{ }^{\circ} \mathrm{C}$ on average. Category 1 sub basin has largest precipitation amount as well as highest temperature because of its southwest location close to ocean. Category 3 to 5 will have increase of precipitation around 1.5 to $2 \mathrm{~mm}$ with increasing temperature. Category 2 will have smallest increase of precipitation, around $0.5 \mathrm{~mm}$ with increasing temperature.

\section{Probabilities of joint distribution of temperature and precipitation in future scenario:}

Figure 16 represents likeliness of two variables with joint distribution for all the $10 \mathrm{sub}$ basins in CRB in wet season for future period based on their joint distribution functions. The figure should be read in similar context to Figure 13, as it projects the similar parameters in similar pattern for wet season. In wet season, the most likely occurrence of precipit5ation ranges at a given temperature range is relatively constant for all the $10 \mathrm{sub}$ basins in CRB, but the ranges of precipitation are different for different sub-basins. For Mica, at higher temperatures the range in precipitation is relatively higher than any of the sub-basins otherwise a constant range is almost maintained (within a particular sub-basin) irrespective of temperature changes. Thus it can be conclusively said that the ranges of 
precipitation (mainly red color ranges) are not influenced by temperature values. In other words, the most likely happening precipitation is nearly constant within temperature changes. This can be attributed to the fact that although the temperatures are rising but average temperatures are still sub-freezing and thus the holding capacity of clouds won't change in that case. There are insignificant variations with some of the sub-basins where precipitation ranges are increasing with temperature but comparatively very low changes e.g. Priest Rapids, Revelstoke and Waneta. This would have a severe consequence on spring flooding or harvesting seasons in the area. 

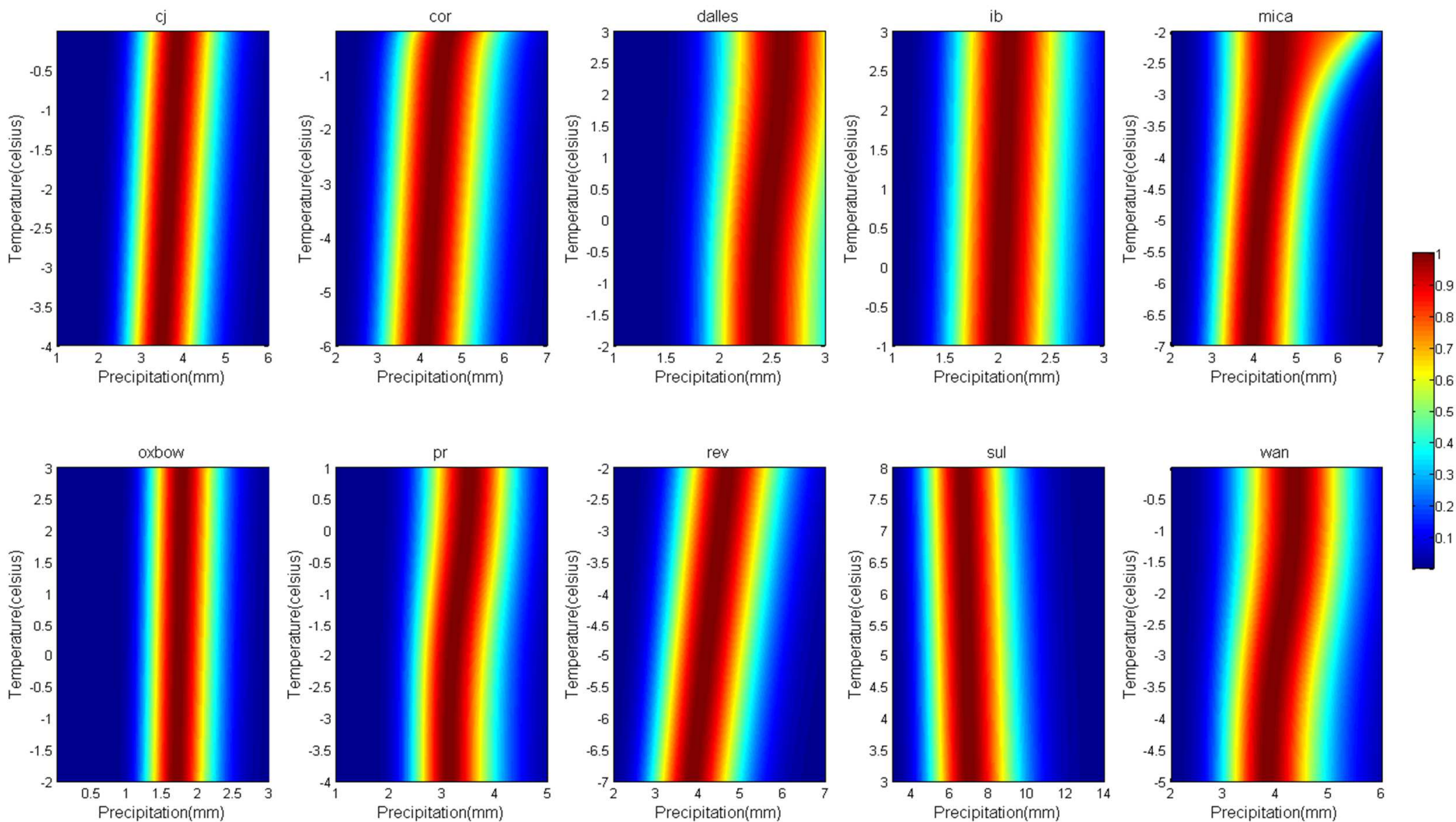

Figure 16 Likelihood of precipitation ranges given a particular temperature in future data (2070-2099) during wet season in each of the 10 subbasins in CRB. Conditional Probability density Function of precipitation against certain temperature is plotted and scaled for probability ( 0 to 1$)$, for visualization purpose (red color- most likelihood and blue color- least likelihood). The conditional probability density associated with each color line refers to this figure color bar. 


\section{Discussion}

\subsection{Summary of current studies}

We have applied Copula based coupling (probabilistic distribution) to temperature and precipitation as climatic variables across 10 sub-basins in CRB for future scenario (20702099). Trends and changes in these climatic variables are compared with Copula based coupled distribution from historical, and probabilities of one variable in relation to other are also studied for future changes using conditional PDFs. All the analysis was performed on multi-model ensemble of 10 GCMs (downscaled with BCSD) across CRB (divided into sub-basins) using ensemble mean with bootstrap sampling for generating multi-model ensemble. The multi-model ensemble was advantageous due to simplification, efficiency, and computationally less demanding; and efficiently produced statistics of mean and variance of the sample GCMs. Bootstrap sampling helped to combine the strengths of multiple models together and consider the uncertainty inside the multi-models combination for temperature and precipitation. The method was helpful in producing mean statistics and variability from $10 \mathrm{GCMs}$ in terms of MAE and frequency based analysis, both in dry and wet season across the sub-basins.

We further explored the relationship between temperature and precipitation in each of the sub-basin using Copula based joint distribution, which enabled us to study/model any level of correlation, dependence or independence regardless of each variable's suitable theoretical distribution and complex relationships. The main summary from Joint CDFs of precipitation and temperature are:

1. The temperature and precipitation is depicting positive and upwards trends in all sub-basins and all time scales considered. 
2. Geographical location of sub-basins plays an important roles in degree of changes observed in both the parameters.

3. South-east of the basin is usually projecting warmer and drier conditions.

4. South-west projections hints towards wetter and warmer trends.

5. Trends of positive (wetter) and warmer conditions are significant in north of the CRB with south or southeast parts predicting higher temperatures with little changes in precipitation.

6. Interdependence of temperature and precipitation is varied during dry season with most of the sub-basins predicting inverse relation i.e. with increasing given temperature the ranges of precipitation (most likely occurring) received would decrease.

7. Whereas in wet season, precipitation ranges (most likely occurring) seemed to be almost constant within temperature changes i.e. the most likely occurring range of precipitation is not affected by how much the temperature rises.

The most important application of the above study is to analyze the impact of climate on the $\mathrm{CRB}$ with combined relationships of precipitation and temperature and overcoming the usual impasse that is mostly worked on by providing only separate projections of temperature and precipitation. For most impact studies/applications the joint behavior of said climatic variables is especially used, e.g. drought analysis, agriculture production, irrigation amongst others. The results of this study provides additional and valuable information about how precipitation and temperature are jointly affected under climate change scenario, which in turn will provide sufficient management and strategies to meet 
the challenges in future. It would be helpful in improvising decision making abilities under different levels of risks with high level of certainty/confidence.

\subsection{Further works}

Climate change signals have been continuously observed so far and historical resource management strategies will not be sufficient to meet the challenges of future changes in climate. Rather, these changes demand new strategies. The present study considers the combined relationship of temperature and precipitation under future climate change impact and thus would provide additional and valuable information for various management practices e.g. agriculture, ecosystem, water resource and energy. This would further assist them to adapt future climate change's influence instead of relying on the individual change trends of temperature and precipitation.

In continuation to this study, we would like to concentrate our efforts on two-fold approach: Firstly, we would like to study the spatial distribution of various sectors (agriculture, ecosystem, water resource and energy) that could be influenced by these projected changes in CRB; secondly, identify and quantify the impacts of climate changes on certain key and strategic areas that are important for $\mathrm{CRB}$ e.g. water resource, agriculture, ecosystem, using joint relationship between various variables involved. 


\section{Concluding remarks}

In order to understand the consequence of climate change for the region we usually rely upon information from past events, observations and forecast to understand our natural and human resources. Forecast have been improved by various GCM but impact studies still considers interdependent variables separately. Application of the combined relationship of climatic variables (e.g. temperature and precipitation) will be additionally useful and significant way to understand climate change impact comprehensively. In the present study we have established combined relationship of temperature and precipitation and studied future changes in the relations.

Warmer temperature with increasing amount of precipitation have been depicted in several sub basins in CRB for the wet seasons (from October to March) in future period (20702099), especially TW Sullivan exhibit significant increasing precipitation with warmer temperature among all the sub basins. Warm temperatures will result in more winter precipitation falling as rain rather than snow throughout CRB. The primary impact from this combined change will be a shift in the timing of snowmelt and in turn the peak river flow from late spring to winter or even lead to river flood for cold season whereas drought for warm season. This combined change will further continue to affect the water quality, salmon living and snowpack availability and so on. This situation is especially obvious in the Pacific Northwest.

For dry seasons (from April to September) in the future period, warmer temperature with slightly changes in precipitation have been presented in several basins in CRB, especially Dalles, Ice Harbor, Oxbow sub basins. The mainly impact from this combined change will 
rise the occurring probability of wild fire and drought in these regions, due to higher temperature companied with less precipitation. Fire frequency and intensity have already increased in the past 50 years. Drought and hotter temperatures have also led to increase the risk of fire. This combined change will further continue to affect the hydropower production and fish production. The amount of water stored in reservoir will be lower from late spring through early fall, affecting water supply for hydropower production and the ability of the system to operate lower flow for fish production (Littell et al. 2009). 


\section{References}

Akaike, H. (1974). A new look at the statistical model identification. Automatic Control, IEEE Transactions on, 19(6), 716-723.

Backlund, P., Janetos, A., Schimel, D., \& Walsh, M. (2008). The effects of climate change on agriculture, land resources, water resources, and biodiversity in the United States. The effects of climate change on agriculture, land resources, water resources, and biodiversity in the United States.

Buishand, T. A., \& Brandsma, T. (1999). Dependence of precipitation on temperature at Florence and Livorno (Italy). Climate Research, 12(1), 53-63.

Cantelaube, P., \& TERRES, J. M. (2005). Seasonal weather forecasts for crop yield modelling in Europe. Tellus A, 57(3), 476-487.

Cayan, D. R., Redmond, K. T., \& Riddle, L. G. (1999). ENSO and Hydrologic Extremes in the Western United States*. Journal of Climate, 12(9), 2881-2893.

Collins, M. (2007). Ensembles and probabilities: a new era in the prediction of climate change. Philosophical Transactions of the Royal Society A: Mathematical, Physical and Engineering Sciences, 365(1857), 1957-1970.

Cong, R. G., \& Brady, M. (2012). The interdependence between rainfall and temperature: copula analyses. The Scientific World Journal, 2012.

Cong, R. G., \& Brady, M. (2012). The interdependence between rainfall and temperature: copula analyses. The Scientific World Journal, 2012.

Duan, Q., Ajami, N. K., Gao, X., \& Sorooshian, S. (2007). Multi-model ensemble hydrologic prediction using Bayesian model averaging. Advances in Water Resources, 30(5), 1371-1386.

Elsner, M. M., Littell, J., \& Binder, L. C. W. (Eds.). (2009). The Washington climate change impacts assessment: evaluating Washington's future in a changing climate. Climate Impacts Group.

Favre, A. C., El Adlouni, S., Perreault, L., Thiémonge, N., \& Bobée, B. (2004). Multivariate hydrological frequency analysis using copulas. Water resources research, 40(1). 
Feng, S., Hu, Q., Huang, W., Ho, C. H., Li, R., \& Tang, Z. (2014). Projected climate regime shift under future global warming from multi-model, multi-scenario CMIP5 simulations. Global and Planetary Change, 112, 41-52.

Genest, C., \& Rémillard, B. (2008, December). Validity of the parametric bootstrap for goodness-of-fit testing in semiparametric models. In Annales de l'Institut Henri Poincaré: Probabilités et Statistiques (Vol. 44, No. 6, pp. 1096-1127).

Gershunov, A., \& Barnett, T. P. (1998). ENSO influence on intraseasonal extreme rainfall and temperature frequencies in the contiguous United States: Observations and model results. Journal of Climate, 11(7), 1575-1586.

Gillett, N. P., Allan, R. J., \& Ansell, T. J. (2005). Detection of external influence on sea level pressure with a multi-model ensemble. Geophysical Research Letters, 32(19).

Halmstad, A., M.R. Najafi, and H. Moradkhani (2012), Analysis of Precipitation Extremes with the Assessment of Regional Climate Models over the Willamette River BasinU.S., Hydrological Processes, 27, 2579-2590, DOI: 10.1002/hyp.937.

Halmstad, A., Najafi, M. R., \& Moradkhani, H. (2013). Analysis of precipitation extremes with the assessment of regional climate models over the Willamette River Basin, USA. Hydrological Processes, 27(18), 2579-2590.

Hamlet, A. F., \& Lettenmaier, D. P. (1999). Effects of climate change on hydrology and water resources in the Columbia River Basin1.

IPCC (2007). "Climate change 2007: the physical sciences basis Contribution of Working Group 1 to the Fourth Assessment Report of the Intergovernmental Panel on Climate Change" ed S Solomon, D Qin, M Manning, Z Chen, M Marquis, K B Averyt, M Tignor and H L Miller Cambridge: Cambridge University Press p 966

IPCC (2013). "Climate change 2013: the physical science basis Contribution of Working Group I to the Fifth Assessment Report of the Intergovernmental Panel on Climate Change.” ed T F Stocker, D Qin, G K Plattner, M Tignor, S K Allen, J Boschung, A Nauels, Y Xia, V Bex and P M Midgley Cambridge: Cambridge University Press 
Jung, I., H. Chang, and H. Moradkhani (2011), Quantifying uncertainty in urban flooding analysis by combined effect of climate and land use change scenarios, Hydrology and Earth System Science, 15, 617-633.

Jung, I., H. Moradkhani, and H. Chang (2012), Uncertainty Assessment of Climate Change Impact for Hydrologically Distinct River Basins, Journal of Hydrology, 466-467, p7387, 10.1016/j.jhydrol.2012.08.002.

Kao, S. C., \& Govindaraju, R. S. (2008). Trivariate statistical analysis of extreme rainfall events via the Plackett family of copulas. Water Resources Research, 44(2).

Karl, T. R., \& Melillo, J. M. (Eds.). (2009). Global climate change impacts in the United States. Cambridge University Press.

Knutti, R., Furrer, R., Tebaldi, C., Cermak, J., \& Meehl, G. A. (2010). Challenges in combining projections from multiple climate models. Journal of Climate, 23(10), $2739-2758$.

Lambert, S. J., \& Boer, G. J. (2001). CMIP1 evaluation and intercomparison of coupled climate models. Climate Dynamics, 17(2-3), 83-106.

Leung, L. R., \& Wigmosta, M. S. (1999). POTENTIAL CLIMATE CHANGE IMPACTS ON MOUNTAIN WATERSHEDS IN THE PACIFIC NORTHWEST1.

Leung, L. R., Qian, Y., Bian, X., Washington, W. M., Han, J., \& Roads, J. O. (2004). Midcentury ensemble regional climate change scenarios for the western United States. Climatic Change, 62(1-3), 75-113.

Littell, J. S., Elsner, M. M., Binder, L. W., \& Snover, A. K. (2009). The Washington Climate Change Impacts Assessment: Evaluating Washington's Future in a Changing Climate-Executive Summary. The Washington Climate Change Impacts Assessment: Evaluating Washington's Future in a Changing Climate.

Livneh, B., Rosenberg, E.A., Lin, C., Mishra, V., Andreadis, K.M., Maurer, E.P., and Lettenmaier, D.P. (2013). "Extension and spatial refinement of a long-term hydrologically based dataset of land surface fluxes and states for the conterminous United States." Journal of Climate, doi:10.1175/JCLI-D-12-00508.1. 
Madadgar, S., \& Moradkhani, H. (2013). A Bayesian framework for probabilistic seasonal drought forecasting. Journal of Hydrometeorology, 14(6), 1685-1705.

Madadgar, S., \& Moradkhani, H. (2014). Improved Bayesian multimodeling: Integration of copulas and Bayesian model averaging. Water Resources Research, 50(12), 95869603.

Madadgar, S., Moradkhani, H., \& Garen, D. (2014). Towards improved post-processing of hydrologic forecast ensembles. Hydrological Processes, 28(1), 104-122.

Mantua, N. J., Hare, S. R., Zhang, Y., Wallace, J. M., \& Francis, R. C. (1997). A Pacific interdecadal climate oscillation with impacts on salmon production. Bulletin of the american Meteorological Society, 78(6), 1069-1079.

Moradkhani H., R.G., Baird, and S. Wherry (2010), Impact of Climate Change on Floodplain Mapping and Hydrologic Ecotones, Journal of Hydrology, 395, 264-278.

Mote, P., Canning, D., Fluharty, D., Francis, R., Franklin, J., Hamlet, A., Hershman, M., Holmberg, M., Gray-Ideker, K., Keeton, W. S., Lettenmaier, D., Leung, R., Mantua, N., Miles, E., Noble, B., Parandvash, H., Peterson, D. W., Snover, A., and Willard, S.: 1999, Impacts of Climate Variability and Change, Pacific Northwest, National Atmospheric and Oceanic Administration, Office of Global Programs, and JISAO/SMA Climate Impacts Group, Seattle, WA, 110 pp.

Najafi M.R. and H. Moradkhani (2013), Analysis of Runoff Extremes using Spatial Hierarchical Bayesian Modeling, Water Resources Research, 49, 1-15, DOI:10.1002/wrcr.20381.

Najafi, M., H. Moradkhani and S. Wherry (2011), Statistical Downscaling of Precipitation using Machine Learning with Optimal Predictor Selection, Journal of Hydrologic Engineering, 16(8), 650-664.

Najafi, M.R. and H. Moradkhani (2014), A Hierarchical Bayesian Approach for the Analysis of Climate Change Impact on Runoff Extremes, Hydrological Processes, 28, 6292-6308, DOI: 10.1002/hyp.10113.

Palmer, T. N., Doblas-Reyes, F. J., Hagedorn, R., \& Weisheimer, A. (2005). Probabilistic prediction of climate using multi-model ensembles: from basics to applications. 
Philosophical Transactions of the Royal Society B: Biological Sciences, 360(1463), 1991-1998.

Piao, S., Ciais, P., Huang, Y., Shen, Z., Peng, S., Li, J., ... \& Fang, J. (2010). The impacts of climate change on water resources and agriculture in China. Nature, 467(7311), 4351.

Pierce, D. W., Das, T., Cayan, D. R., Maurer, E. P., Miller, N. L., Bao, Y., ... \& Tyree, M. (2013). Probabilistic estimates of future changes in California temperature and precipitation using statistical and dynamical downscaling.Climate Dynamics, 40(3-4), 839-856.

Raftery, A. E., Gneiting, T., Balabdaoui, F., \& Polakowski, M. (2005). Using Bayesian model averaging to calibrate forecast ensembles. Monthly Weather Review, 133(5), 1155-1174.

Rajeevan, M., Pai, D. S., \& Thapliyal, V. (1998). Spatial and temporal relationships between global land surface air temperature anomalies and Indian summer monsoon rainfall. Meteorology and Atmospheric Physics, 66(3-4), 157-171.

Rana, A., and Moradkhani, H. (2014). "Climate change Impact Assessment in Columbia River Basin using multi downscaled-Scenario Analysis" Submitted Manuscript (Climate Dynamics)

Risley, J., H. Moradkhani, L. Hay, and S. Markstrom (2011), Statistical Trends in Watershed Scale Response to Climate Change in Selected Basins Across the United States, AMS Earth Interaction, 15 (14) 1-26.

Salvadori, G., \& De Michele, C. (2006). Statistical characterization of temporal structure of storms. Advances in Water Resources, 29(6), 827-842.

Salvadori, G., \& De Michele, C. (2010). Multivariate multiparameter extreme value models and return periods: A copula approach. Water resources research, 46(10).

Samadi S.Z., C.A. Wilson, H. Moradkhani (2013), Uncertainty Analysis of Statistical Downscaling Models Using Hadley Centre Coupled Model, Journal of Theoretical and Applied Climatology, 1-18, doi:10.1007/s00704-013-0844-x. 
Shiau, J. T. (2006). Fitting drought duration and severity with two-dimensional copulas. Water resources management, 20(5), 795-815.

Sklar, M. (1959). Fonctions de répartition à $\mathrm{n}$ dimensions et leurs marges. Université Paris 8.

Taylor, K.E., Stouffer, R.J., Meehl, G.A. (2012). "An Overview of CMIP5 and the experiment design." Bull. Amer. Meteor. Soc., 93, 485-498, doi:10.1175/BAMS-D-1100094.1.

Tebaldi, C., \& Knutti, R. (2007). The use of the multi-model ensemble in probabilistic climate projections. Philosophical Transactions of the Royal Society A: Mathematical, Physical and Engineering Sciences, 365(1857), 2053-2075.

Tebaldi, C., \& Sansó, B. (2009). Joint projections of temperature and precipitation change from multiple climate models: a hierarchical Bayesian approach. Journal of the Royal Statistical Society: Series A (Statistics in Society), 172(1), 83-106.

Thomson, M. C., Doblas-Reyes, F. J., Mason, S. J., Hagedorn, R., Connor, S. J., Phindela, T., ... \& Palmer, T. N. (2006). Malaria early warnings based on seasonal climate forecasts from multi-model ensembles. Nature, 439(7076), 576-579.

Wuebbles, D., Meehl, G., Hayhoe, K., Karl, T. R., Kunkel, K., Santer, B., ... \& Sun, L. (2014). CMIP5 climate model analyses: climate extremes in the United States. Bulletin of the American Meteorological Society, 95(4), 571-583.

Zhang, L., \& Singh, V. P. (2007). Gumbel-Hougaard copula for trivariate rainfall frequency analysis. Journal of Hydrologic Engineering, 12(4), 409-419.

Zhang, L., \& Singh, V. P. (2007). Trivariate flood frequency analysis using the GumbelHougaard copula. Journal of Hydrologic Engineering, 12(4), 431-439.

Zhao, W., \& Khalil, M. A. K. (1993). The relationship between precipitation and temperature over the contiguous United States. Journal of climate, 6(6), 1232-1236. 